\title{
THE EFFECT OF TESTING DIRECTION ON DHC GROWTH RATE USING Zr-2.5Nb PLATE
}

\author{
by \\ Sean Hanlon \\ B.Eng \\ A thesis submitted to \\ The Faculty of Graduate Studies and Research \\ In partial fulfillment of the requirements for the degree of \\ Masters of Applied Science \\ Ottawa-Carleton Institute for Mechanical and Aerospace Engineering \\ Department of Mechanical and Aerospace Engineering \\ Faculty of Engineering \\ Carleton University \\ Ottawa, Ontario \\ Canada
}

Date: September 16th, 2013

Copyright $@$ Sean Hanlon 2013

The undersigned hereby recommend to

the Faculty of Graduate Studies and Research

acceptance of this thesis 


\section{THE EFFECT OF TESTING DIRECTION ON DHC GROWTH RATE USING Zr-2.5Nb PLATE

\author{
submitted by \\ Sean Hanlon
}

In partial fulfillment of the requirements for the degree of

Masters of Applied Science

External Examiner

Glenn A. McRae, Thesis Supervisor

Metin I. Yaras, Chair

Department of Mechanical and Aerospace Engineering

Carleton University

Date: September 16th, 2013 


\begin{abstract}
Delayed Hydride Cracking (DHC) is a fracture mechanism responsible for several failures of zirconium alloy components. The $\mathrm{Zr}-2.5 \mathrm{Nb}$ alloy is used to manufacture CANDU pressure tubes, which are the primary pressure boundary in CANDU reactors. The rate of crack propagation in these tubes depends on direction. CANDU pressure tubes have anisotropic grain structure and texture due to extrusion and heat treatment. Disk-shaped hydrides preferentially form on certain crystallographic planes that are hypothesized to be responsible for the difference in DHC growth rates in certain directions. If bulk hydrides slow crack growth, then no directional difference in crack velocity will be observed when no bulk hydrides are present; i.e, where the DHC test temperature is reached by cooling to temperatures above the terminal solid solubility of precipitation (TSSP). Furthermore, below TSSP, where bulk hydrides are present, the crack velocities should begin to diverge as temperature is decreased, as oriented hydrides impede the crack growth to different extents in different directions. In this study, DHC crack velocities are determined using cantilever beam specimens with cracks propagating in both the longitudinal and through-thickness directions with and without bulk hydrides present, i.e., below and above TSSP. The DHC crack velocities in the longitudinal direction were observed to be higher than the corresponding through-thickness crack velocities with or without bulk hydrides present. Thus, the hypothesis is disproved; the orientation of bulk hydrides relative to the direction of DHC cracking does not explain the direction difference in crack velocities. Alternative hypotheses are presented.
\end{abstract}




\section{Acknowledgements}

There are a great deal of people who influenced this work, and I would like to sincerely thank them all.

First and foremost I would like to thank my supervisor, Professor Glenn McRae for his guidance, encouragement, and financial support throughout my research at Carleton University. With his help I've gained considerable insight into both science and life in general.

I would like to express my gratitude to Kit Coleman for sharing his vast knowledge of nuclear science with me. Without Kit's guidance and advice I could not have completed this thesis.

This work was supported by Atomic Energy of Canada, Limited. Special thanks to Alain Douchant for lab access, Mona Primeau for DHC testing and analysis support, Pat Wilson for DSC testing and analysis, and Ken Kidd for material procurement and machining advice.

Many thanks to the faculty, staff, and students of the Department of Mechanical and Aerospace Engineering who always made my time at Carleton enjoyable.

I am greatly indebted to my parents for their love, support, encouragement, and innumerable sacrifices.

I would like to thank my family and friends, who were always there to support me when I needed it most. 


\section{Table of Contents}

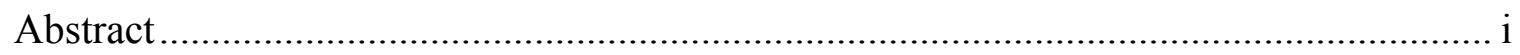

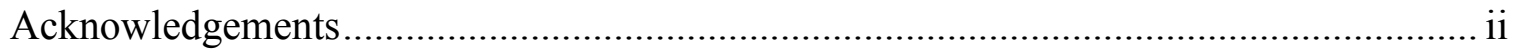

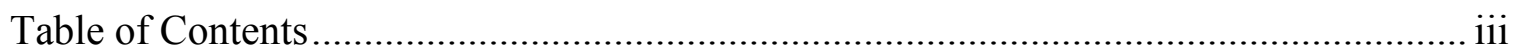

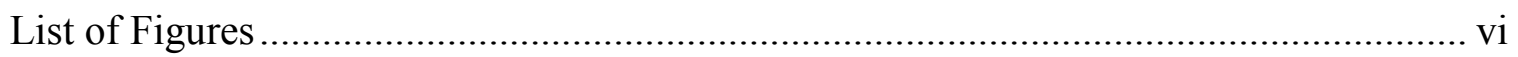

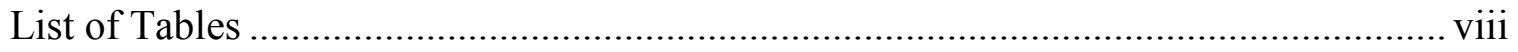

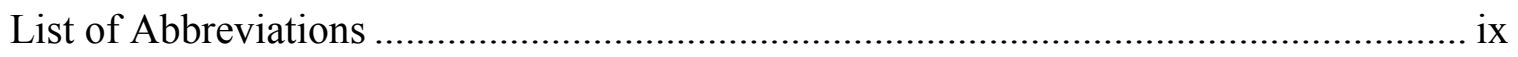

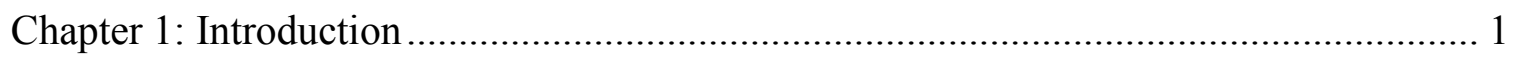

1.2 Delayed Hydride Cracking …………………............................................. 3

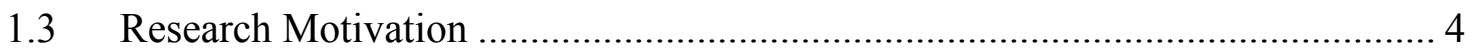

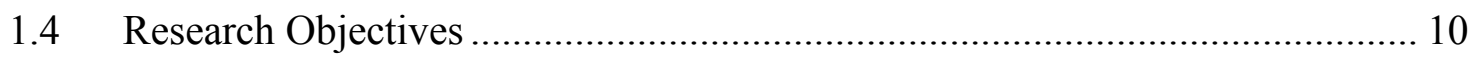

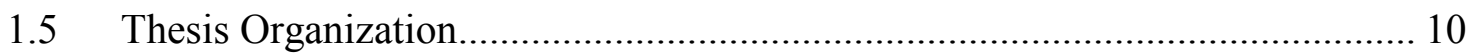

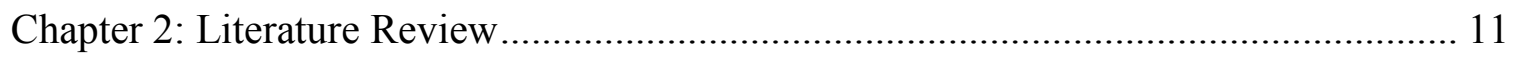

$2.1 \quad$ Leak-Before-Break ................................................................................... 11

2.2 Pressure Tube Microstructure ...................................................................... 14

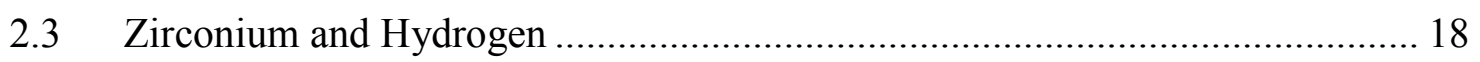

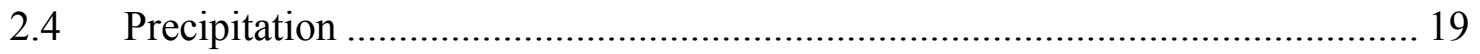

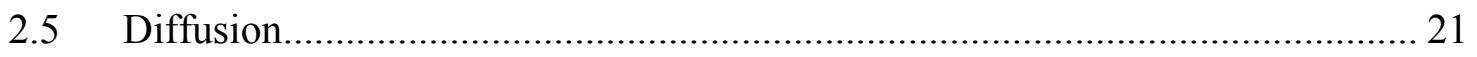

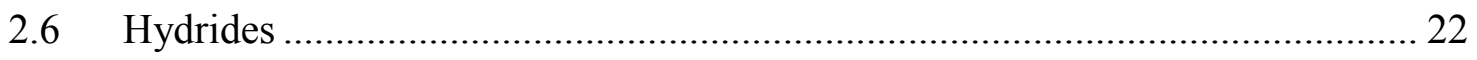

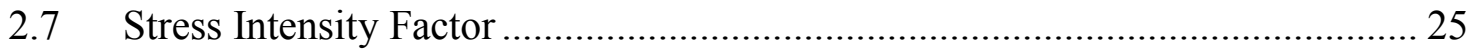

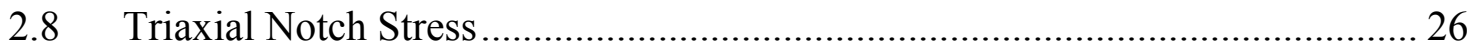

2.9 Through-Thickness vs. Longitudinal Crack Velocity ....................................... 28

2.9.1 Stress Gradient Anisotropy .................................................................... 28

2.9.2 Beta Phase Distribution..................................................................... 32

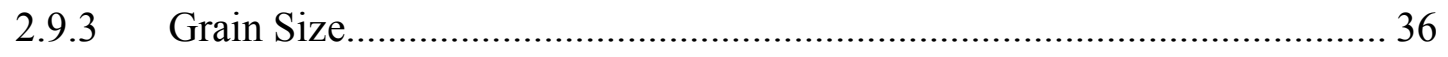

2.10 Comments on Explanations for the Velocity Difference ……............................ 39

2.11 History of Delayed Hydride Cracking ………………...................................... 43

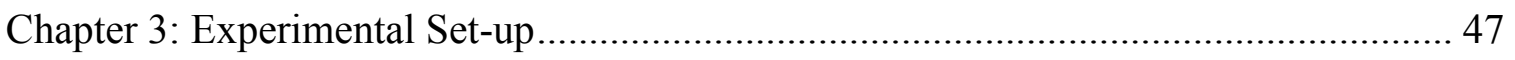

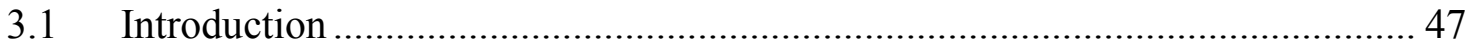




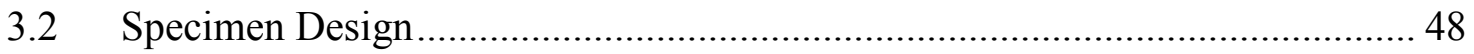

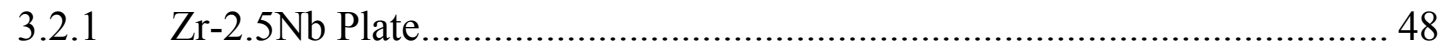

3.2.2 Cantilever Beam Specimens ............................................................... 51

3.2.3 Hydrogen Addition .................................................................................. 51

3.2.4 Differential Scanning Calorimetry .......................................................... 52

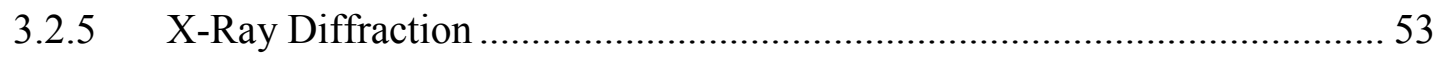

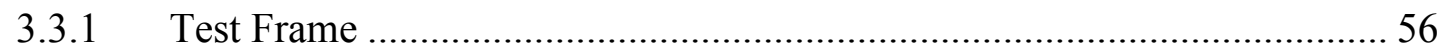

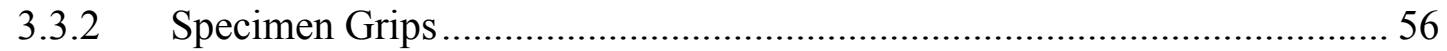

3.3.3 Load Control System …………………………................................... 57

3.3.4 Acoustic Emission ................................................................................. 57

3.3.5 Temperature Control System ................................................................... 58

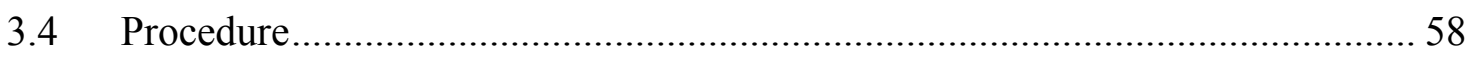

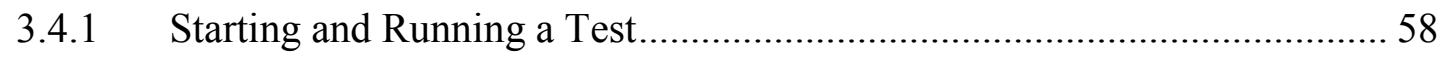

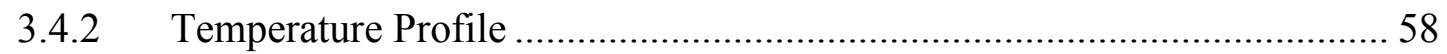

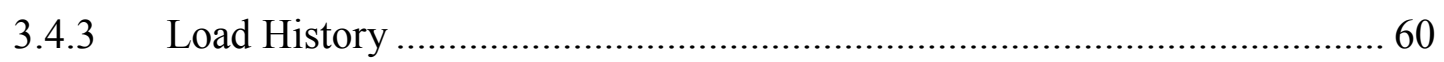

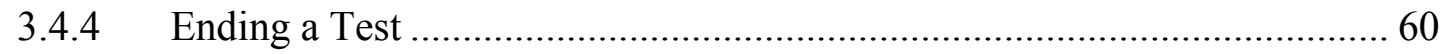

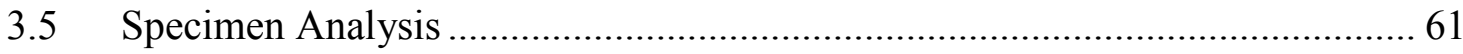

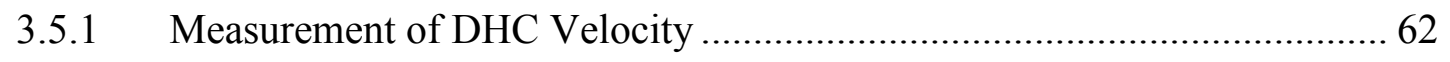

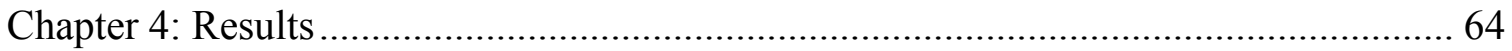

Chapter 5: Discussion .......................................................................................... 71

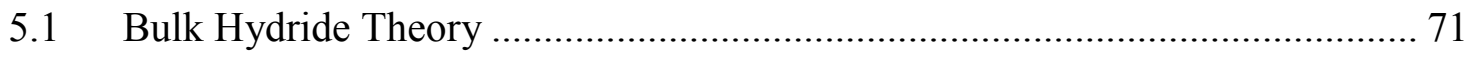

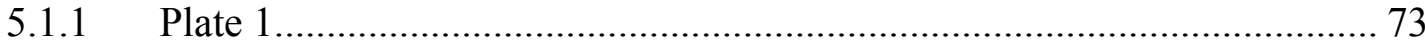

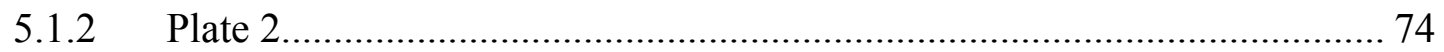

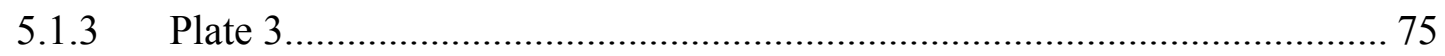

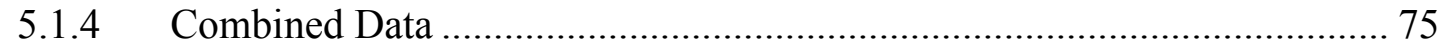

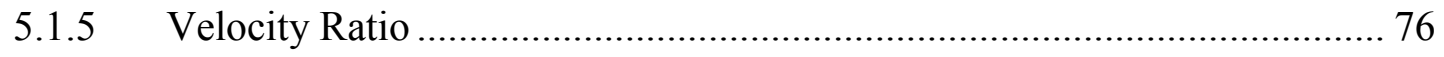

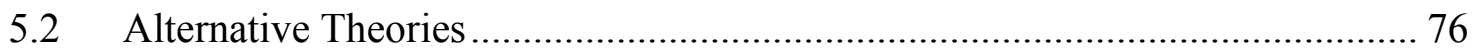

5.2.1 $\quad \alpha-\beta$ Boundary Anisotropic Distribution Theory ......................................... 76

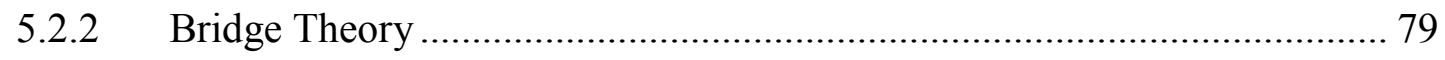

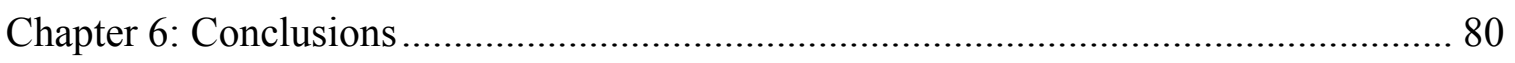




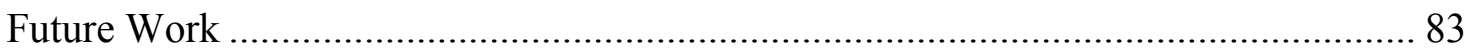

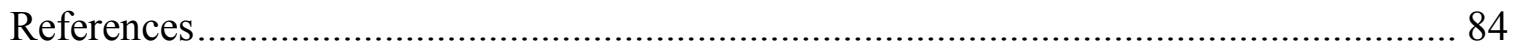

APPENDIX A: Plate Manufacturing Procedure.......................................................... 96

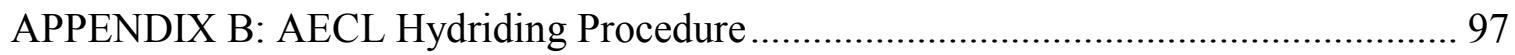

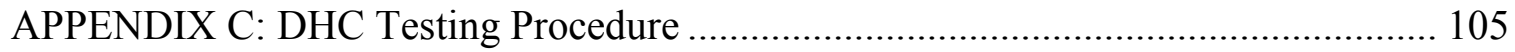

APPENDIX D: ASTM Standard for Cantilever Beam Stress Intensity ........................ 111

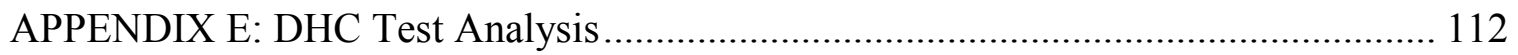

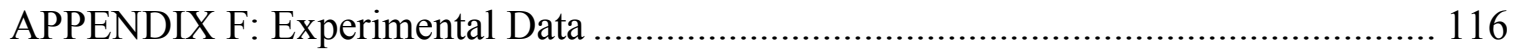

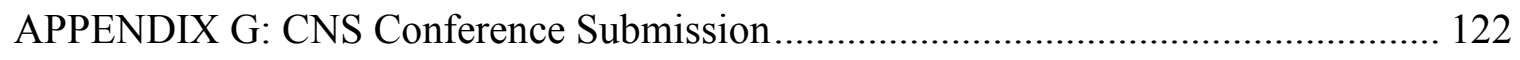

APPENDIX H: 2012 CNS Conference Poster ............................................................ 127 


\section{List of Figures}

Figure 1 - Schematic diagram of a CANDU reactor core and heat transport system [Rae 1997] ................2

Figure 2 - Schematic diagram of a CANDU fuel channel [Moan 1990]..................................................2

Figure 3 - Pressure tube section showing HCP unit cell with basal plane normal in transverse direction .... 6

Figure 4 - Through-thickness crack at $250^{\circ} \mathrm{C}$. Cracking direction is from top to bottom (through-thickness

direction). Hydrides perpendicular to direction of propagation ……....................................................

Figure 5 - Longitudinal crack at $250^{\circ} \mathrm{C}$. Cracking direction is from top to bottom (longitudinal direction).

Hydrides parallel with direction of propagation................................................................................

Figure 6 - Longitudinal and through-thickness velocity CSA predictions and longitudinal/through-thickness

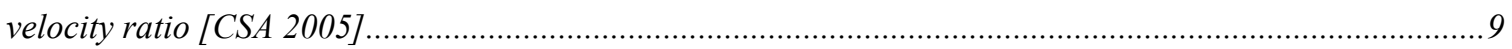

Figure 7 - Schematic diagram of crack dimensions at onset of leaking [Moan 1990] ..................................13

Figure 8 -Microstructure of CANDU pressure tube made from cold-worked Zr-2.5Nb. Dark areas are the

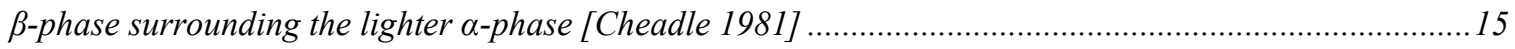

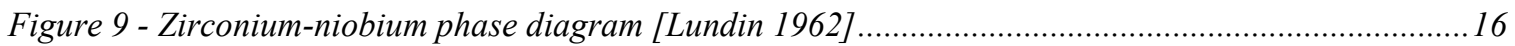

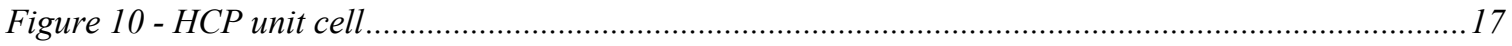

Figure $11-2 D$ and $3 D$ pole figures of $Z r-2.5 \mathrm{Nb}$ material used in this study .......................................17

Figure 12: Zirconium - Hydrogen phase diagram [Zuzek 1990] ………...........................................18

Figure 13 - CSA terminal solid solubility for precipitation curve for hydrogen in Zr-2.5Nb [CSA 2005] ... 19

Figure 14-DSC curve on cooling a sample from a cantilever beam specimen tested in this study

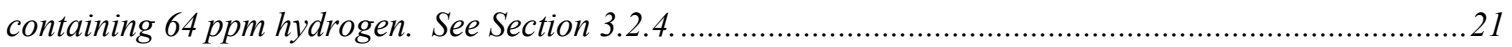

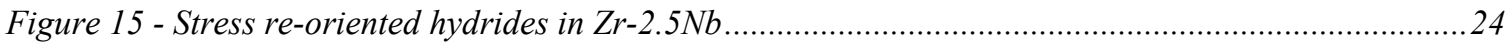

Figure 16 - Schematic diagram showing dependence of DHC velocity on $K_{I}$ with three stages: Stage 1) no cracking up to a threshold, called $K_{I H}$, after which the cracking rate changes rapidly with $K_{I}$. Stage 2)

Stable crack growth, having little rate change with increase in $K_{I}$. Stage 3) The onset of unstable cracking

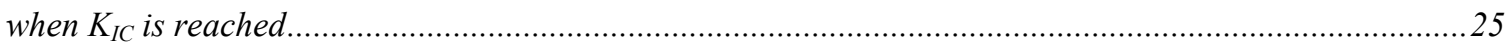

Figure 17 - Schematic diagram of the stress field at a flaw .................................................................26

Figure 18 - Use of Tresca criterion to predict plastic zone size and stress gradient [Bell 2001] ................27

Figure 19 - Schematic diagram of cantilever beam specimens from flattened pressure tube [Kim 2002]....29

Figure 20 - DHC velocity of flattened pressure tube cantilever beam specimens with cracking from $170{ }^{\circ} \mathrm{C}$

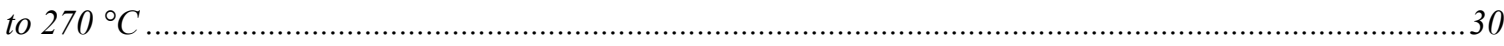

Figure 21 - Strain hardening in the radial and longitudinal directions $\quad(=(U T S-Y S) / Y S)$ as a function of $1 / T$

Figure 22 - Steeper stress gradient ahead of the crack tip in the longitudinal direction of the Zr-2.5Nb pressure tube than the radial direction [Kim 2001] ........................................................................... 31

Figure 23 - The effect of temperature on DHC velocity in the axial (a) and radial (b) directions [Jovanovic $2001]$

Figure 24 - Ratio of the DHC velocities as a function of temperature for specimens annealed at $1 *, 24$, and 1000 hours at $400{ }^{\circ} \mathrm{C}$. ${ }^{*}$ For $\beta$-phase decomposition, 36 h at $300{ }^{\circ} \mathrm{C}$ equates to 1 h at $400{ }^{\circ} \mathrm{C}$ [Jovanovic

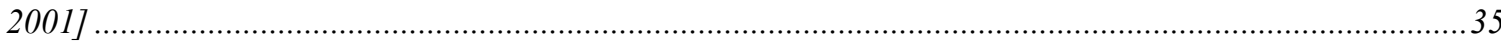

Figure 25 - Effect of grain size on time to fracture at several stress intensities [Coleman 1979] ................38 Figure 26 - Axial and radial crack velocities at $130{ }^{\circ} \mathrm{C}$ in quenched and aged 'KANUPP' pressure tubes compared to axial and radial velocity confidence limits in cold-worked pressure tubes [Cheadle 1996]....39 Figure 27 - A through-wall crack at two rolled joints in Zr-2.5Nb pressure tubes in Pickering 3 (a) and Pickering 4 (b). The coloured bands represent periods of cracking and subsequent oxidation. The tube wall thickness was $4 \mathrm{~mm} . \quad$ [Causey 1977]...... 
Figure 28 - Schematic diagram of over-rolled joint: (a) position of the roller, (b) location of cracking, (c)

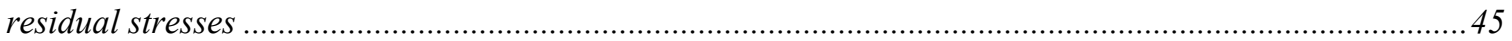

Figure 29 - Plate and specimen geometry (A: radial specimen, B: longitudinal specimen) ......................50

Figure 30 - Schematic diagram of a DHC cantilever beam rig .............................................................55

Figure 31 - Cantilever beam rig with enclosure removed ..............................................................55

Figure 32 - Cantilever beam rig with arms removed, enclosure attached ..............................................55

Figure 33 - Close-up view of grips and specimen ..............................................................................57

Figure 34 - Temperature profile for DHC Tests. Left - test temperature above TSSP: no bulk hydrides present. Right - test temperature below TSSP: bulk hydrides present .......................................................59

Figure 35 - Breaking specimen to expose fracture surfaces .................................................................62

Figure 36 - Plate 1 (65 ppm) through-thickness and longitudinal DHC crack velocities as a function of

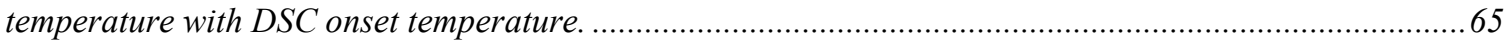

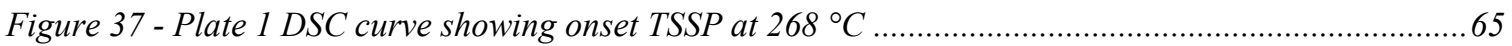

Figure 38 - Plate 1 (65 ppm) through-thickness and longitudinal DHC crack velocities (log) as a function

of 1000/temperature.

Figure 39 - Plate 2 (100 ppm) through-thickness and longitudinal DHC crack velocities as a function of temperature

Figure 40 - Plate 2 through-thickness and longitudinal DHC crack velocities (log) as a function of 1000/temperature

Figure 41 - Plate 3 (40 ppm) through-thickness and longitudinal DHC crack velocities as a function of

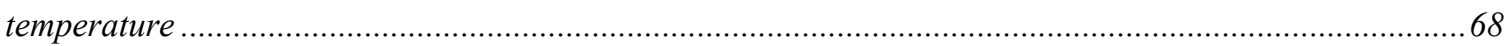

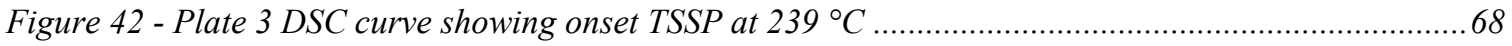
Figure 43 - Plate 3 (40 ppm) through-thickness and longitudinal DHC crack velocities (log) as a function of 1000/temperature.....

Figure 44 - Combined through-thickness and longitudinal DHC crack velocities as a function of temperature

Figure 45 - Combined through-thickness and longitudinal DHC crack velocities (log) as a function of 1000/temperature 70

Figure 46 - Velocity ratio as a function of temperature for each plate, and for the combined data from all three plates. 70 Figure 47 - Plate 1 Fracture Surfaces. Top: Through-thickness (left) and longitudinal (right) tested above onset TSSP. Bottom: Through-thickness (left) and longitudinal (right) tested below onset TSSP (same as

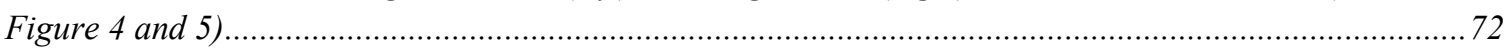

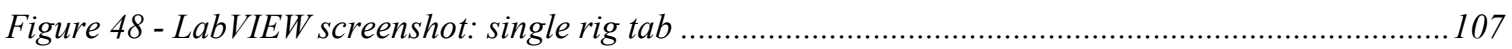

Figure 49 - LabVIEW screenshot: specimen ID subtab .......................................................... 108

Figure 50 - LabVIEW screen shot - grip parameters subtab ........................................................ 108 


\section{List of Tables}

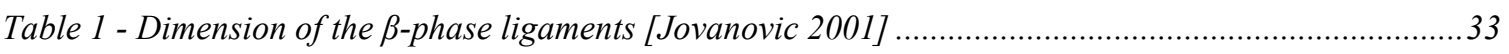

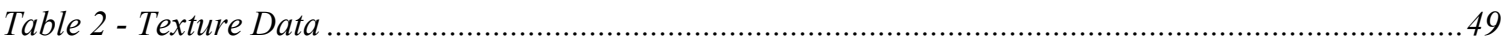

Table 3 - Transverse tensile test results for $\mathrm{Zr}$-2.5Nb plate material and pressure tube material...............50 


\title{
List of Abbreviations
}

\author{
AECL - Atomic Energy of Canada, Limited \\ BCC - Body Centered Cubic \\ BCT - Body Centered Tetragonal \\ CB - Cantilever Beam \\ CCL - Critical Crack Length \\ DHC - Delayed Hydride Cracking \\ DSC - Differential Scanning Calorimetry \\ EDM - Electrical Discharge Machining \\ FCC - Face Centered Cubic \\ HCP - Hexagonal Close Packed \\ HVEMS - Hot Vacuum Extraction Mass Spectrometry \\ LBB - Leak Before Break \\ LN - Longitudinal Normal \\ PPM - Parts Per Million by weight \\ RN - Radial Normal \\ TN - Transverse Normal \\ TSSP - Terminal Solid Solubility for Precipitation
}




\section{Chapter 1}

\section{Introduction}

This thesis tests a hypothesis for the difference between longitudinal and throughthickness $\underline{\text { Delayed }}$ Hydride $\underline{\text { Cracking }}$ (DHC) in CANDU pressure tubes. Chapter 1 begins with a review of pressure tubes in CANDU reactors and DHC, which is followed by a summary of the arguments and the objectives of this thesis. Chapter 1 concludes with the general organization of the thesis.

\subsection{The CANDU Reactor}

CANDU reactors use heavy water as the moderator and as the coolant. The reactor uses natural uranium fuel. A schematic diagram for the CANDU core and heat transport system is shown in Figure 1. The core of the reactor is contained in the calandria vessel, which is labeled 6 in Figure 1. Approximately 380 horizontal fuel channel assemblies go through the core. In Figure 1, four of these assemblies are shown schematically. Each assembly holds twelve or thirteen fuel bundles; Figure 1 shows six bundles.

Each fuel channel locates and supports the fuel bundles in the core. The fuel channel assembly consists of a pressure tube, a calandria tube, annulus spacers and an end fitting (Figure 2). CANDU pressure tubes are about $6 \mathrm{~m}$ in length, with a diameter of $10 \mathrm{~cm}$ and a wall thickness of $4 \mathrm{~mm}$. The ends of each pressure tube are cold rolled into stainless steel end fittings. 


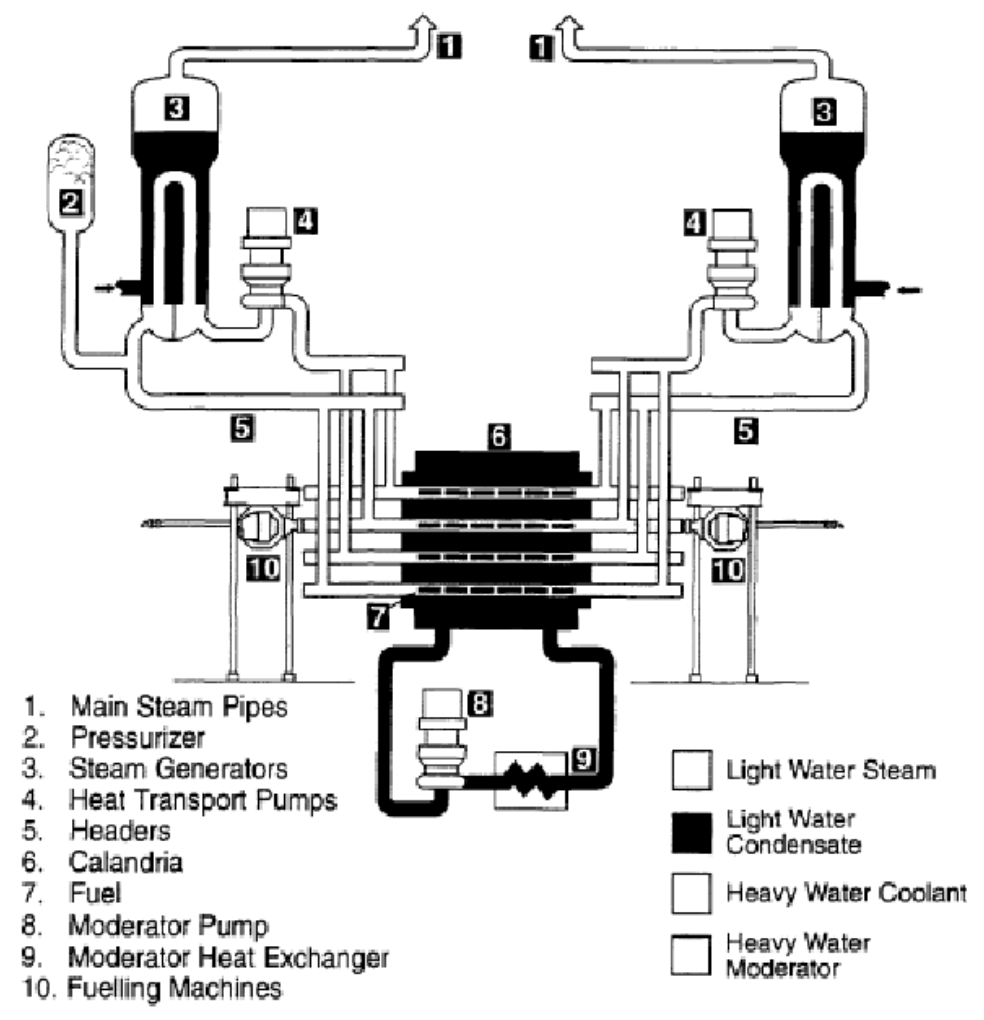

Figure 1 - Schematic diagram of a CANDU reactor core and heat transport system

[Rae 1997]

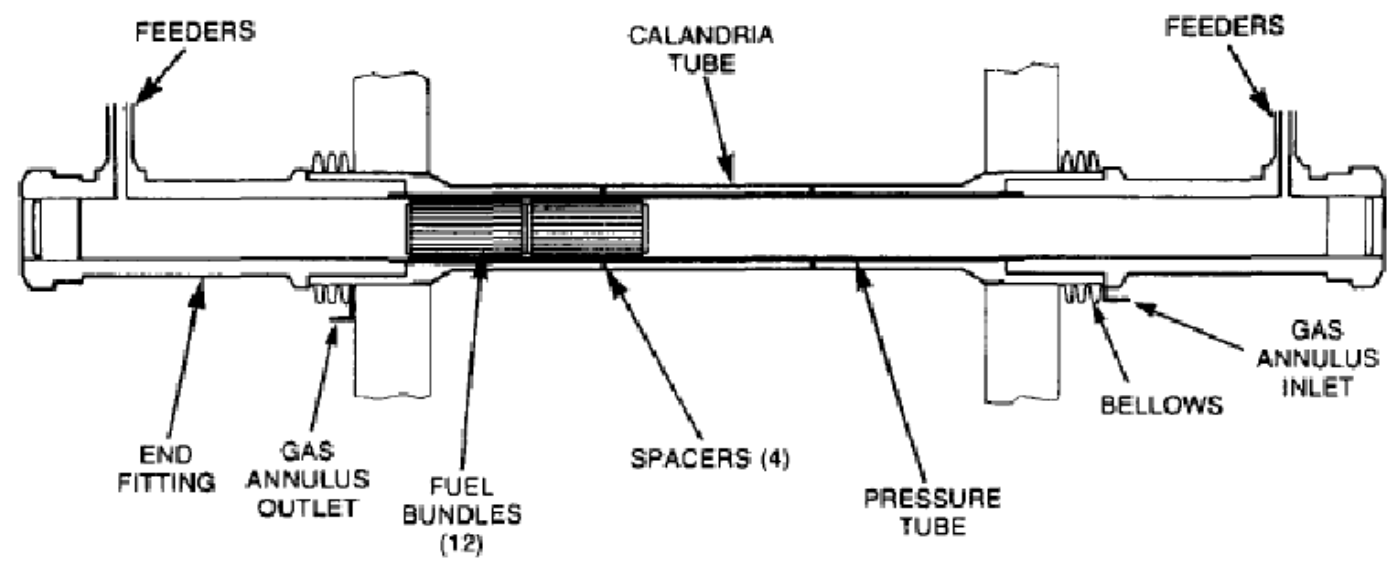

Figure 2 - Schematic diagram of a CANDU fuel channel [Moan 1990] 
CANDU pressure tubes are exposed to temperature up to $310{ }^{\circ} \mathrm{C}$ and an internal pressure of up to 11.3 MPa [Puls 1997]. The in-service conditions of the pressure tubes cause changes in dimensions and material properties such as sag, elongation, and diametral expansion [Rodgers 2008]. Flaws in the pressure tube can be introduced during manufacturing, installation, or during service. Hydrogen is picked up during service due to corrosion and ingress at the rolled joints. If a flaw increases the local tensile stress, hydrogen will tend to locally accumulate and hydride precipitation may result. This can lead to a cracking mechanism called Delayed Hydride Cracking [Moan 1990].

\subsection{Delayed Hydride Cracking}

Zirconium alloys are used for several nuclear applications due to their good corrosion performance, low neutron capture cross section, and sufficient strength and toughness. Current pressure tubes are fabricated using the alloy $\mathrm{Zr}-2.5 \mathrm{Nb}$. During the corrosion of $\mathrm{Zr}-2.5 \mathrm{Nb}$, hydrogen is released, some fraction of which is absorbed by the pressure tube. When the $\underline{T}$ erminal $\underline{\text { Solid }} \underline{\text { Solubility of }}$ Precipitation (TSSP) for hydrogen in zirconium is exceeded, disk-shaped hydrides are formed. Hydrides are brittle and can lead to short term loss of toughness and time-dependent fracture. The latter is called DHC. The time dependence of DHC is related to the movement of hydrogen in solution due to the gradient of chemical potential, which can be written in terms of gradients of hydrogen concentration, temperature, and stress [McRae 2010]. DHC requires a component to contain a stress riser, such as a crack or notch, and a source of tensile stress. There are three basic steps involved in DHC. These are (1) the diffusion of sufficient hydrogen to nucleate a hydride at a stress riser followed by (2) growth of the hydride until (3) fracture of the hydride occurs [McRae 2010]. These steps then repeat as the crack grows.

DHC has been responsible for several failures of zirconium alloy components in nuclear reactors, including several zirconium alloy pressure tubes in different CANDU and RBMK reactors between 1974 and 1986. DHC has limits associated with hydrogen 
concentration, stress intensity factor and temperature history [Coleman 2011]. Staying within these limits and utilizing conservative safety margins allow for safe operation of zirconium components.

A DHC crack travels either from the inside surface to the outside surface (CANDU) or vice versa (RBMK) in the through-thickness direction [Platonov 1988], and grows in the longitudinal direction. The cracking rates in the through-thickness and longitudinal directions are not the same; see Section 1.3, Figure 6 [CSA 2005]. If the crack penetrates the tube, water from the heat transport system will leak into the annulus gas where it is detected. The through-wall leaking of the heat transport heavy water provides a safe method of detecting DHC before catastrophic failure can occur and this forms the basis of the leak-before-break (LBB) principle. When the leakage is detected, the reactor is safely shutdown and the pressure tube replaced. LBB is explained in detail in Section 2.1.

\subsection{Research Motivation}

During normal reactor operation, there is the hoop stress in the pressure tube created by the internal pressure. The stresses inside a thin-walled cylindrical pressure vessel can be approximated by the following equations [Dieter 1961]:

$$
\begin{gathered}
\sigma_{\theta}=\frac{P r}{t} \\
\sigma_{\text {long }}=\frac{P r}{2 t} \\
\sigma_{\text {rad }}=-P
\end{gathered}
$$

Where $P$ is the internal pressure, $r$ is the radius of the cylinder, $t$ is the wall thickness, and $\sigma_{\theta}, \sigma_{\text {long }}, \sigma_{\text {rad }}$, are the hoop, longitudinal, and radial stresses, respectively. These 
equations (1) show the hoop stress will be double the longitudinal stress. The radial stress is much smaller than either the hoop or longitudinal stress, because $\frac{r}{t}$ is a large number in the thin wall approximation.

In this study, DHC testing is done in the longitudinal and through-thickness directions on the transverse plane, which is the plane on which the largest stress, the hoop stress, is acting. In CANDU reactors, where $r=50 \mathrm{~mm}, t=4 \mathrm{~mm}$, equation 1 yields $\sigma_{\theta}=141 \mathrm{MPa}, \sigma_{\text {long }}=71 \mathrm{MPa}, \sigma_{\text {rad }}=-11.3 \mathrm{MPa}$. DHC crack velocity testing was performed on the transverse plane because it has the highest stress and is where the threshold for DHC, $\mathrm{K}_{\mathrm{IH}}$, is first exceeded. Other external stresses or residual stresses from fabrication or installation can cause hydride re-orientation and lead to DHC (see Section 2.9).

CANDU pressure tubes are composed of $\mathrm{Zr}-2.5 \mathrm{Nb}$, with at least $90 \%$ of the volume being $\alpha$-phase zirconium (Zr) with $\underline{\text { Hexagonal }}$ Close $\underline{\text { Packed }}$ (HCP) crystal structure. Figure 3 shows a pressure tube section with the three main directions, as well as a representative HCP crystal showing the dominant direction of the $\alpha$-phase basal plane normal. For more details on pressure tube microstructure see Section 2.2.

There are two types of hydrides described in this study: bulk hydrides and DHC hydrides. Bulk hydrides and DHC hydrides have different precipitation characteristics and different orientations. Bulk hydrides precipitate throughout the bulk of the specimen when the specimen is cooled to temperatures below the TSSP temperature, and when precipitated the bulk hydrides normals are parallel to the through-thickness direction. For more detail, see Section 2.3. DHC hydrides nucleate, grow, and fracture in regions of high tensile stress, see Section 1.2. In this study, DHC hydrides have their normals in the transverse direction: the direction of highest stress. 


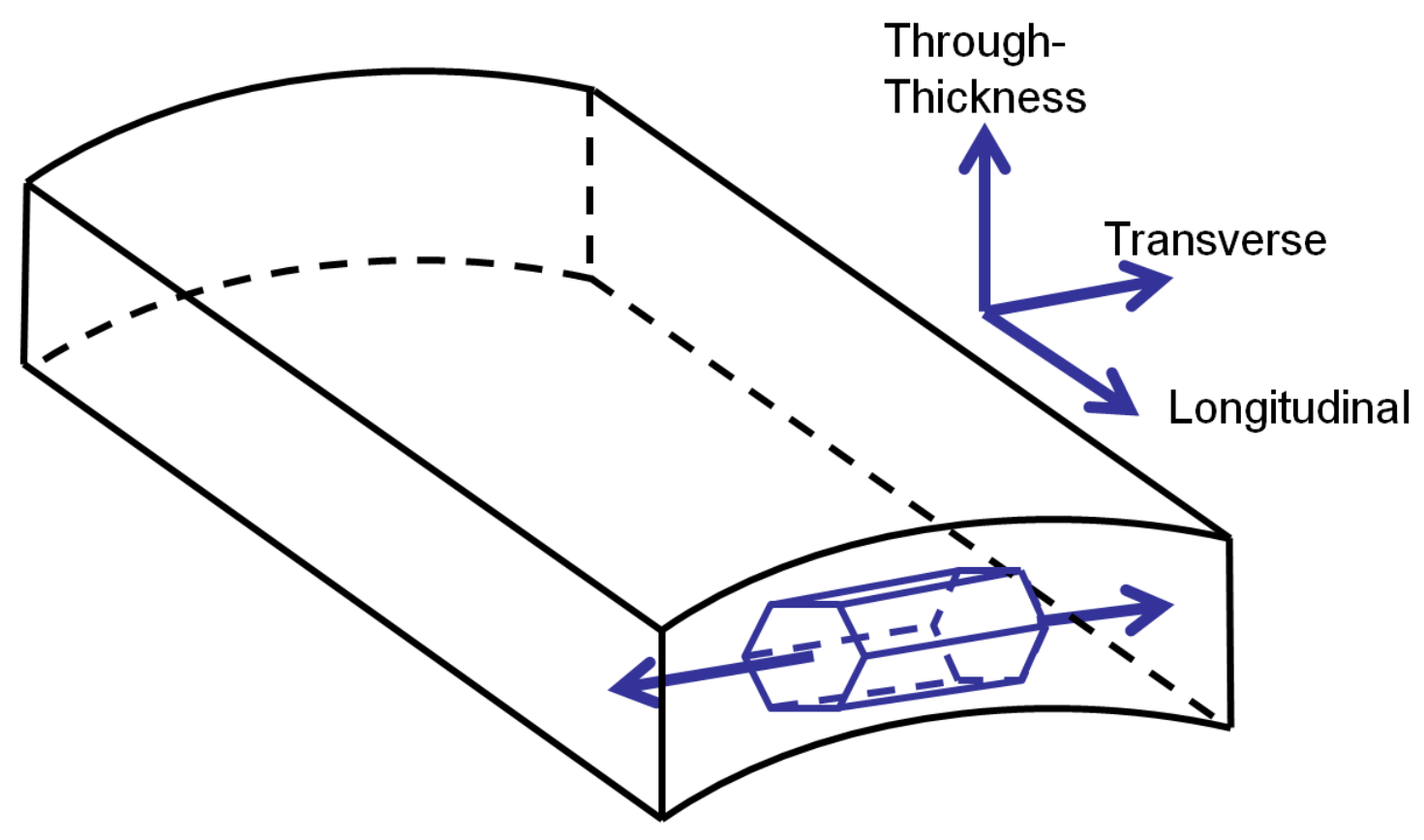

Figure 3 - Pressure tube section showing HCP unit cell with basal plane normal in transverse direction

DHC can proceed in either the longitudinal or through-thickness direction in the transverse plane. Figures 4 and 5 show the fracture surfaces of cantilever beam specimens after DHC velocity tests, the details of these tests are presented in Section 3.4. These fracture surfaces show bulk hydrides lining up either parallel or perpendicular to the direction of DHC propagation. Figure 4 shows a fracture surface that has cracked in the through-thickness direction while Figure 5 shows DHC that has propagated in the longitudinal direction. Both Figures 4 and 5 show bulk hydrides with normals in the through-thickness direction. In Figure 4, the DHC hydride looks as if it had to crack around the bulk hydride, while in Figure 5 the DHC hydride does not look as if it interacted with the bulk hydride to the same extent. The through-thickness crack grows parallel to the bulk hydride normal, while the longitudinal crack grows perpendicular to the bulk hydride normal. This thesis examines whether these oriented hydrides are 
responsible for the different crack velocities in the longitudinal and through-thickness directions.

The fractured specimens shown in Figures 4 and 5 were tested at $250{ }^{\circ} \mathrm{C}$, which is below the TSSP temperature of hydrogen in zirconium for these specimens. More detail on TSSP is found in Section 2.4. At temperatures below TSSP some fraction of the hydrogen in the specimen will precipitate as hydrides. The disk-shaped hydrides in pressure tube material will generally precipitate with its normal in the through-thickness direction (see Figure 3 and Section 2.6).

In addition to the biaxial stress in the bulk given by equation 1, there is a triaxial stress at the root of a flaw because of different geometry in this region [Knott 1973]. See Section 2.8 for more detail.

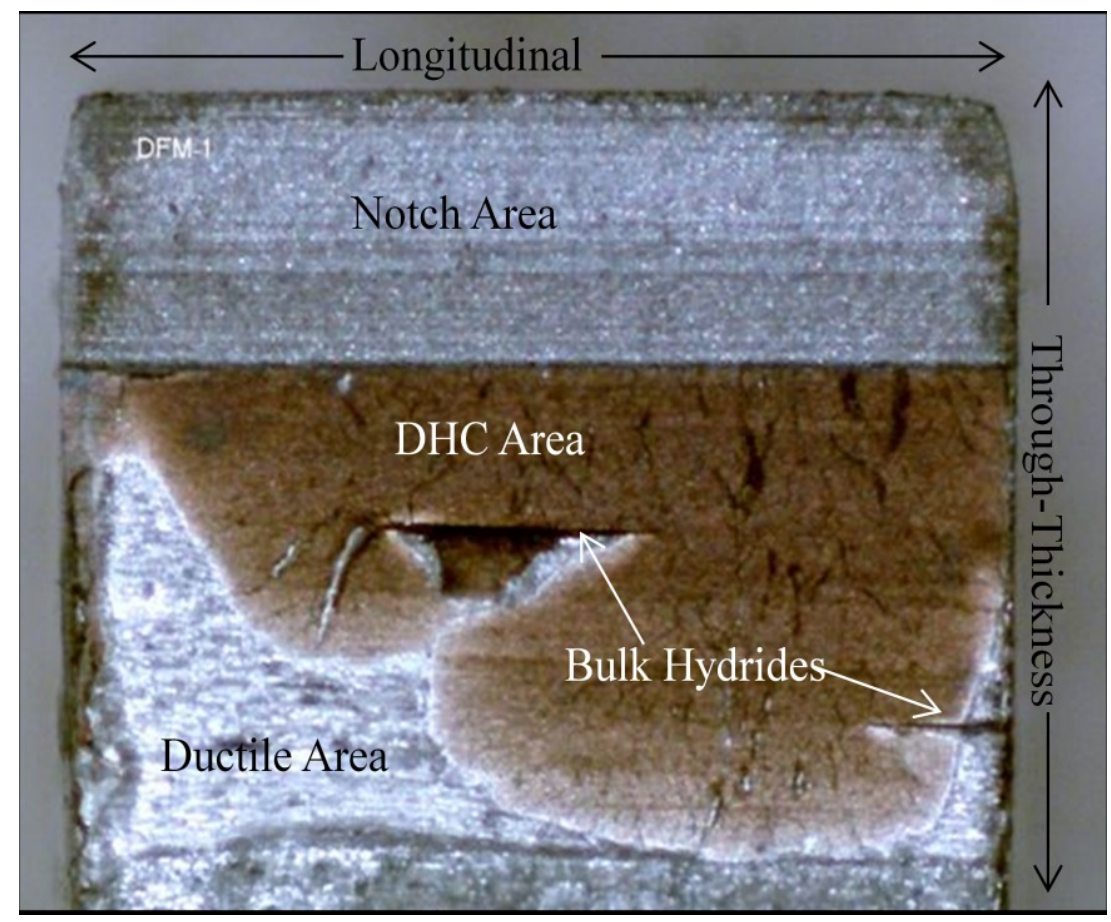

Figure 4 - Through-thickness crack at $250^{\circ} \mathrm{C}$. Cracking direction is from top to bottom (through-thickness direction). Hydrides perpendicular to direction of propagation 


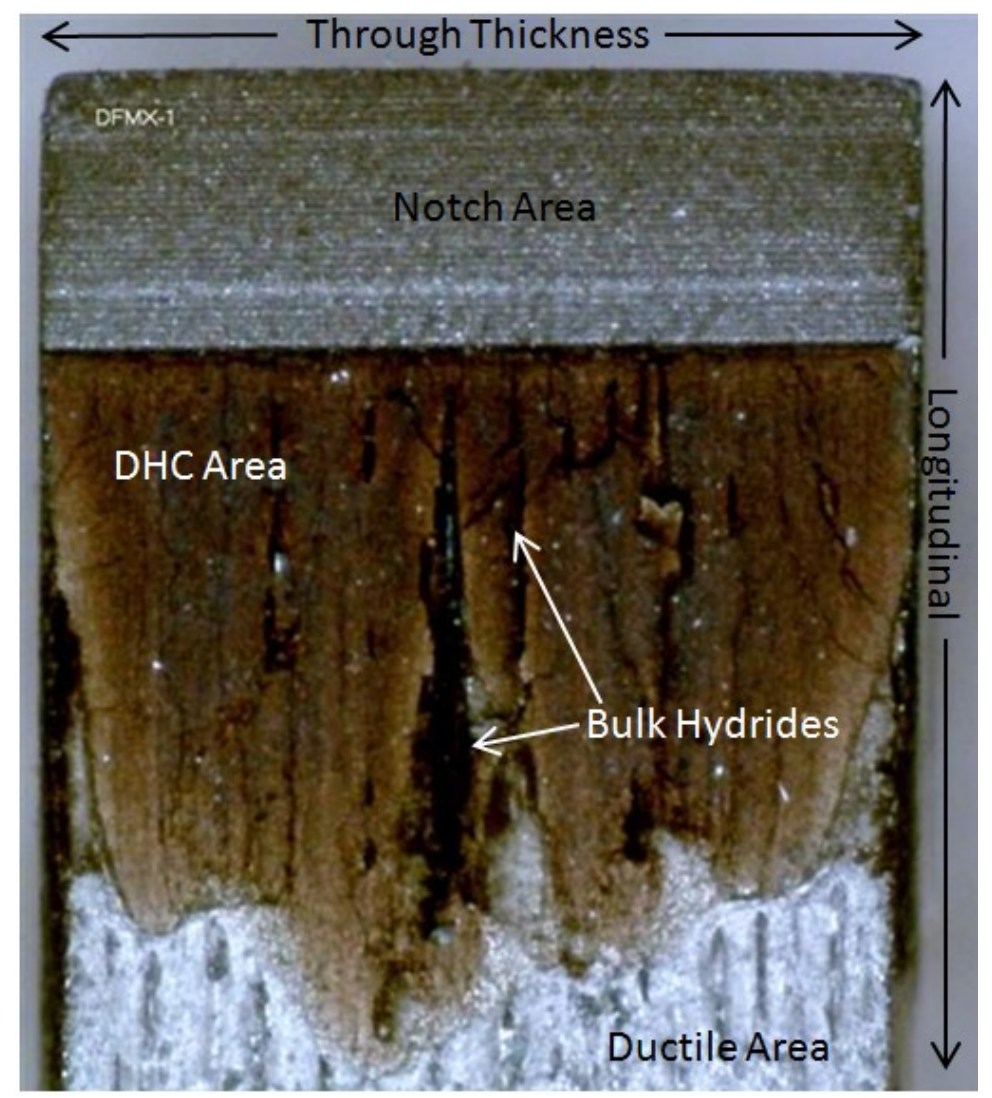

Figure 5 - Longitudinal crack at $250^{\circ} \mathrm{C}$. Cracking direction is from top to bottom (longitudinal direction). Hydrides parallel with direction of propagation.

The fracture surfaces in Figures 4 and 5 suggest that longitudinal and through-thickness DHC cracks interact with bulk hydrides in different ways. Through-thickness cracking seems to be impeded by the bulk hydrides to a greater extent than the longitudinal cracking. The apparent impediment provided by the bulk hydrides will therefore slow the growing DHC hydride more in the through-thickness direction than the longitudinal direction when bulk hydrides are present. If bulk hydrides explain the difference between longitudinal and through-thickness crack velocities, then there should be no difference if there are no bulk hydrides present. These conditions are obtained when specimens are cooled to temperatures just above TSSP, where DHC occurs in the absence of bulk hydrides [Coleman 1979]. 
Thus, the DHC velocities should be the same at temperatures above TSSP, but should be different below. The through-thickness and longitudinal crack velocities as predicted by the CSA equations are shown in Figure 6, along with the velocity ratio [CSA 2005].

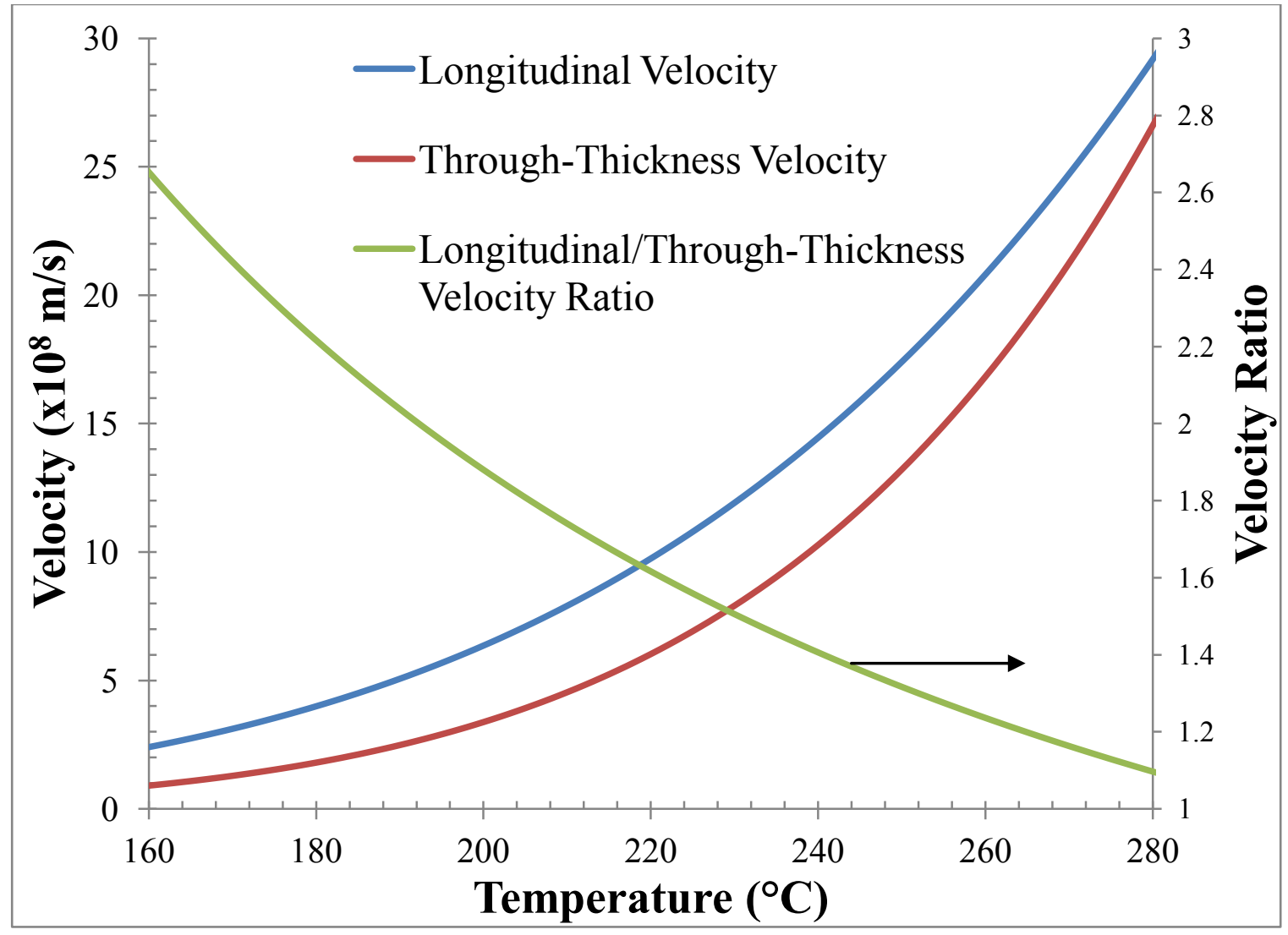

Figure 6 - Longitudinal and through-thickness velocity CSA predictions and longitudinal/through-thickness velocity ratio [CSA 2005]

Figure 6 shows a velocity ratio between 1 and 3. Typical DHC velocity data can vary by a factor of two [IAEA 2004]. To be able to discern the velocity ratio required improved experimental design and multiple measurements to ensure statistical significance, see Chapter 3. 


\subsection{Research Objectives}

The main objective of this thesis was to test whether or not bulk hydrides slow throughthickness cracks to a greater extent than longitudinal cracks. Other objectives of this thesis were:

- To review previous explanations for the difference between through-thickness and longitudinal DHC crack velocities

- To eliminate the geometry effect of curved pressure tubes (cantilever beam specimens manufactured from plate material were tested with the same geometry in the longitudinal and through-thickness directions)

- To improve DHC velocity measurement testing procedure to discern better the differences between longitudinal and through-thickness crack velocities

\subsection{Thesis Organization}

Following this introduction is a literature review in Chapter 2. The literature review describes Delayed Hydride Cracking (DHC), the factors that influence DHC growth rates, and previous explanations for the difference between longitudinal and throughthickness cracking. Chapter 2 also contains a history of DHC in reactors. Chapter 3 includes a description of experimental procedure, the materials used, specimen design, testing, and post-test specimen analyses. Detailed diagrams of experimental rigs and specimen geometry are provided. The experimental results are shown in Chapter 4. Longitudinal and through-thickness velocities for three different bulk hydrogen concentrations are presented, at test temperatures both above and below TSSP. In Chapter 5 the results are discussed in terms of the hypothesis that the orientation of bulk hydrides explains the difference between longitudinal and through-thickness crack velocities. The data suggests that this hypothesis is incorrect. Alternative hypotheses are then presented. Chapter 6 contains conclusions along with suggestions for future work. 


\section{Chapter 2}

\section{Literature Review}

\subsection{Leak-Before-Break}

CANDU reactors contain approximately 380 pressure tubes that are horizontally oriented within the calandria vessel (Figure 1). The pressure tubes are within calandria tubes (Figure 2), with the annulur space between them filled with dry $\mathrm{CO}_{2}$ gas. The heavy water coolant passes through the pressure tube at operating temperatures between $250{ }^{\circ} \mathrm{C}$ and $300{ }^{\circ} \mathrm{C}$, at an average pressure of $10 \mathrm{MPa}$ [Coleman 1988].

Within the normal operating limits of CANDU pressure tubes, three main factors affect the initiation of cracking: stress, environment and material sensitivity. Prevention of crack initiation can be achieved by design, manufacturing procedures, or operational practice [Moan 1990]. If a crack develops in a pressure tube, unstable crack propagation

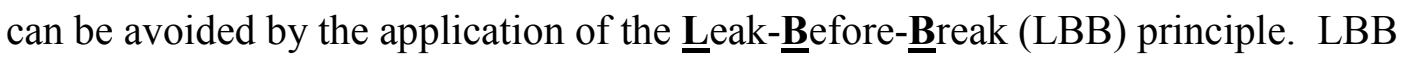
requires:

A. The crack length when a through-wall crack develops to be less than the $\underline{\text { ritical }}$ Crack Length (CCL) for unstable fracture;

B. The leak is detected;

C. Appropriate action is taken to prevent the growing DHC crack from exceeding CCL [Moan 1990].

If a crack propagates by DHC through the wall of a tube, the LBB concept requires timely detection of a leak as well as appropriate action such as shutdown, depressurization and cool-down to ensure the crack does not grow to the CCL [Moan 1990]. 
During service, the probability that LBB will be effective decreases with time because of deuterium ingress into the tubes during service and irradiation damage reducing the fracture toughness. The following parameters affect LBB and change with time [Cheadle 1996]:

- The presence of defects and their size and shape. Defects can grow on the surface during service from fretting and wear.

- The concentration of hydrogen isotopes increases during service. The temperature at which DHC occurs increases with a subsequent increase in crack growth rate, so detection time is decreased.

- Pressure tubes sag during service, increasing the potential to form hydride blisters at locations where a hot pressure tube contacts a cold calandria tube.

- The minimum defect size to initiate DHC may decrease with irradiation damage.

- The CCL is reduced with irradiation damage.

- The reduced capacity to detect leaks in the annulus gas system due to increased moisture ingress from other sources. Rate of increase in dew point will distinguish these slow increases from the relatively fast change with a leak.

DHC cracks initiate at flaws, which are locations with higher tensile stress than in the bulk. The crack grows in both the through-thickness (radial) and longitudinal (axial) directions until it penetrates the wall of the tube and starts leaking. Figure 7 shows the geometry of the growing crack. 


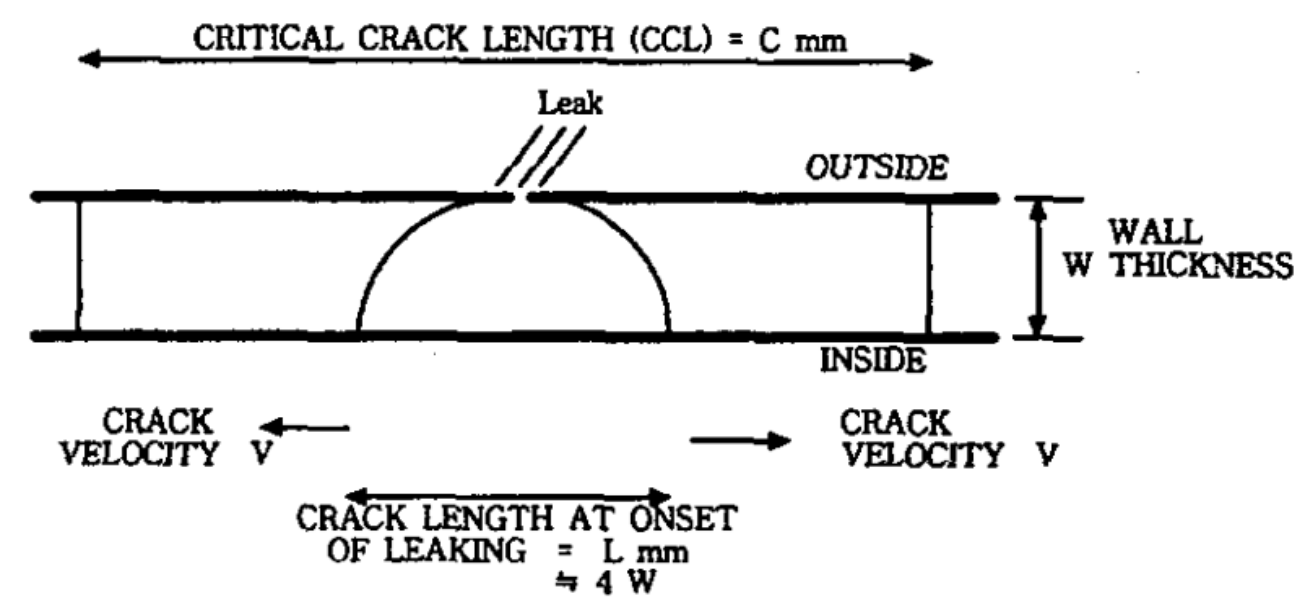

$\begin{aligned} & \text { TIME AVAILABLE } \\ & \text { TO TAKE ACTION }\end{aligned}=\frac{c-4 \mathrm{~W}}{2 \mathrm{~V}}$

Figure 7 - Schematic diagram of crack dimensions at onset of leaking [Moan 1990]

The crack velocity, V, and CCL are temperature dependent and will change with time during start-up and shutdown procedures [Walker 1990]. In cold-worked $\mathrm{Zr}-2.5 \mathrm{Nb}$ pressure tubes, DHC tends to be twice as fast in the longitudinal direction when compared with the through-thickness direction [Moan 1990]. At through-wall penetration, a leak of coolant into the annulus gas system begins and the crack continues to grow towards both end fittings in the longitudinal direction. The time, $t$, to detect the leak and shut down the reactor can be calculated by [Coleman 1988]:

$$
t=\frac{\mathrm{CCL}-L_{0}}{2 \mathrm{~V}} \text { for } L_{0}<\mathrm{CCL}
$$

The minimum value of CCL $(44.7 \mathrm{~mm})$ was calculated from small specimen fracture toughness tests, which give conservative estimates compared to burst tests [Cheadle 1996]. A maximum crack velocity at the inlet operating temperature of $245^{\circ} \mathrm{C}$ was determined to be $2.7 \times 10^{-7} \mathrm{~m} / \mathrm{s}$ [Cheadle 1996]. The initial crack length, $L_{0}$, is assumed to be $16 \mathrm{~mm}$ because the measured length in Pickering and Bruce accidents was generally $16 \mathrm{~mm}$ or less [Moan 1990]. Substituting these values into the equation (2), the time 
available for reactor operators to detect the leaking crack and shut the reactor down is 18 hours. Flow rate, $Q$, in $\mathrm{kg} / \mathrm{h}$, into the annulus gas system is given by [AECL 1]:

$$
Q=0.7618 L-14.86, L>20 \mathrm{~mm}(3)
$$

where $L$ is the crack length in $\mathrm{mm}$. At $L=30 \mathrm{~mm}$, equation (3) yields a flow rate of $8 \mathrm{~kg} / \mathrm{h}$. This leak rate can depend on the crack morphology [Dundulis 2010]. Testing of the annulus gas system shows that alarms will trip with leaks of less than a few $\mathrm{g} / \mathrm{hr}$, confirmed by Nho et al. (1997). The response of the system to a leak depends on the size of the leak, on its location, on the dewpoint of the system when the leak occurred and on the flow rate of the $\mathrm{CO}_{2}$ gas. A leak can be detected by monitoring the dewpoint and its rate of increase; when either of these exceeds a specified value alarms are triggered [Moan 1990].

A leaking DHC crack should be detected safely, enabling the nuclear plant to be shut down before unstable crack propagation occurs [Ali 2010, Xie 1999]. LBB is achieved in pressure tubes because there is sufficient time to detect the leak before failure [Moan 1990, Cheadle 1996].

\subsection{Pressure Tube Microstructure}

The current zirconium alloy used for CANDU pressure tubes is $\mathrm{Zr}-2.5 \mathrm{Nb}$. Niobium is the main alloying element with a concentration specified between 2.4 and 2.8 weight $\%$ (wt \%). The $\mathrm{Zr}-2.5 \mathrm{Nb}$ ingots are extruded and cold-worked to form the pressure tube. These processes determine the crystallographic texture. There are two distinct types of anisotropy in pressure tube material: the grain shape and the crystallographic structure. The cold-working of the pressure tubes flattens the HCP $\alpha-Z r$ grains as shown in Figure 8. The longitudinal direction is parallel to the extrusion direction. An approximation of the pressure tube grain size is as follows: average thickness in the radial direction of 0.4 
$\mu \mathrm{m}$, and average lengths of $3 \mu \mathrm{m}$ and $20 \mu \mathrm{m}$ in the transverse and axial directions, respectively [Cheadle 1981].

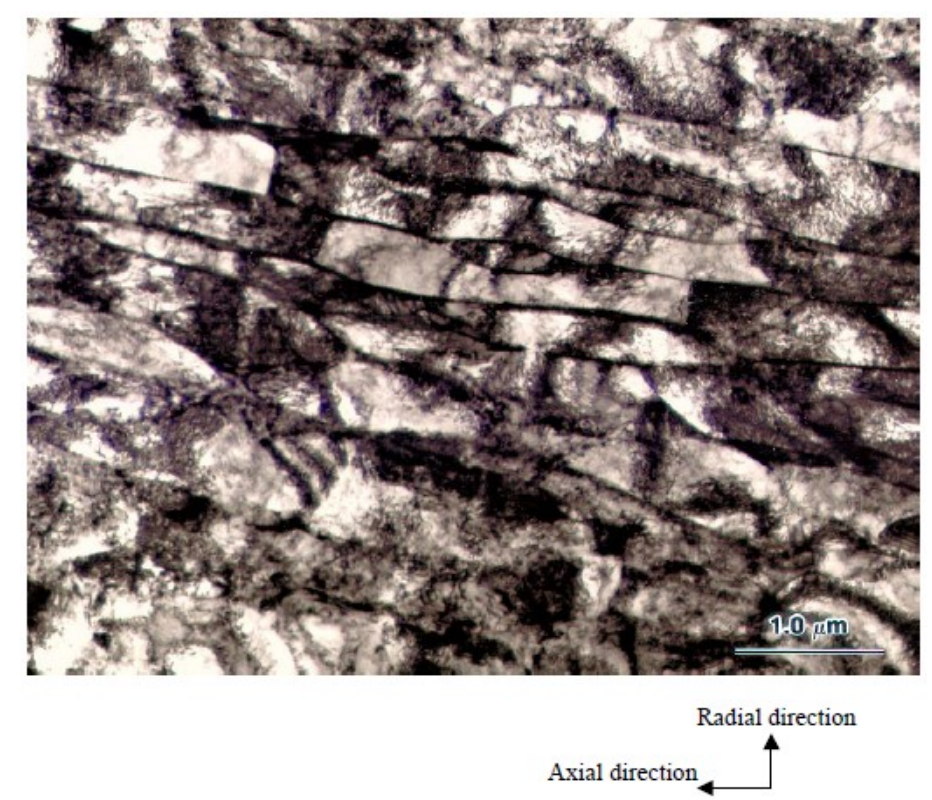

Figure 8 - Microstructure of CANDU pressure tube made from cold-worked Zr2.5Nb. Dark areas are the $\beta$-phase surrounding the lighter $\alpha$-phase [Cheadle 1981]

The $\alpha$-grains in CANDU pressure tube material are surrounded by an intermittent shell of niobium $(\mathrm{Nb})$ rich $\beta$-Zr phase. The $\beta$-phase is Body Centred Cubic (BCC) and represents a small volume fraction within the pressure tube. The $\beta$-phase morphology and the volume fraction are highly dependent on heat treatment [Jovanovic 2001]. The Zr-Nb phase diagram is shown in Figure 9. A $\mathrm{Zr}-2.5 \mathrm{Nb}$ ingot is an $\alpha+\beta-\mathrm{Zr}$ alloy when heated to $780{ }^{\circ} \mathrm{C}$. As the ingot is cooled the $\alpha$-phase follows the $\alpha-\mathrm{Zr}$ line and has less than $1 \%$ $\mathrm{Nb}$. The niobium concentration in the $\beta$-Zr phase is given by curve between $0 \% \mathrm{Nb}$ at 862 ${ }^{\circ} \mathrm{C}$ and $20 \% \mathrm{Nb}$ at $610{ }^{\circ} \mathrm{C}$. At about $610{ }^{\circ} \mathrm{C}$ the $\beta$-Zr phase contains $20 \% \mathrm{Nb}$. As the ingot is cooled below $610^{\circ} \mathrm{C}$, the $\beta-\mathrm{Zr}$ phase is metastable; it thermodynamically prefers to transform into the $\alpha-\mathrm{Zr}$ and $\beta-\mathrm{Nb}$ phases. However, the kinetics of the $\beta-\mathrm{Zr}$ decomposition are slow. The $\beta-\mathrm{Nb}$ phase has a $\mathrm{Nb}$ concentration of over $80 \%$. The 
pressure tubes are heat treated at $400{ }^{\circ} \mathrm{C}$ for 24 hours [Cheadle 1981] which decomposes the $\beta$-Zr. The resulting enriched $\beta$ phase contains $40 \% \mathrm{Nb}$. About $0.5 \%$ of the Niobium is in the $\alpha$-phase at room temperature, leaving $2 \%$ in the $\beta$-phase. If the $\beta$-phase has not decomposed it would contain $20 \%$ Niobium and the $\beta_{1}$ phase would be about $10 \%$ by volume. Fully decomposed $\beta-\mathrm{Nb}$ phase is about $88 \% \mathrm{Nb}$ at room temperature, resulting in a $\beta$-phase fraction of only $2.3 \%$. As-received material with the resulting $\beta$-phase containing $40 \% \mathrm{Nb}$ would have a $\beta$-phase volume fraction of $5 \%$.

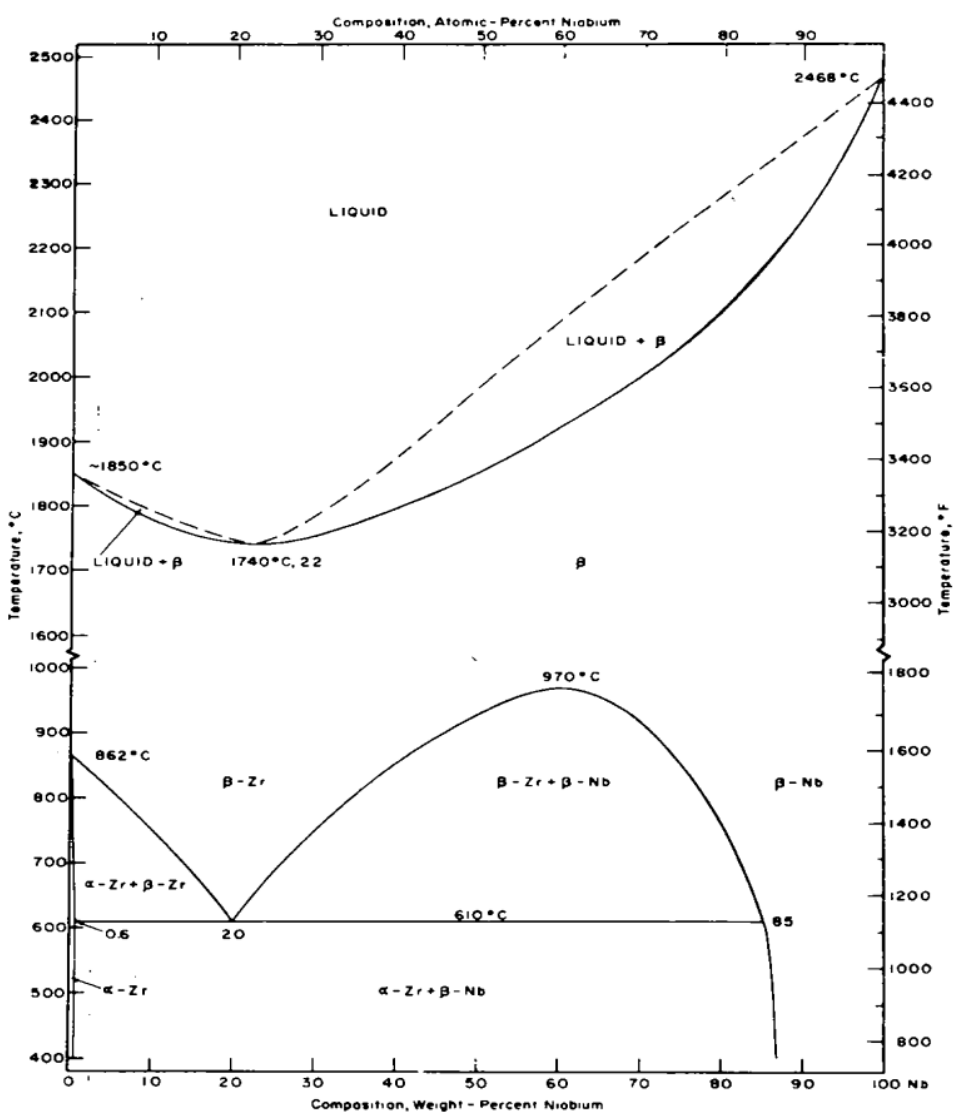

Figure 9 - Zirconium-niobium phase diagram [Lundin 1962] 
HCP crystals are anisotropic due to their hexagonal prism shaped unit cell. Figure 10 shows the hexagonal basal planes at the top and bottom as well as the six rectangular prism planes on the sides of the HCP unit cell.

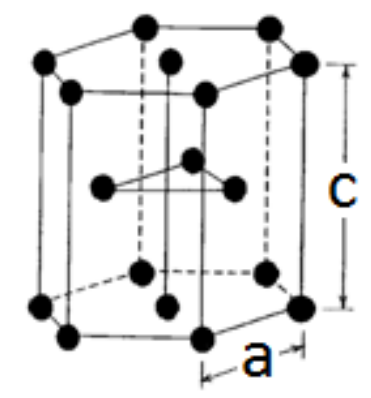

Figure 10 - HCP unit cell

If the directions of the c-axes are not randomly distributed, the material has texture. One way of describing the texture is to use Kearns' Factors. The factors quantify the fraction of c-axes, basal plane normals, oriented in the principle directions: transverse (FT), radial $\left(F_{R}\right)$, and axial $\left(F_{A}\right)$ [Kearns 1965]. The three Kearns' factors sum to 1. Typical Kearns' factors for pressure tubes are: $F_{T}=0.61, F_{R}=0.35$ and $F_{A}=0.04$. These Kearns' factors demonstrate the strong texture of pressure tubes. See Section 3.2.5 for a description of the X-Ray diffraction technique used to produce pole figures.
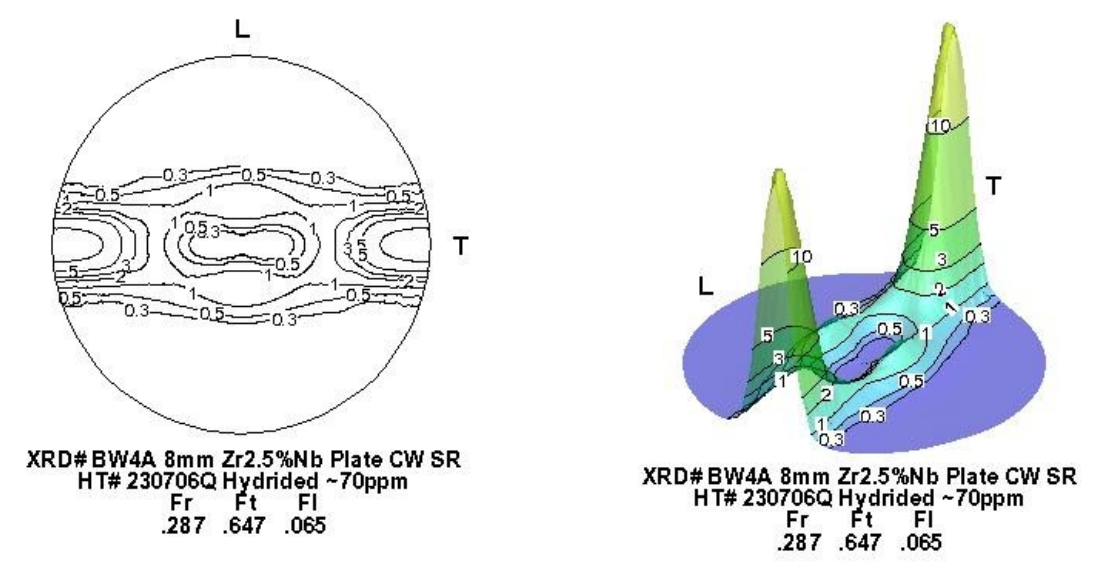

Figure 11 - 2D and 3D pole figures of $\mathrm{Zr}-2.5 \mathrm{Nb}$ material used in this study 
Figure 11 shows a pole diagram that visually represents the Kearns' factors of the material used in this study. The 2-D pole diagram has the following direction representations: transverse peaks at the east and west positions, longitudinal peaks at the north and south positions, and radial peaks at the centre. The $3 \mathrm{D}$ pole diagram in Figure 11 shows the strongest peaks at the transverse locations, with small peaks around the radial location and almost no longitudinal peaks.

\subsection{Zirconium and Hydrogen}

The $\mathrm{Zr}-\mathrm{H}$ phase diagram is shown in Figure 12 [Zuzek 1990]. The part of the diagram relevant in this study is the $\alpha \rightarrow \alpha+\delta / \gamma$ solvus line (see Figure 12 'region of interest').

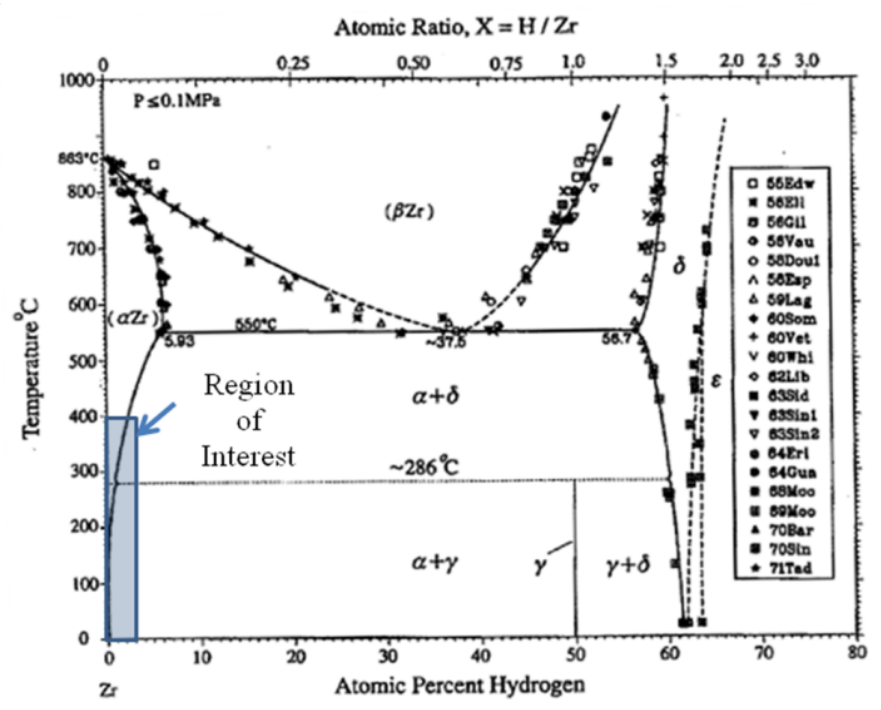

Figure 12: Zirconium - Hydrogen phase diagram [Zuzek 1990]

The hydride stable at high temperatures, designated the $\delta$-phase, is $\underline{\text { Face }} \underline{\text { Centred }} \underline{\mathbf{C u b i c}}$ (FCC) with a composition of $\mathrm{ZrH} 1.6$. $\delta$ hydrides are predicted to form at temperatures higher than $180^{\circ} \mathrm{C}$ [Root 2003]. $\gamma$-hydrides may form during lower temperature cracking and have a composition of $\mathrm{ZrH}$ with a $\underline{B}$ ody $\underline{\text { Centred }}$ Tetragonal (BCT) structure. Hydrogen has a low solubility in the $\alpha$-phase: a maximum value of 5.93 atomic percent, 
or 655 parts per million by weight $\left(5.93 * \frac{1.008 \mathrm{~g} / \mathrm{mol}_{\mathrm{H}}}{91.224 \mathrm{~g} / \mathrm{mol}_{\mathrm{Zr}}} * \frac{1000000}{100}=655 \mathrm{ppm}\right)$ at $550{ }^{\circ} \mathrm{C}$, as shown in Figure 12. The phase diagram shows that hydrogen is a $\beta$-stabilizer. For $\beta$-phase TSS see Sawatzky et al. (1982).

\subsection{Precipitation}

The region of interest in the phase diagram in Figure 12 is shown in Figure 13 in terms of $\underline{\text { Parts }} \underline{\mathbf{P}}$ er Million by weight (ppm) hydrogen in zirconium. The solvus curve in Figure 13 , TSSP, is the temperature at a specific hydrogen concentration where hydrides will begin precipitation on cooling [Pan 1996, Erickson 1964].

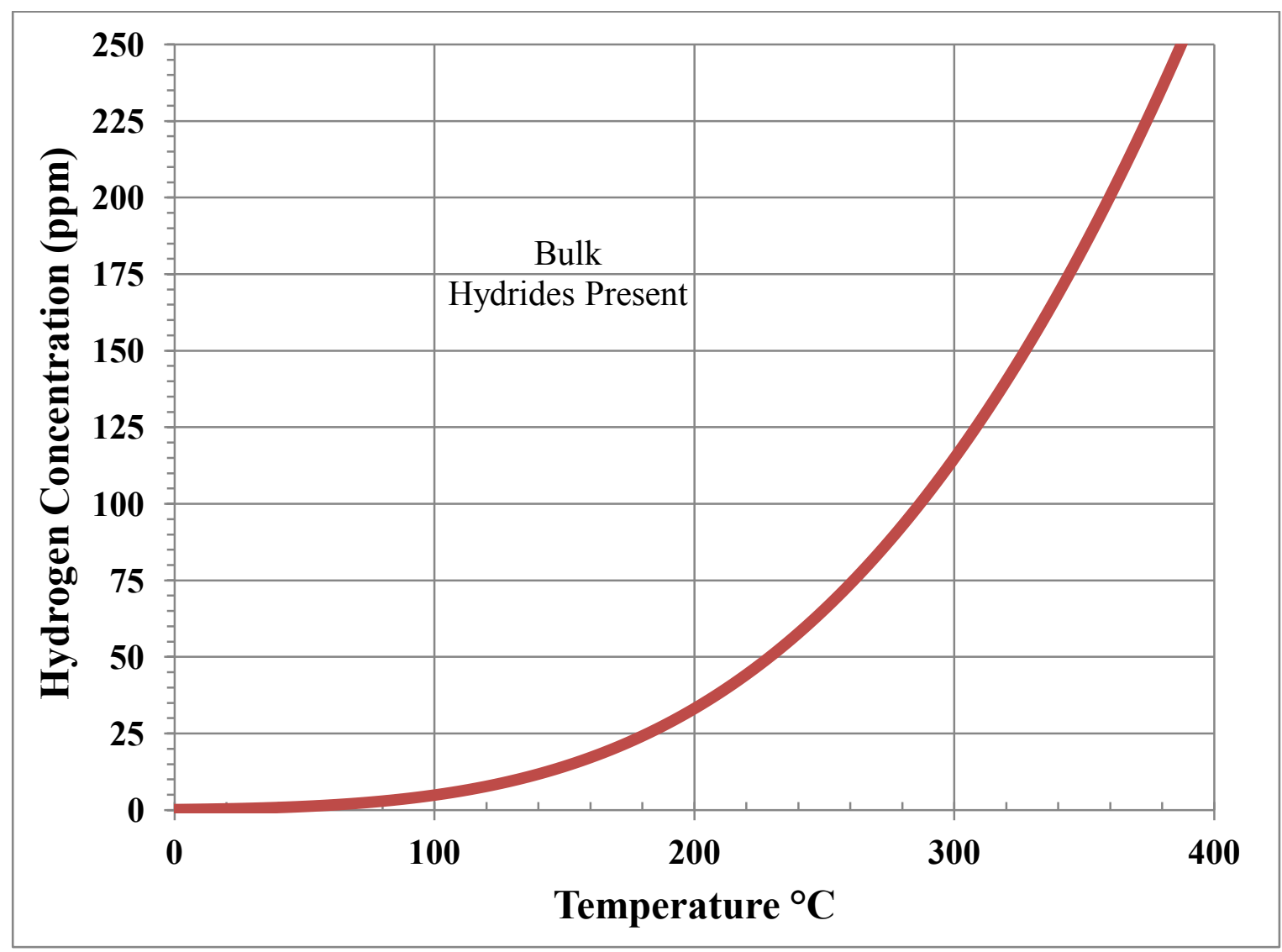

Figure 13 - CSA terminal solid solubility for precipitation curve for hydrogen in $\mathrm{Zr}$ 2.5Nb [CSA 2005] 
The solvus is where hydrogen in solution is in equilibrium with hydrogen as hydride. When $\mathrm{Zr}-2.5 \mathrm{Nb}$ containing hydrogen is heated to a temperature where all hydrogen is in solution and then cooled to form hydrides, the concentration of hydrogen in solution is given by equation 4, shown in Figure 13 [CSA 2005].

$$
C_{p}=41100 \exp \left(\frac{-28000}{8.314 T_{p}}\right)
$$

where $C_{p}$ is the concentration for precipitation and $T_{p}$ is the temperature for precipitation. For example, the TSSP temperature at $66 \mathrm{ppm}$ is approximately $250{ }^{\circ} \mathrm{C}$. The limit for the maximum allowed as-received hydrogen concentration in pressure tubes is $5 \mathrm{ppm}$ [Theaker 1994]. At a concentration of 5 ppm, bulk hydrides begin to precipitate at $100{ }^{\circ} \mathrm{C}$ on cooling.

An objective of this study was to analyze the DHC velocities for specimens cooled to test temperatures above and below TSSP, see Section 3.4.2. The temperature at which hydrides precipitate can be determined using $\underline{\text { Differential }} \underline{\text { Scanning }} \underline{\text { Calorimetry (DSC) }}$ (Section 3.2.4). There are several features on a DSC curve that have been associated with hydride dissolution [Khatamian 2006].

During cooling, DSC curves can be analyzed to determine the maximum-slope temperature, peak temperature, as well as an onset temperature, shown in Figure 14. The onset temperature is where the heat flow curve first begins to deviate exothermically because of hydride precipitation. In this study, the onset temperature is used to determine the temperature at which hydrides precipitate on cooling. 


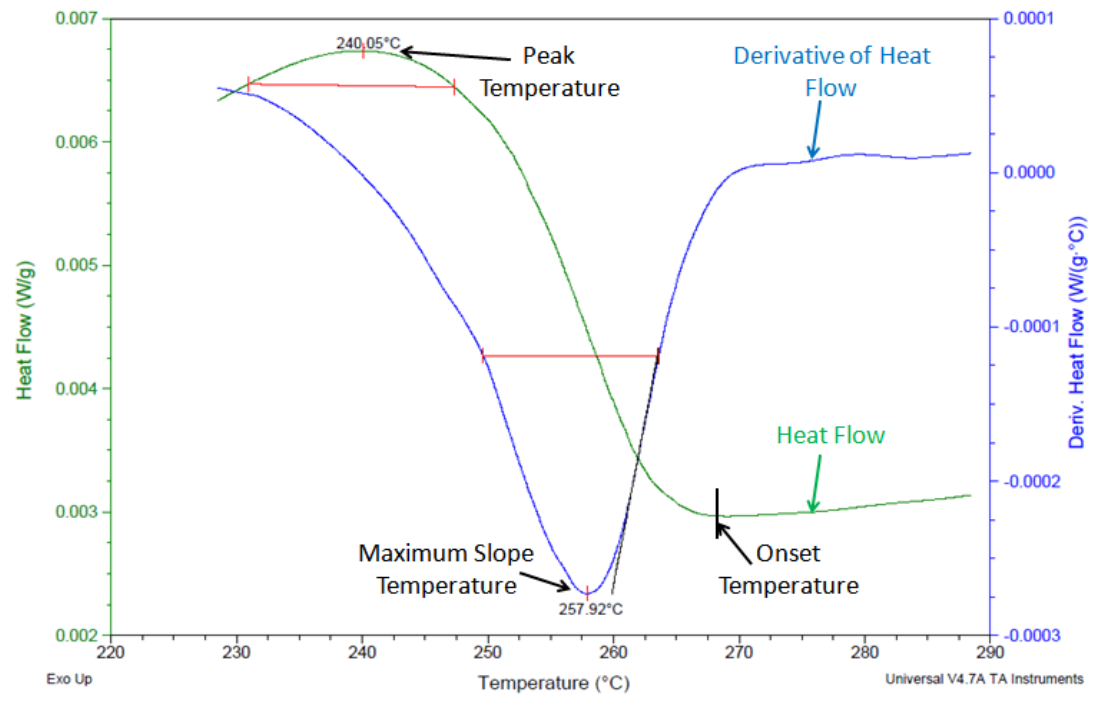

\section{Figure 14 - DSC curve on cooling a sample from a cantilever beam specimen tested in this study containing 64 ppm hydrogen. See Section 3.2.4.}

\subsection{Diffusion}

The force moving hydrogen in zirconium can be described in terms of the gradient in chemical potential. Hydrogen moves interstitially within the zirconium matrix with a flux proportional to a diffusion coefficient. Crack velocity is proportional to the hydrogen flux, thus it is also proportional to the diffusion coefficient [McRae 2010].

In a heavy water reactor, deuterium will ingress into the pressure tubes during the corrosion process. In this study, protium, not deuterium, was used because zirconium hydrides and deuterides behave the same chemically, and diffusion of the lighter protium is faster than deuterium, so the DHC crack velocities are higher and the experimental times are shorter. In addition, using protium avoids the costs of electrolytic deuteriding. Isotopic diffusion varies as the square root of the mass ratio, thus protium has a predicted diffusion coefficient $41 \%$ higher than deuterium. Experimental results showed protium having a diffusion coefficient 50\% higher than deuterium [Gulbransen 1954]. 
Diffusion rates are different in different phases within the pressure tube, with diffusion being faster in the $\beta$-phase than in the $\alpha$-phase by almost two orders of magnitude

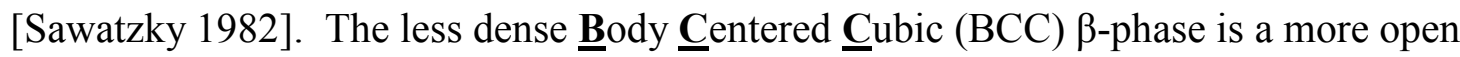
structure than the HCP $\alpha$-phase; the atomic packing factor is less for BCC versus HCP lattices. A lower packing factor allows the hydrogen in the $\beta$-phase more space to occupy interstitial positions and lower activation energy when moving interstitially. In asextruded $\mathrm{Zr}-2.5 \mathrm{Nb}$, the $\beta$-phase is essentially continuous and acts as a diffusion short cut, speeding up hydride growth rates. The $\beta$-phase continuity can be reduced by heattreatment to an extent determined by time at a given temperature [Skinner 1990]. Pressure tubes are subjected to a 24 hour anneal at $400{ }^{\circ} \mathrm{C}$, which partially decomposes the $\beta$-phase [Jovanovic 2001].

The gradient in chemical potential responsible for moving hydrogen in zirconium can be written in terms of gradients of concentration, temperature, and stress. In the absence of other gradients, hydrogen moves from high to low concentration, high to low temperature, and to regions under tension. Hydrogen moves to regions of tension because of the tensile elastic strain, which creates larger interstitial spaces for the hydrogen to occupy.

\subsection{Hydrides}

Hydride nucleation and growth can occur anywhere in the $\mathrm{Zr}-2.5 \mathrm{Nb}$ microstructure, including at grain boundaries and twin boundaries. When $\mathrm{Zr}-2.5 \mathrm{Nb}$ is cooled, the size of the hydride precipitates depends on the cooling rate. After fast cooling or quenching, many small hydrides are present, while after slow cooling there are fewer but larger hydrides [Ells 1968]. 
Many experiments to observe hydride orientation have been performed since hydride nucleation, growth and fracture was recognized as the cause of DHC [Simpson 1974]. When hydrides are precipitated in annealed $\mathrm{Zr}-2.5 \mathrm{Nb}$, the hydride normal is almost perpendicular to the basal plane of the $\alpha$-phase HCP structure [Parry 1962]. These observations suggest the crystallographic texture might be correlated with the distribution of hydrides. Pressure tubes are cold-worked with the compressive direction of coldworking through the thickness of the tube: see Figure 4 and 5 where hydride normals are in the through-thickness direction. Hydrides tend to precipitate with their normal parallel to the compressive direction of working, contrary to the effect of texture, which would align the hydride normal in the transverse direction [Parry 1962].

Tensile stress can cause hydrides to re-orient with plate normals parallel to the stress [Louthan 1963]. With no stress reorientation, hydrides in a pressure tube will generally have normals in the radial direction. In material with no cold work and a random texture the hydride normals will be in all directions. By convention, a hydride with a normal in the radial direction is called a circumferential hydride. If a hoop stress is applied, and the pressure tube is cooled, some hydrogen will precipitate as hydrides with normals parallel to the direction of stress, in this case the transverse direction. Hydrides with a normal in the transverse direction are called radial hydrides. On cooling under hoop stress a pressure tube will have both circumferential and radial hydrides. A micrograph showing stress reoriented hydrides in a cold-worked $\mathrm{Zr}-2.5 \mathrm{Nb}$ pressure tube is shown in Figure 15. In this example, a tube containing $110 \mathrm{ppm}$ hydrogen in the form of circumferential hydrides was heated to $320^{\circ} \mathrm{C}$ and then cooled to room temperature under a hoop stress of $420 \mathrm{MPa}$. About $70 \mathrm{ppm}$ of the hydrogen would be in solution at the peak temperature and would re-precipitate as radial hydrides upon cooling, resulting in a final microstructure consisting of both circumferential and radial hydrides. In Figure 15, the hydrides are the dark jagged lines within the lighter $\alpha$-phase grains. These lines are twodimensional cuts of the three-dimensional disk-shaped hydrides. 
Hydride can consist of many small hydrides stacked with all their normals perpendicular to the HCP basal plane. When hydrides are close, the strain of one hydride helps to nucleate its neighbors. The hydride could look like many short lines lined up with small gaps in between using the resolution of an electron microscope [Weatherly 1981]. At the lower resolutions found in light microscopy, the gaps between the small hydrides can disappear and the many small hydrides resemble one much larger hydride with a normal orthogonal to the individual hydride normals [Parry 1966].
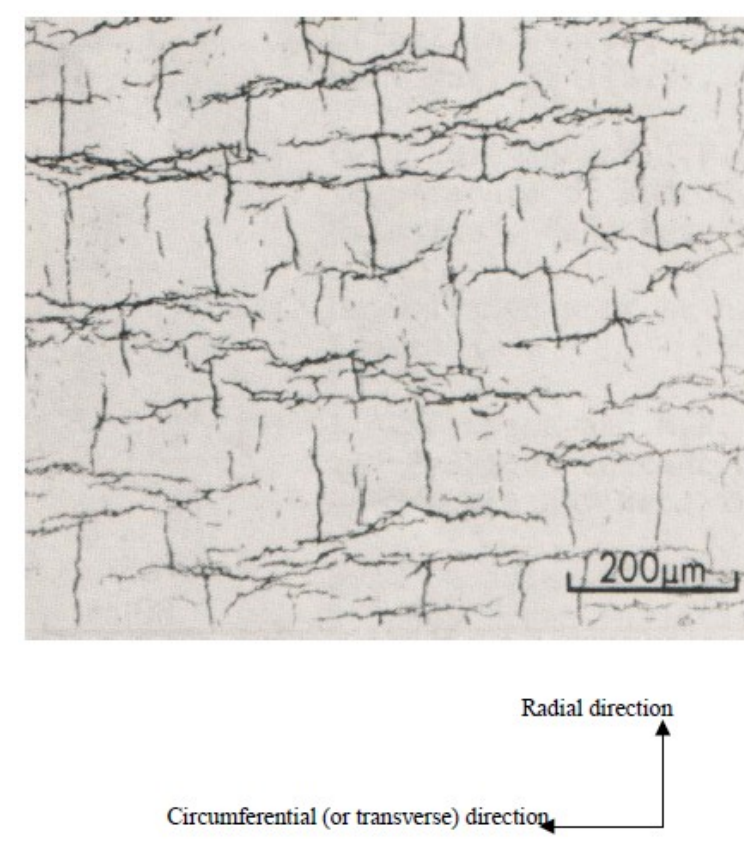

Figure 15 - Stress re-oriented hydrides in $\mathrm{Zr}-2.5 \mathrm{Nb}$

Residual stress fields can have the same re-orienting effect as an external stress. If the residual stresses are removed, i.e. by annealing, the hydrides can reconfigure to their original orientation [Hardie 1973]. 


\subsection{Stress Intensity Factor}

The steps for DHC are listed in Section 1.2, one of which is the fracture of a hydride. For a hydride to fracture, a minimum stress intensity factor, $\mathrm{K}_{\mathrm{IH}}$, is required. The relationship between $\mathrm{K}_{\mathrm{I}}$ and crack velocity is shown in Figure 16. Below $\mathrm{K}_{\mathrm{IH}}$ the crack growth rate is zero, so DHC will not occur. At $\mathrm{K}_{\mathrm{IH}}$, the crack growth rate increases rapidly with increasing stress intensity from zero to a stable crack growth rate. When the stress intensity factor reaches $\mathrm{K}_{\mathrm{IC}}$ unstable crack growth occurs. The crack velocity in the unstable region can be several orders of magnitude larger than in the stable crack growth region and is independent of the effective hydrogen diffusion coefficient. DHC is the name given to cracking in the stable growth region. DHC velocities are measured as a function of stress intensity factor, $\mathrm{K}_{\mathrm{I}}$, in the stable crack growth region [Coleman 2008]. From experiments on $\mathrm{Zr}-2.5 \mathrm{Nb}$ specimens, $\mathrm{K}_{\mathrm{IH}}$ is between 4.5 and $11 \mathrm{MPa} \sqrt{\mathrm{m}}$ [Coleman 1982]. $\mathrm{K}_{\mathrm{IC}}$ is estimated to be between $60 \mathrm{MPa} \sqrt{\mathrm{m}}$ and $110 \mathrm{MPa} \sqrt{\mathrm{m}}$ [Aitchison 1969].

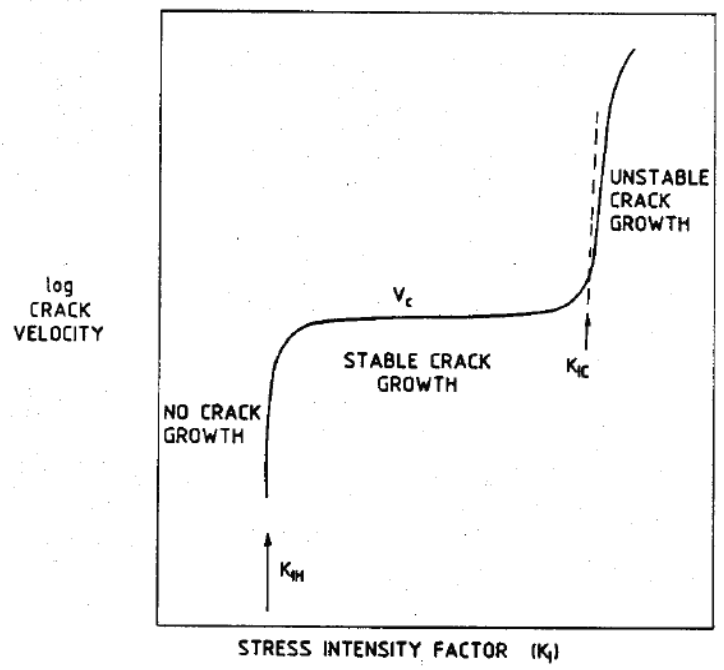

Figure 16 - Schematic diagram showing dependence of DHC velocity on $\mathrm{K}_{\mathrm{I}}$ with three stages: Stage 1) no cracking up to a threshold, called $K_{I H}$, after which the cracking rate changes rapidly with $K_{I}$. Stage 2) Stable crack growth, having little rate change with increase in $K_{I}$. Stage 3) The onset of unstable cracking when $K_{I C}$ is reached 


\subsection{Triaxial Notch Stress}

A stress state higher than that in the bulk will be present in local regions around flaws under applied stress. A notch is an example of a flaw. The stress state will depend on the geometry of the flaw, with the worst case being a very sharp crack creating the highest rise in stress. A schematic diagram of a stress field at a flaw is shown in Figure 17.

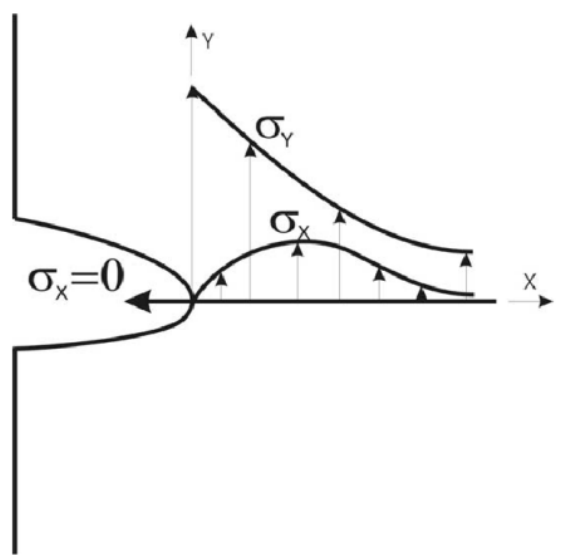

Figure 17 - Schematic diagram of the stress field at a flaw

Even if the bulk applied stress is uniaxial, the stress state at the notch will be at least biaxial. At the free surface of the notch the stress will be zero. The stresses $\sigma_{\mathrm{x}}$ and $\sigma_{\mathrm{y}}$ at the root of the notch are principal stresses $\sigma_{1}$ and $\sigma_{2}$. Due to the stress concentration they are large and therefore so are the strains $\varepsilon_{1}$ and $\varepsilon_{2}$. By Hooke's law the strain at the surface, where $\varepsilon_{\mathrm{z}}$ is not constrained, in the $z$ direction is given by:

$$
\varepsilon_{z}=-v \frac{\sigma_{x}}{E}-v \frac{\sigma_{y}}{E} \text { where } \sigma_{z}=0
$$

However, within the specimen the strain in the $z$ direction is constrained by surrounding material which causes a tension $\sigma_{\mathrm{z}}$. If $\varepsilon_{\mathrm{z}}$ is completely constrained then: 


$$
\begin{gathered}
\varepsilon_{z}=\frac{\sigma_{z}}{E}-v \frac{\sigma_{x}}{E}-v \frac{\sigma_{y}}{E}=0 \\
\sigma_{z}=v\left(\sigma_{x}+\sigma_{y}\right)
\end{gathered}
$$

If the notch is very sharp, $\sigma_{x}=\sigma_{y}$, so:

$$
\sigma_{z}=2 v\left(\sigma_{x}\right)
$$

At the free surface in the $z$ direction the stress $\sigma_{z}$ is zero, therefore the stress state is biaxial, this limit is referred to as plane stress. At points internal along the $\mathrm{z}$ axis $\sigma_{\mathrm{z}}$ is not zero, therefore the stress state is triaxial, this limit is referred to as plane strain. Figure 18 shows that the notch tip stresses are much higher in plane strain than in plane stress: in plane strain yielding occurs at $\sigma_{z}=3 F_{t y}$ while in plane stress $\sigma_{z}=F_{t y}$. Therefore, the plane strain condition can more easily lead to the fracture of a hydride [Broek 1982]. A Poisson's ratio, $v$, of 0.33 is assumed in Figure 18.

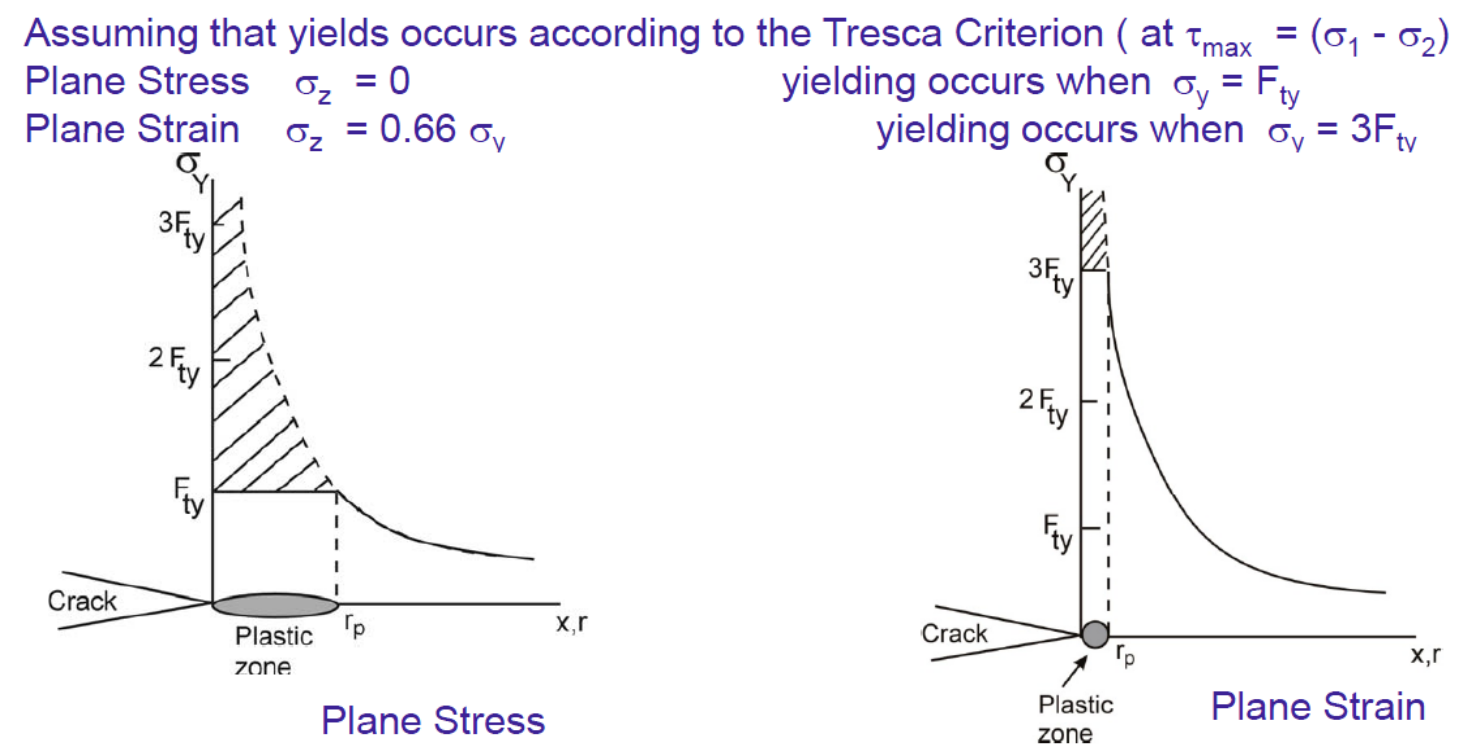

Figure 18 - Use of Tresca criterion to predict plastic zone size and stress gradient [Bell 2001] 
The concepts of plane stress and plane strain can be applied to notched DHC velocity samples. It has been shown that the cracking of hydrides depends on the stress state and is promoted by the triaxial state of stress at the notch where stresses are concentrated [Yunchang 1985, Rice 1970, Wilkins 1978, Simpson 1981]. However, the constraint along the breadth of the specimen will be relaxed near the free surfaces; these regions will be in plane stress or a transition between plane stress and plane strain [Simpson 1981].

\subsection{Through-Thickness vs. Longitudinal Crack Velocity}

For $\mathrm{DHC}$ in $\mathrm{Zr}-2.5 \mathrm{Nb}$ pressure tube material the longitudinal crack velocity is generally faster than through-thickness crack velocity, see Section 1.3 Figure 6 [CSA 2005].

Several explanations for the difference in longitudinal and through-thickness crack velocities are outlined in this section.

\subsubsection{Stress Gradient Anisotropy}

A study by Kim et al. (2002) attributed the difference between longitudinal and throughthickness crack velocities to anisotropy of the stress gradient ahead of the crack tip.

It is generally accepted that one of the main driving forces for the diffusion of hydrogen is a stress gradient between the crack tip and the bulk. Kim et al. (2002) theorized that the higher DHC velocity in the longitudinal direction as compared with the radial direction is related to an anisotropic stress distribution near the crack tip. 
The hydride fracture toughness, $\mathrm{K}_{\mathrm{IH}}$, has an anisotropic behavior with crack growth direction: the fracture of a DHC crack in the longitudinal direction of the $\mathrm{Zr}-2.5 \mathrm{Nb}$ pressure tube requires a lower stress intensity factor than a DHC crack in the radial direction [Kim 2002].

Sections of a $\mathrm{Zr}-2.5 \mathrm{Nb}$ pressure tube were flattened and stress relieved at $400{ }^{\circ} \mathrm{C}$ for 72 hours [Kim 2002]. The flattened CB specimens were made with dimensions $20 \mathrm{~mm}$ by 4 $\mathrm{mm}$ by $4 \mathrm{~mm}$, as shown in Figure 19. Both the radial and longitudinal specimens had an initial notch depth of $1.5 \mathrm{~mm}$ and had a $1.5 \mathrm{~mm}$ radius of curvature. These specimens were electrolytically hydrided and annealed to a final concentration of $60 \mathrm{ppm}$ hydrogen before testing. The $\mathrm{DHC}$ test temperature ranged from $180{ }^{\circ} \mathrm{C}$ to $270{ }^{\circ} \mathrm{C}$.
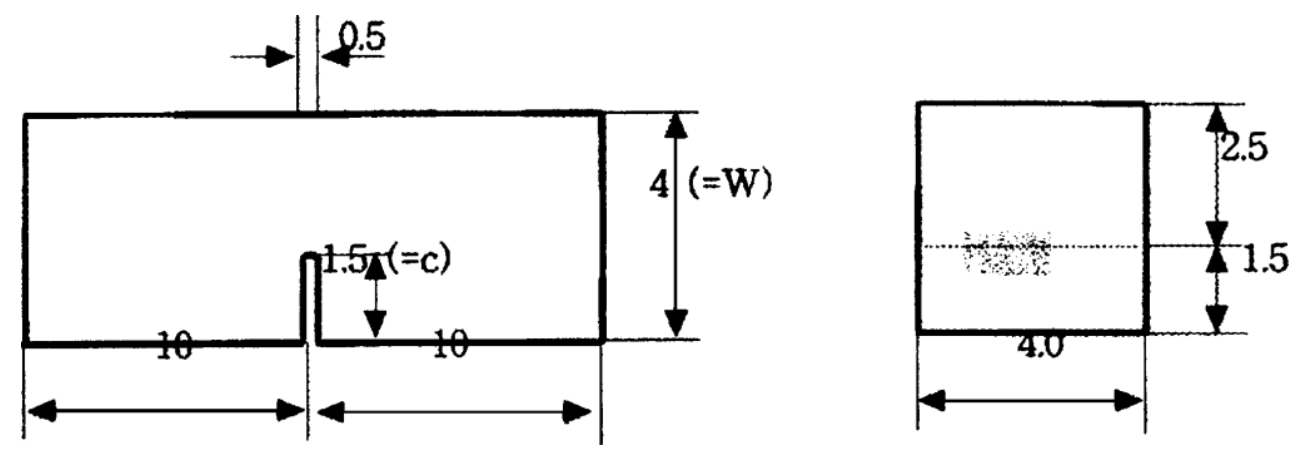

\section{Figure 19 - Schematic diagram of cantilever beam specimens from flattened pressure tube. Figure taken from Kim et al. (2002)}

Figure 20 shows the DHC velocity results of the $\mathrm{Zr}-2.5 \mathrm{Nb}$ pressure tube specimens as a function of orientation. The DHC velocities in the longitudinal direction were higher than those in the through-thickness (radial) direction. Figure 20 shows a gradual decrease in the velocity difference with increasing temperature, which agrees with previous work [Sagat 1994]. 
Kim et al. (2002) measured yield strength and tensile strength for small tensile specimens with length and diameter of $3 \mathrm{~mm}$. The yield strengths in the radial direction were similar to those in the longitudinal direction. However, the tensile strengths in the longitudinal direction were higher than those in the radial direction between room temperature and $320^{\circ} \mathrm{C}$. The difference in tensile strength suggests higher strain hardening after yielding in the longitudinal direction than in the radial direction. The strain hardening of $\mathrm{Zr}$ $2.5 \mathrm{Nb}$ as a function of direction is quantified in Figure 21 where the difference between tensile and yield strength divided by yield strength is shown as a function of temperature. Figure 21 demonstrates that strain hardening is larger in the longitudinal direction than the through-thickness (radial) direction.

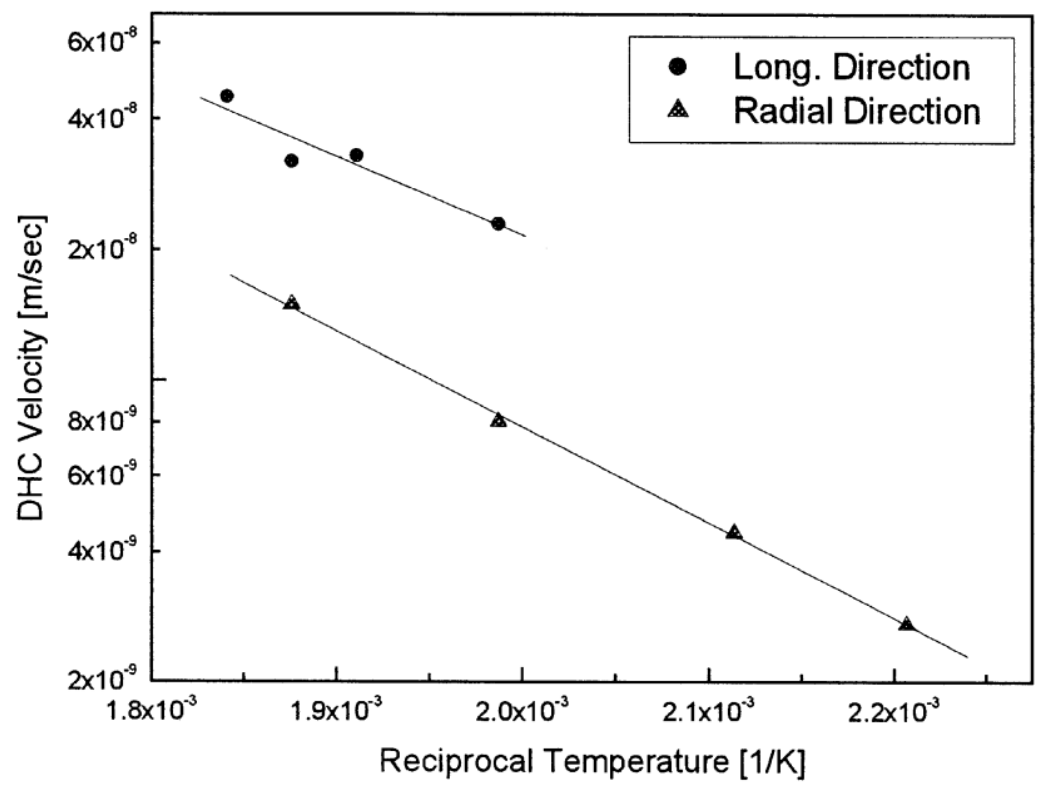

Figure 20 - DHC velocity of flattened pressure tube cantilever beam specimens with cracking from $170{ }^{\circ} \mathrm{C}$ to $270{ }^{\circ} \mathrm{C}$

The difference in the strain hardening in both directions decreases with an increase in temperature. This smaller difference in hardening with temperature may explain the 
apparent trend for a gradual reduction of the difference in DHC velocity with crack direction with increasing temperature, shown in Figure 20 [Kim 2002].

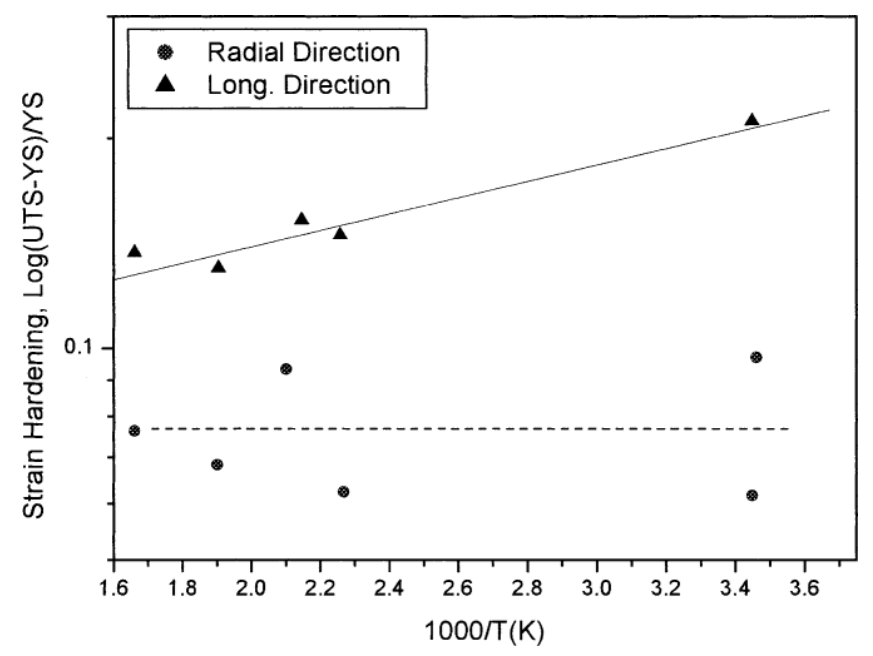

Figure 21 - Strain hardening in the radial and longitudinal directions ( $=($ UTS-YS)/YS ) as a function of $1 /$ T

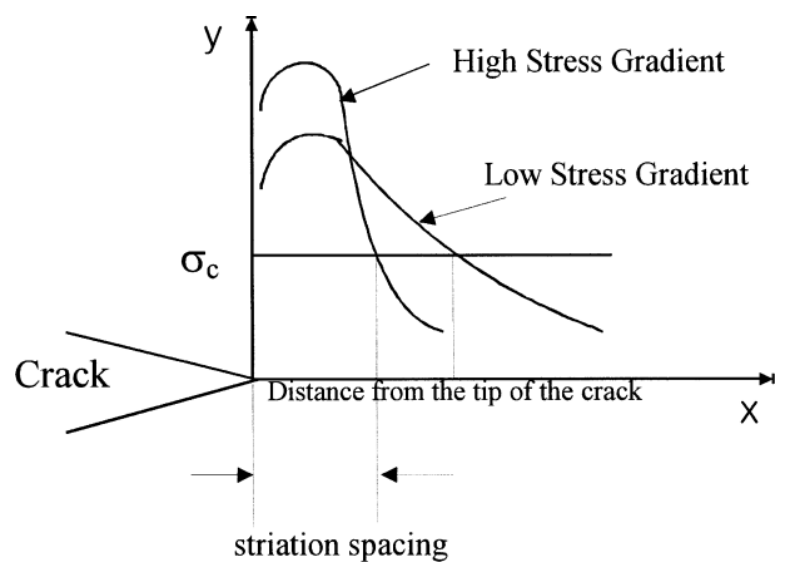

Figure 22 - Steeper stress gradient ahead of the crack tip in the longitudinal direction of the $\mathrm{Zr}-2.5 \mathrm{Nb}$ pressure tube than the radial direction [Kim 2001]

It was suggested that the peak stress ahead of the crack tip is higher in the longitudinal direction due to higher strain hardening than that in the radial direction, leading to a 
higher DHC velocity. The higher peak stress ahead of the crack tip in the longitudinal direction yields a steeper stress gradient ahead of the crack tip than that in the radial direction, as described schematically in Figure 22 [Kim 2002].

A striation is a thin band of ductile failure that separates two hydride brittle fracture areas [Nuttall 1978]. Assuming $\sigma_{c}$ in Figure 22 is the critical stress to fracture the hydrides, the striation spacing will be shorter under the high stress gradient but longer under the lower stress gradient [Kim 2002]. The striation spacing will therefore be shorter in the longitudinal direction where the stress gradient is predicted to be higher than in the radial direction.

Kim et al. (2002) concluded that higher DHC velocity and lower threshold-stress intensity factor, $\mathrm{K}_{\mathrm{IH}}$, in the longitudinal direction of the $\mathrm{Zr}-2.5 \mathrm{Nb}$ pressure tube is caused by stress gradient anisotropy.

\subsubsection{Beta Phase Distribution}

The difference between longitudinal and through-thickness crack velocities has been attributed to the morphology and distribution of the $\mathrm{Zr}-2.5 \mathrm{Nb} \beta$-phase. This section will review studies by Jovanovic et al. (2001) and Skinner and Dutton (1990).

The microstructure of cold-worked $\mathrm{Zr}-2.5 \mathrm{Nb}$ pressure tube consists of grains of $\mathrm{HCP}$ $\alpha$-phase that are elongated in the longitudinal direction and surrounded by an intermittent film of $\mathrm{Nb}$ enriched $\beta-\mathrm{Zr}$ with a composition of between $20 \% \mathrm{Nb}$ and $\sim 90 \% \mathrm{Nb}$, depending on time and temperature. More detail on the $\beta$-phase can be found in Section 2.2 . 
Jovanovic et al. (2001) tested curved cantilever beam specimens to measure DHC velocity in the axial and the radial directions using a cold-worked $\mathrm{Zr}-2.5 \mathrm{Nb}$ pressure tube manufactured for Darlington Nuclear Generating Station. This tube was acquired prior to the final autoclaving at $400{ }^{\circ} \mathrm{C}$ for $24 \mathrm{~h}$. Hydrogen was added by electrolytic hydriding at $90{ }^{\circ} \mathrm{C}$ for $24 \mathrm{~h}$. The specimens had hydrogen concentrations close to $60 \mathrm{ppm}$ after being diffusion annealed at $300{ }^{\circ} \mathrm{C}$ for $36 \mathrm{~h}$. For comparison, Jovanovic et al. (2001) equate this annealing time to $1 \mathrm{~h}$ at $400{ }^{\circ} \mathrm{C}$. Subsequent specimens were annealed for 24 or $1000 \mathrm{~h}$ at $400{ }^{\circ} \mathrm{C}$. DHC velocity tests were performed in both the axial and radial direction for all three annealing conditions. All specimens were loaded to an initial stress intensity factor of $17 \mathrm{MPa} \sqrt{ }$, which is the same stress intensity used in this study.

In general, the $\beta$-phase ligaments become less continuous with increasing annealing time. Scanning Election Microscope (SEM) samples were cut from each annealed tube before the tube was machined into cantilever beam specimens. These samples were examined in an SEM to determine how the $\beta$-phase morphology changed with annealing time at $400{ }^{\circ} \mathrm{C}$. After 1 hour of equivalent annealing, the $\beta$-phase was observed to be thin and relatively long, but not fully continuous. After annealing for $24 \mathrm{~h}$, the $\beta$-phase ligaments became shorter and some discrete $\beta$-phase particles were seen. The $\beta$-phase ligament decomposition had progressed in both the tangential and axial (longitudinal) directions after $1000 \mathrm{~h}$ of annealing. A summary of the $\beta$-phase ligament measurements from the SEM study is shown in Table 1 [Jovanovic 2001].

\section{Table 1 - Dimension of the $\beta$-phase ligaments [Jovanovic 2001]}

\begin{tabular}{lllc} 
Dimension of the $\beta$-phase ligaments & & \\
\hline $\begin{array}{l}\text { Time of } \\
\text { annealing }(\mathrm{h})\end{array}$ & $\begin{array}{l}\text { Length in axial } \\
\text { direction }(\mathrm{nm})\end{array}$ & $\begin{array}{l}\text { Length in tangential } \\
\text { direction }(\mathrm{nm})\end{array}$ & $\begin{array}{l}\text { Length in radial } \\
\text { direction }(\mathrm{nm})\end{array}$ \\
\hline 1 & $\mathrm{a}$ & $200-4000$ & $50-300$ \\
24 & $300-8000$ & $200-2.250$ & $100-400$ \\
1000 & $100-1700$ & $100-1000$ & $40-200$ \\
\hline
\end{tabular}

\footnotetext{
${ }^{a}$ It was not possible to carry out accurate measurements due to irregular boundaries between the $\alpha$-phase and the $\beta$-phase.
} 
The rapid diffusion provided by continuous $\beta$-phase was hypothesized to increase the effective diffusion coefficient of hydrogen in the $\mathrm{Zr}-2.5 \mathrm{Nb}$ samples. When the continuity of the $\beta$-phase was disrupted by heat treatment, the effective diffusion coefficient and DHC velocity both decreased. The DHC velocity is proportional to the diffusivity, where a reduction in diffusivity will decrease the DHC velocity. Jovanovic et al. (2001) show that the maximum DHC velocity was obtained with a continuous $\beta$-phase. There was a progressive decrease of the velocity as the $\beta$-phase decomposed with longer annealing time. The study suggests that $\beta$-phase decomposition slows the crack velocity.

Figure 23 shows the DHC velocity results. The DHC radial velocity results were reduced by a factor of three at $240{ }^{\circ} \mathrm{C}$ for specimens annealed at $400{ }^{\circ} \mathrm{C}$ for $1 \mathrm{~h}$ compared with those annealed at $400{ }^{\circ} \mathrm{C}$ for $1000 \mathrm{~h}$. However, the DHC axial velocity results were reduced by a factor of five for the same annealing conditions and test temperature. Jovanovic et al. (2001) argue the factor of three is accounted for by the reduction in strength during annealing. This strength change could be attributed to the reduction of residual stresses during the annealing. The strength ratio in the axial and the radial direction was approximately the same after the 1000 hour anneal, so strength alone could not account for the factor of five for the axial velocities. The difference between the factor of three and five is hypothesized to be because of the decomposition of the $\beta$-phase, which interrupted the fast diffusion pathways for hydrogen in the longitudinal direction more than in the radial direction.

Figure 24 shows the axial (longitudinal) / radial (through-thickness) DHC velocity ratios for different annealing times at $400{ }^{\circ} \mathrm{C}$. The average axial/radial DHC velocity ratio, which was approximately 1.9 for the 1 -h specimens, decreased to 1.2 with $1000 \mathrm{~h}$ of annealing. Since matrix strength changes were comparable on all three planes, strength changes during annealing should have had little effect on the velocity ratio [Jovanovic 2001]. Therefore, the decomposition of the $\beta$-phase was hypothesized to be responsible 
for the reduction in longitudinal/through-thickness DHC velocity ratio with annealing time. The high diffusivity of hydrogen in the $\beta$-phase ligaments was deemed more important for longitudinal diffusion than through-thickness diffusion [Jovanovic 2001].
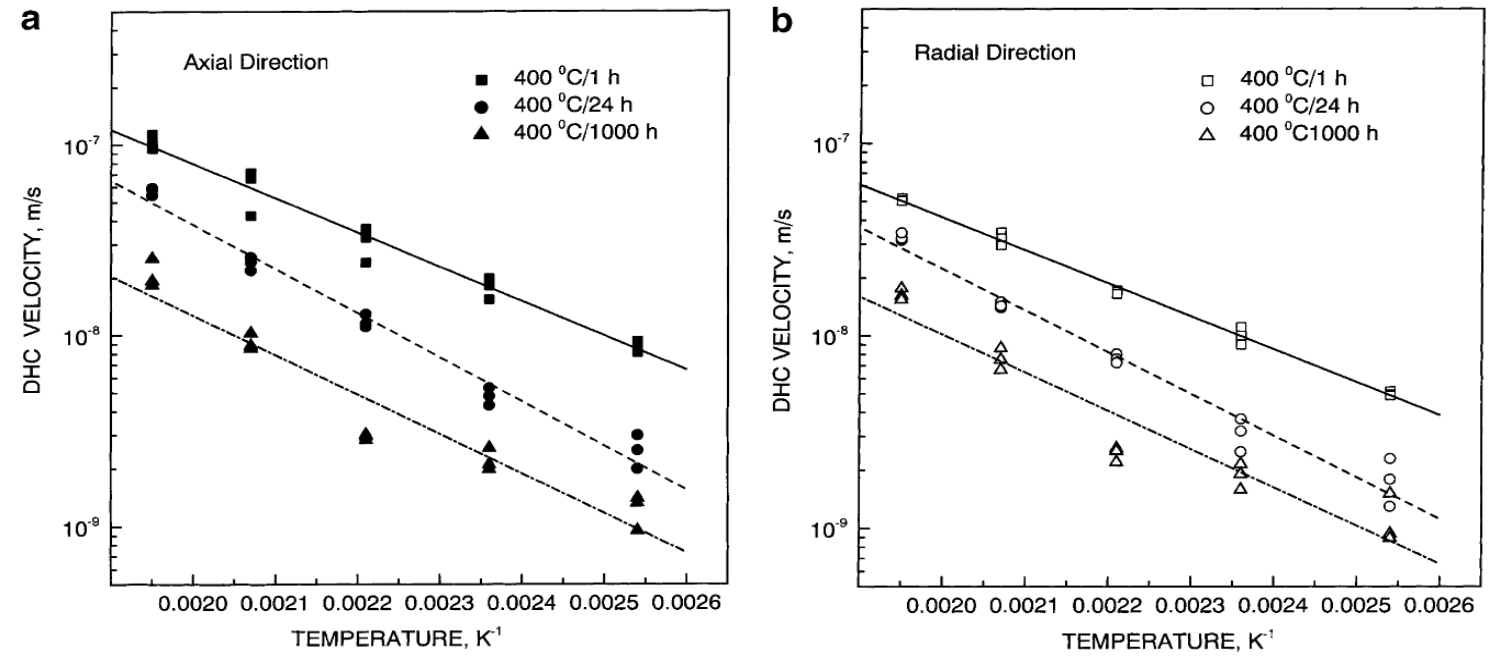

Figure 23 - The effect of temperature on DHC velocity in the axial (a) and radial (b) directions [Jovanovic 2001]

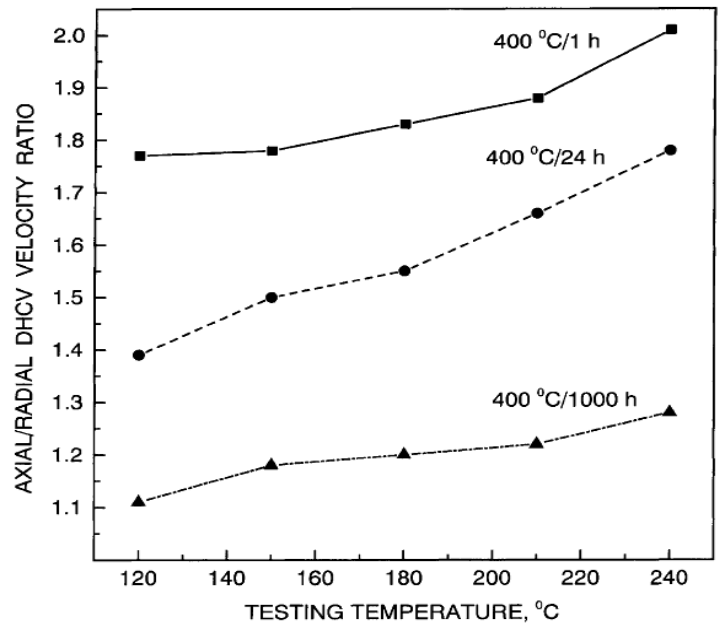

Figure 24 - Ratio of the DHC velocities as a function of temperature for specimens annealed at $1 *, 24$, and 1000 hours at $400{ }^{\circ} \mathrm{C}$. *For $\beta$-phase decomposition, $36 \mathrm{~h}$ at $300{ }^{\circ} \mathrm{C}$ equates to $1 \mathrm{~h}$ at $400{ }^{\circ} \mathrm{C}$ [Jovanovic 2001] 
The Sawatzky et al. (1982) study demonstrated that the presence of the $\beta$-phase in $\mathrm{Zr}-2.5 \mathrm{Nb}$ enhances hydrogen diffusivity up to an order of magnitude, compared with pure $\alpha$-phase alloys. The effective diffusion coefficient is maximized when the $\beta$-phase is present as a continuous network of fast-diffusion paths, which is the condition of an asextruded $\mathrm{Zr}-2.5 \mathrm{Nb}$ pressure tube. The diffusivity is reduced when the material is heattreated to cause decomposition and break-up of the $\beta$-phase ligaments. For example, the autoclaving treatment of a pressure tube after extrusion, $400{ }^{\circ} \mathrm{C}$ for 24 hours, reduces the effective diffusion coefficient of hydrogen by a factor of 5 . Additional heat treatments cause further $\beta$-phase decomposition which results in a further factor of 3 reduction, which approaches the relatively low diffusion coefficient of the $\alpha$-phase [Skinner 1990]. The effect of $\beta$-phase morphology provides an explanation for a number of experimental DHC observations:

1. The ratio of the crack velocities in autoclaved and hydrided $\mathrm{Zr}-2.5 \mathrm{Nb}$ to Zircaloy2 is 3 [Puls 1982]

2. The ratio of the crack velocities in as-extruded and autoclaved and hydrided Zr$2.5 \mathrm{Nb}$ is 5 [Simpson 1984]

3. Increasing the temperature from $310^{\circ} \mathrm{C}$ to $390{ }^{\circ} \mathrm{C}$ for a 10 day homogenization treatment on autoclaved and hydrided $\mathrm{Zr}-2.5 \mathrm{Nb}$ reduced the crack velocity by about 5 times [Amouzouvi 1987]

4. During in-reactor service, the $\beta$-phase decomposes to a greater extent at the hotter outlet end than the cooler inlet end: a difference of $45^{\circ} \mathrm{C}$. The corresponding crack velocities differ by a factor of 3 , with the velocity being higher for material from the inlet at the same test temperature [Sagat 1994].

\subsubsection{Grain Size}

Coleman et al. (1979) proposed that the difference in length between grain boundaries in longitudinal and through-thickness directions causes the observed difference between crack velocities. 
DHC cracks in Pickering pressure tubes were semi-elliptical, with the axial crack length about 1.5 to 2 times the radial crack length. The initial notch and stress are symmetrical, so it was concluded that DHC cracks grow faster in the axial direction than in the radial direction of the pressure tube. Crystallographic texture in $\mathrm{Zr}-2.5 \mathrm{Nb}$ pressure tubes was deemed to have little effect because the majority of basal plane normals are perpendicular to the transverse fracture plane and therefore the directions in the tranverse plane, the axial (longitudinal) and radial (through-thickness) directions, should be equivalent [Coleman 1979].

It was suggested difference in axial and radial crack velocities could be attributed to the different grain lengths in the two directions [Coleman 1979]. The microstructure of coldworked $\mathrm{Zr}-2.5 \mathrm{Nb}$ is anisotropic. In the radial direction more grain boundaries per length of crack growth have to be crossed than in the axial direction and thus the quantum of crack advance is smaller in the radial direction. The importance of microstructure is confirmed by the following observations [Coleman 1979]:

- in two batches of $\mathrm{Zr}-2.5 \mathrm{Nb}$ with similar yield stress and chemical composition, machined into round notched bars, time to fracture was shorter, thus crack velocity was higher, in the material with the larger grain size (Figure 25): up to a factor of 10 for a 3fold increase in grain size;

- in cold-worked Zircaloy-2 the grain aspect ratio is between 2 and 4 and the DHC velocities in the axial and radial directions are similar (c.f. 50 for $\mathrm{Zr}-2.5 \mathrm{Nb}$ ). 


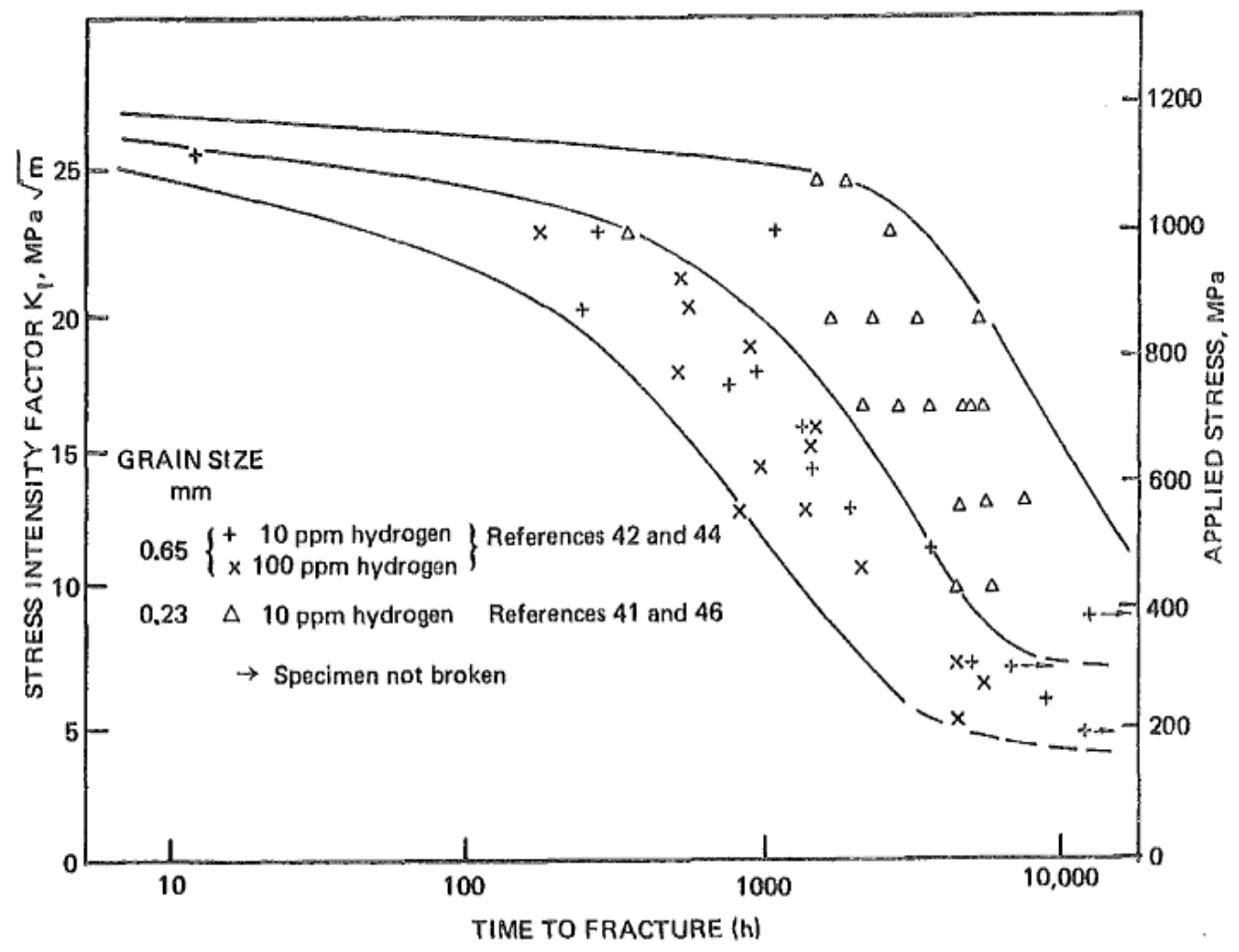

Figure 25 - Effect of grain size on time to fracture at several stress intensities [Coleman 1979]

A further study examined quenched and aged pressure tubes with a smaller grain aspect ratio. In $\mathrm{Zr}-2.5 \mathrm{Nb}$, the quenching and aging heat treatment produces a higher strength, a more random crystallographic texture and a smaller grain aspect ratio than found in coldworked tubes. Cheadle et al. (1996) showed that the difference between longitudinal and through-thickness DHC velocities values for water-quenched and aged $\mathrm{Zr}-2.5 \mathrm{Nb}$ pressure tubes was smaller than for cold-worked tubes, see Figure 26 (where velocity is near the upper bound for cold-worked $\mathrm{Zr}-2.5 \mathrm{Nb}$ in the radial direction and near the lower bound in the axial direction) [Cheadle 1996]. Thus the difference in crack velocities was attributed to the difference in the microstructure of the tubes [Cheadle 1996]. 


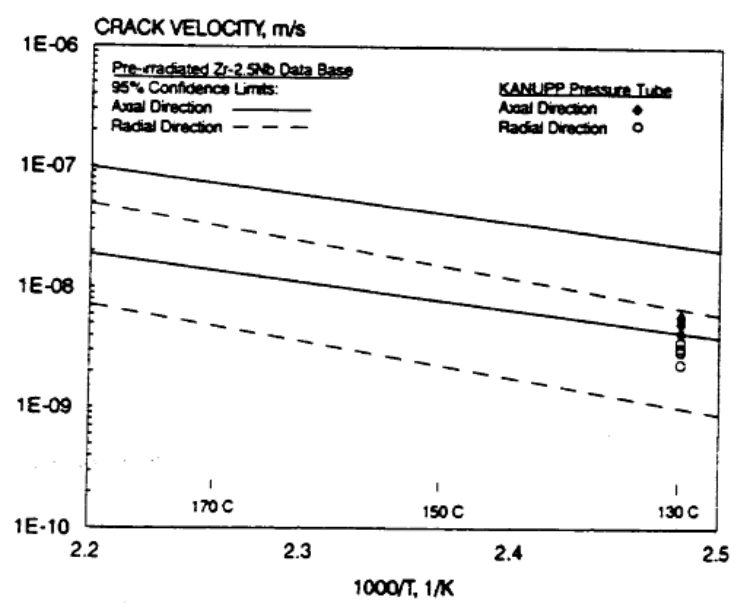

Figure 26 - Axial and radial crack velocities at $130{ }^{\circ} \mathrm{C}$ in quenched and aged 'KANUPP' pressure tubes compared to axial and radial velocity confidence limits in cold-worked pressure tubes [Cheadle 1996]

Differences in grain size have also been hypothesized to affect the likelihood of hydride fracture because hydrides may grow longer with larger grain size. For example, with 100 ppm hydrogen in a specimen of grain size $80 \mu \mathrm{m}$ the hydrides were up to $150 \mu \mathrm{m}$ in length with thicknesses of about $5 \mu \mathrm{m}$, whereas in a $20 \mu \mathrm{m}$ grain size test piece the hydrides had a maximum length of about $50 \mu \mathrm{m}$ and thicknesses of 1-2 $\mu \mathrm{m}$ [Coleman 1966]. Size effects, where larger particles fracture at lower strains or stresses, have been reported for other systems [Simpson 1981].

\subsection{Comments on Explanations for the Velocity Difference}

As shown in Section 2.9, there are three proposed theories to account for the difference between longitudinal and through-thickness DHC crack velocities: stress gradient anisotropy, $\beta$-phase continuity and $\alpha$-grain size. 
The stress gradient anisotropy theory poses that the velocity difference can be attributed to greater strain hardening in the longitudinal direction. However, this theory is not consistent with triaxial stress at the crack tip (see Section 2.8). In plane strain, the material surrounding the tip of a crack only reaches the yield strength. The hydride forms at the crack tip and then fractures, assuming $\mathrm{K}_{\mathrm{IH}}$ for the hydride has been reached. The crack grows by brittle hydride fracture, not by plastic deformation of the zirconium lattice, which would have to occur if the tensile strength was reached.

In addition, any differential strain hardening should have no effect on the longitudinal and through-thickness crack velocities because they crack on the same transverse plane. Figure 17 shows the stresses at a crack tip, where $\sigma_{\mathrm{y}}$ represents the stress in the transverse direction. This transverse stress will be the same whether the crack is propagating in the longitudinal or through-thickness direction. Hydrides are predicted to fracture because of the transverse component of stress, at the crack tip, which is the same for both directions.

The stress gradient between the stress riser and the bulk drives the movement of hydrogen to the notch [McRae 2010]. The triaxial stress surrounding the crack tip moves the hydrogen towards the crack from all directions. The $\beta$-phase will act as a diffusion shortcut and will speed crack growth regardless of cracking direction. The reduction of velocity with annealing time is expected due to the reduction of yield strength and the decomposition of the $\beta$-phase, which results in a smaller effective diffusion coefficient. However, the velocity ratio approaching 1.0 with annealing time requires an alternative explanation: it cannot be due to anisotropic diffusion because the hydrogen diffuses from all directions.

The grain size theory provides a correlation between the number of boundaries crossed and the crack velocity, but does not provide a cause. Coleman et al. (1979) observed that 
when grain sizes were different by a factor of 3 , the velocity ratio was 10 . However, for $\mathrm{Zr}-2.5 \mathrm{Nb}$ cold-worked pressure tube grains, the aspect ratio is 50 , but the velocity ratio is about 2. Larger grains have smaller surface-area-to-volume ratios, so a $\beta$-phase shell can be more continuous for larger grains than for smaller grains. Increased $\beta$-phase continuity results in a higher effective diffusion coefficient, which increases crack velocity [Skinner 1990]. Thus, the effect of larger grains on velocity may be partially explained by $\beta$-phase continuity.

It has not been shown that grain boundaries slow a growing DHC crack. Even if a hydride can grow larger in larger grains the diffusion coefficient should be the same as that of smaller grains, so hydrogen will be migrating to the hydride at the same rate through the bulk. The time required for hydride fracture is insignificant compared with the required diffusion time, so there should be no reason for a decreased velocity unless the grain boundary slows down the growing DHC crack.

Not all the experimental data presented in Section 2.9 are consistent. The velocity ratio as a function of temperature is reported in different studies to go down, remain the same, or go up with temperature. In Section 1.3, Figure 6, the CSA standard describes a decrease of the ratio of longitudinal/through-thickness velocities as the temperature increases, with the ratio being above 2 below $180^{\circ} \mathrm{C}$ and approaching 1 at $280^{\circ} \mathrm{C}$. In Section 2.9.1, Figure 20, Kim et al. (2002) reported the difference in the DHC velocity between the radial and longitudinal directions becomes slightly smaller with increasing temperature between $170^{\circ} \mathrm{C}$ and $280^{\circ} \mathrm{C}$, with the ratio being approximately 2 at $280^{\circ} \mathrm{C}$. Other studies have shown similar trends to those shown by Kim et al. (2002) [Cheadle 1996, Sagat 1994]. In Section 2.9.2, Figure 24, Jovanovic et al. (2001) report data where the longitudinal/through-thickness DHC velocity ratio increases with temperature. After a 24 hour anneal at $400{ }^{\circ} \mathrm{C}$ the ratio increases from 1.4 at $120^{\circ} \mathrm{C}$ to above 1.7 at $240{ }^{\circ} \mathrm{C}$. Thus, there is a need for more precise measurements. 
The studies referenced in Section 2.9 tested only at temperatures below TSSP where bulk hydrides have precipitated. For example, Jovanovic et al. (2001) test at temperatures where "there was only enough hydrogen to reach the precipitation solvus (TSSP) throughout the specimen." However, cracking is possible at temperatures above TSSP; hydrides in the bulk are not required for DHC [Coleman 1979]. The presence of bulk hydrides, because of their orientation relative to the cracking direction, could confound the difference between longitudinal and through-thickness crack velocities.

An objective of this study (Section 1.4) was to remove confounding factors, i.e. to test specimens of identical geometry using the same material, experimental rigs and specimen grips, with the only difference being the direction of cracking. In the Kim et al. (2002) study, cantilever beams specimens were flattened, possibly creating local residual stresses (see Section 2.11), and annealed, possibly removing some of the cold-work. In the Jovanovic et al (2001) study, different grips were used to test the longitudinal and through-thickness specimens. Other studies used different specimen types for different testing directions [Sagat 1994]. In this thesis, these confounding effects were eliminated (Chapter 3).

From the above comments, it appears that there is no complete explanation for the velocity difference. The micrographs in Figures 4 and 5 suggest the orientation of bulk hydrides could be a contributing factor. These observations prompted the current study, in which DHC velocities in the longitudinal and through-thickness directions were tested at temperatures above and below TSSP. 


\subsection{History of Delayed Hydride Cracking}

In the early 1970's, several pressure tubes in the Pickering plants were over-rolled into their end-fittings, which are joined to the rest of the heat transport system. The residual stresses caused by over-rolling were not known to be connected to hydrogen damage. In 1974, a DHC crack penetrated through the pressure tube wall thickness near the rolled joint in Pickering 3 and heat transport system water leaked into the dry gas annulus between the pressure and calandria tube [Perryman 1978]. The leak was detected by moisture sensors and the reactor was shut down. The axial extent of cracking at leakage was far below the length of an unstable crack; consequently, Leak-Before-Break was demonstrated. Once a leaking tube was identified, it was removed and replaced. CANDU reactors typically contain 380 pressure tubes, out of which seventeen in Pickering 3 and two in Pickering 4 leaked. The remaining tubes were inspected for damage, and 50 more had to be replaced due to part-through-wall cracks. These Pickering pressure tubes cracked after two years of operation and did not contain extra hydrogen from ingress before cracking began; the small amount of hydrogen present in the as-received tubes was sufficient for cracking [Perryman 1978].

The DHC cracks grew in the longitudinal and through-thickness directions on the transverse plane. The fracture surfaces were examined and found to contain broken hydrides. Several bands of different oxide thickness were observed, with each band on the fracture surface corresponding to a reactor shutdown [Causey 1977]. Three such bands are shown in Figure 27 b). No large stress risers were found and only small surface imperfections such as sand blasting defects or hydrides perpendicular to the tube surface were found. Investigators concluded that these small defects were sufficient to start cracking in the presence of high residual hoop stresses created by the over-rolled joints. 


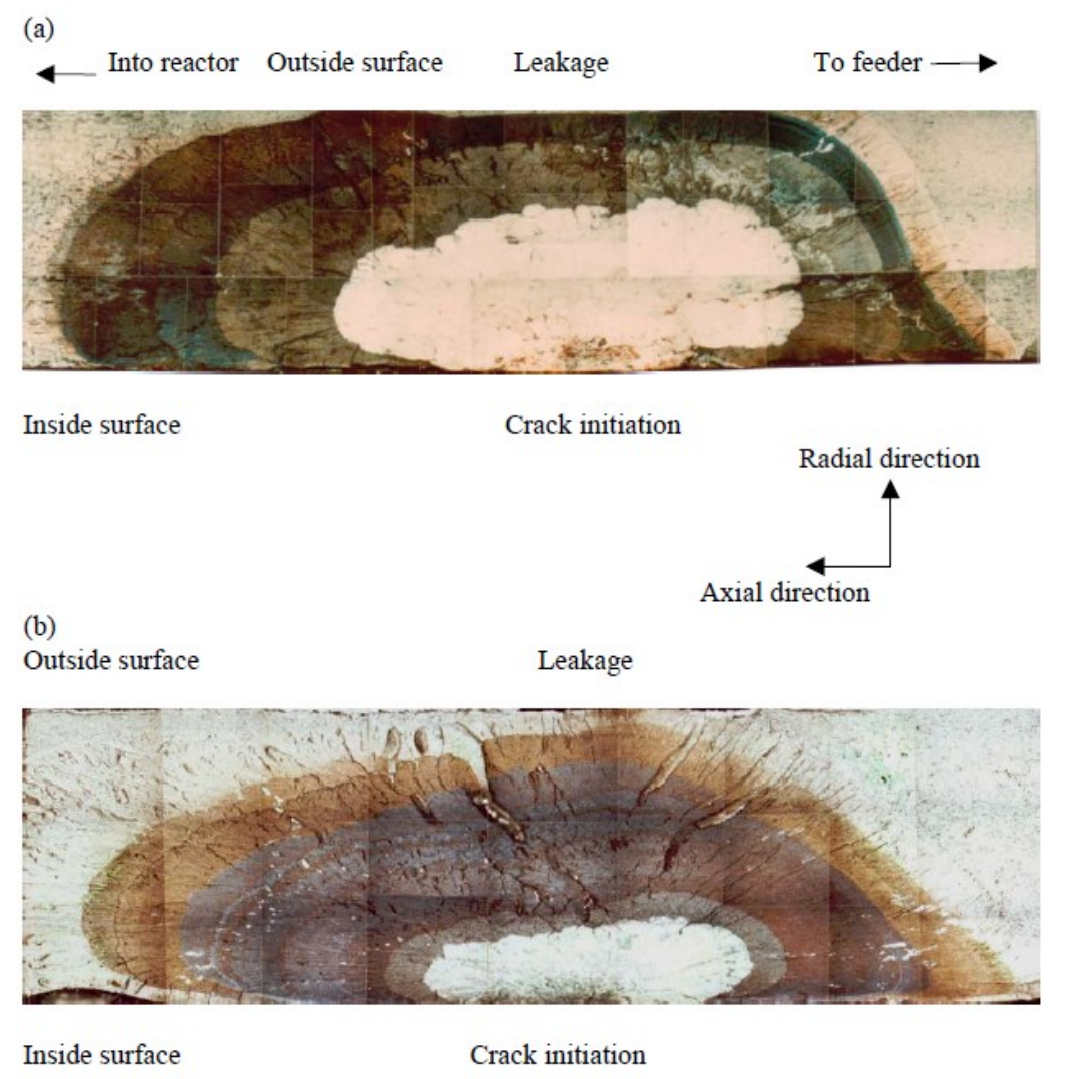

Figure 27 - A through-wall crack at two rolled joints in $\mathrm{Zr}-2.5 \mathrm{Nb}$ pressure tubes in Pickering 3 (a) and Pickering 4 (b). The coloured bands represent periods of cracking and subsequent oxidation. The tube wall thickness was $\mathbf{4} \mathbf{~ m m}$.

[Causey 1977]

In CANDU pressure tubes the largest stress, the hoop stress, is acting in the transverse plane. Most of the basal plane normals have a large component in the transverse direction, see Figure 11 and Figure 29. The basal plane is the most hazardous for DHC, as the higher stress intensity will be more likely to exceed $\mathrm{K}_{\mathrm{IH}}$ and fracture hydrides. The plane with its normal in the through-thickness direction, called the radial plane, will have the least stress and therefore is the safest plane for hydride formation. Other external stresses or residual stresses from fabrication or installation can cause hydride reorientation and lead to DHC. 
One source of residual stress is the forming of the rolled joint, where the pressure tube is joined to the reactor structure. During the rolled joint process the pressure tube end is fit inside a thick-walled tube of stainless steel called the end-fitting. The end fitting contains three circumferential grooves on the inside surface, into which the pressure tube is internally rolled. This rolling creates a seal at the grooves called a rolled joint as shown in Figure 28. If the roller is extended too far into the tapered region of the end fitting large local residual stresses are created [Hunter 1976]. These residual stresses, $\sigma_{\text {residual }}$, were approximately $550 \mathrm{MPa}$. In comparison, the maximum hoop stress from internal water pressure is only $141 \mathrm{MPa}$ : this calculation is provided in Section 1.3.

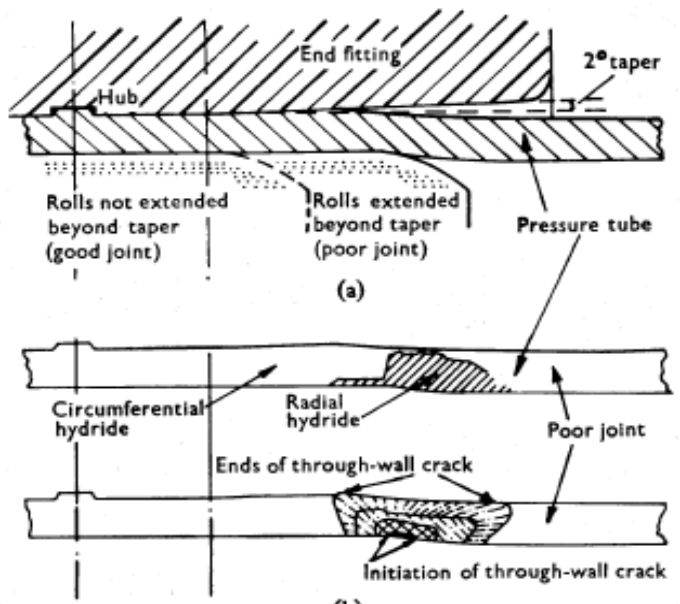

(b)

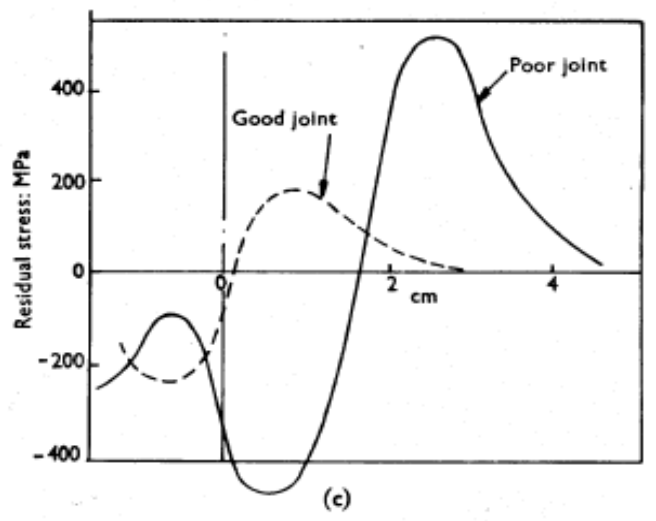

Figure 28 - Schematic diagram of over-rolled joint: (a) position of the roller, (b) location of cracking, (c) residual stresses 
The large residual stresses created regions around small flaws where the stress intensity exceeded $\mathrm{K}_{\mathrm{IH}}$. Higher stress gradients locally increased hydrogen concentration and led to hydride nucleation, growth, and fracture: DHC.

When the leaking cracks in the Pickering reactors were found, the rolled joints in the first two Bruce reactors were already made. Rather than performing a costly re-tube, the large residual stresses were removed by heat-treatment at $500{ }^{\circ} \mathrm{C}$ for $30 \mathrm{~min}$. This heat treatment had a significant beneficial effect: the maximum residual tensile stress had been reduced from about $550 \mathrm{MPa}$ to $100 \mathrm{MPa}$ [Dunn 1982]. Some Bruce-2 pressure tubes had developed small cracks in the transverse plane before annealing. These cracks were able to sustain growth at higher temperatures as extra hydrogen ingressed into the pressure tubes over the course of about four years of reactor operation. Several of these cracks grew through-wall causing four Bruce-2 tubes to leak.

In later reactors, the rolled joints were manufactured with low residual stresses by minimizing the tolerance gap between the pressure tube and the end-fitting (interference fit) as well as ensuring that the rolled part of the pressure tube was firmly supported by not over-rolling. Typically the maximum residual hoop tensile stresses at the inside surface are now less than $100 \mathrm{MPa}$ [Dunn 1982].

Although several DHC induced failures did occur, as a legacy from the initial overrolling, they did little damage to the reactors because they were detected within leakbefore-break margins. No failures have been observed in later reactors. 


\section{Chapter 3}

\section{Experimental Set-up}

\subsection{Introduction}

This chapter describes the experimental equipment and procedure used to test whether bulk hydrides slow through-thickness cracks to a greater extent than longitudinal cracks. The design of the cantilever beam specimens is presented. The objective was to eliminate the geometry effect of curved pressure tubes: a plate of $\mathrm{Zr}-2.5 \mathrm{Nb}$ with pressure tube properties was machined into cantilever beam specimens with the same dimensions for either cracking direction. In addition, an improved DHC velocity measurement testing procedure was created to enable more accurate measurements of the differences between longitudinal and through-thickness crack velocities.

The process of DHC is highly variable and even in well-controlled testing, the crack velocity in fuel cladding can vary by a factor of about three. With such large variation, small numbers of specimens can lead to large variations in apparent temperature dependence [Coleman 2010]. At any given test temperature there are at least two specimens tested to partially compensate for these variations.

Pressure tubes are curved and thin-walled, which makes it difficult to machine cantilever beam specimens, with typical dimensions, for DHC studies in the longitudinal and through-thickness directions. Moreover, the curvature of pressure tubes requires that longitudinal velocity specimens and the through-thickness specimens have different grips. Specimens should be loaded at their shear centre, which is the point on a section 
where a shear force can be applied without inducing torsion. Loading at any other location would create undesirable torsion in the specimen.

In this study, a plate with pressure tube properties, essentially a flat pressure tube, was used to eliminate the need for different rigs or grips. Texture of the plate is similar to that of a pressure tube. Texture results are shown in Table 2 and strength results are shown in Table 3 of Section 3.2.1. The plate thickness was large enough to accommodate the maximum cross-sectional dimension of the specimen: $6.4 \mathrm{~mm}$. Straight cantilever beam specimens of the same dimensions were tested with the same grips.

Specimens in this report were tested on two sets of rigs at the Chalk River Laboratories at $\underline{\text { Attomic }}$ Energy of $\underline{\text { Canada, }}$ Limited (AECL). The rigs designed and commissioned in the 1970's were designated 'old rigs', while the rigs commissioned in 2012 were designated 'new rigs'. Several new software features were added to the new rigs, including a motor step threshold option (Section 3.4.2) and better temperature control than the old rigs (Section 3.3.7). These changes, along with updated hardware and improved specimen design, produced more consistent data than the old rigs (Section 3.4.2).

\subsection{Specimen Design}

\subsection{1 $\mathrm{Zr}-2.5 \mathrm{Nb}$ Plate}

The material used in this study was $\mathrm{Zr}-2.5 \mathrm{Nb}$ plate. Three separate plates were used, each with a different hydrogen concentration. The plates are referred to as plate 1, plate 2 , and plate 3. These plates were cut from a larger plate; therefore all plate properties were the same before hydriding. The plate fabrication method is shown in Appendix A. 
Kearns' texture factors were determined using X-ray diffraction, see Section 3.2.5. The results in Table 2 show that the plate texture is within pressure tube guidelines in all three directions. Figure 11 of Section 2.2 shows 2D and 3D pole figures.

\begin{tabular}{|l|c|c|}
\cline { 2 - 3 } \multicolumn{1}{|c|}{ Direction } & $\begin{array}{c}\text { Typical Values } \\
{[\text { Bickel 2008] }}\end{array}$ & Plate \\
\hline Longitudinal $\left(F_{l}\right)$ & $0.05<F_{l}<0.08$ & 0.06 \\
\hline Radial $\left(F_{r}\right)$ & $0.30<F_{r}<0.34$ & 0.29 \\
\hline Transverse $\left(F_{t}\right)$ & $0.60<F_{t}<0.63$ & 0.65 \\
\hline
\end{tabular}

Table 2 - Texture Data

Figure 29 shows geometries, planes, and directions that are used throughout this report, including: the DHC specimen and notch geometry and the tensile test specimen geometry. The longitudinal (LN), transverse (TN) and through-thickness (RN) directions are also shown; these are equivalent to the axial, circumferential and radial directions in a pressure tube, respectively. In this report, all specimens tested had DHC cracks in the transverse plane, which is the plane that has a normal parallel to the circumferential direction in a tube.

The transverse direction in a pressure tube has the highest tensile stress, so the plate tensile specimens were stressed in the transverse plane. The axis of the tensile specimen and the direction of loading is in the transverse normal (TN) direction, as shown in Figure 29. The strength in the transverse direction is provided in Table 3 . The hexagonal prism in Figure 29 represents the strongest texture direction of the zirconium $\alpha$-phase basal planes, with $65 \%$ of basal plane normals in the transverse direction. 


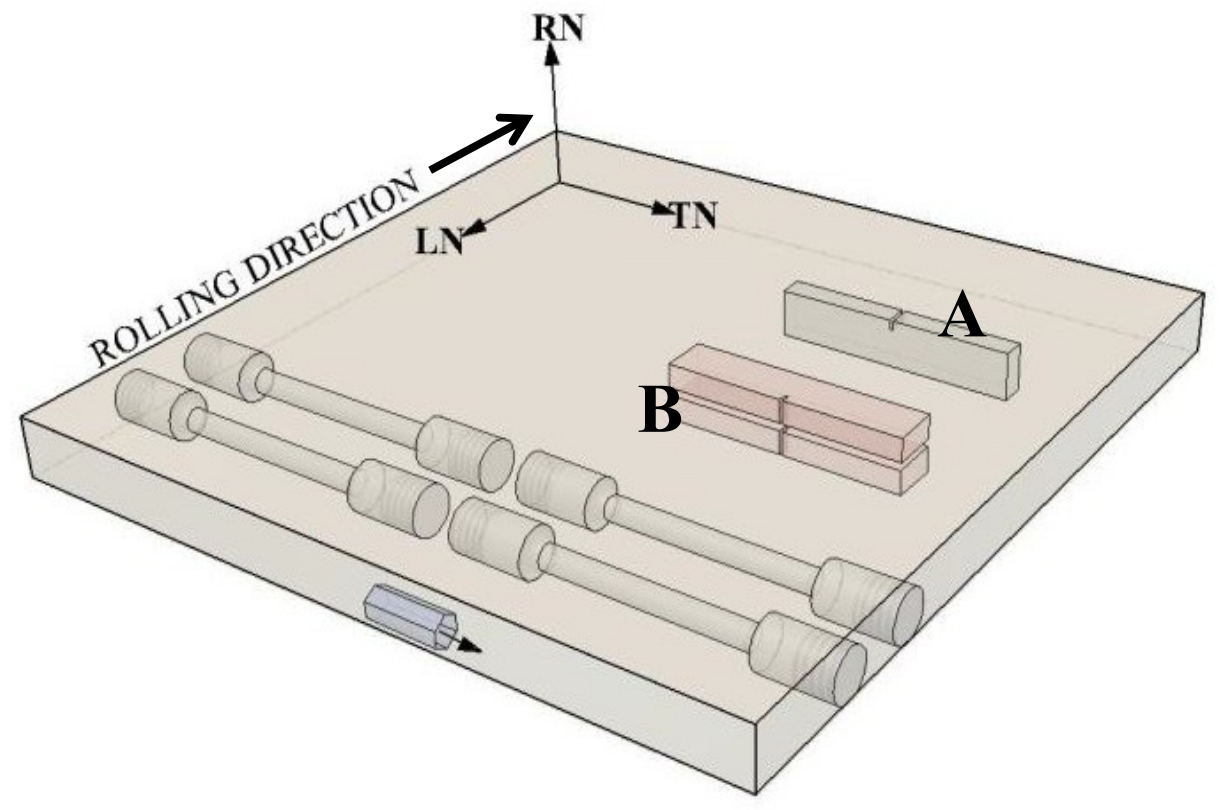

Figure 29 - Plate and specimen geometry (A: radial specimen, B: longitudinal specimen)

\begin{tabular}{|l|c|c|c|}
\cline { 2 - 4 } \multicolumn{1}{c|}{} & Specimen 1 & Specimen 2 & $\begin{array}{c}\text { Pressure Tube } \\
\text { Average }\end{array}$ \\
\hline Test Temp $\left({ }^{\circ} \mathrm{C}\right)$ & 20 & 250 & 250 \\
\hline UTS (MPa) & 844 & 577 & 640 \\
\hline $0.2 \%$ Yield (MPa) & 732 & 501 & 584 \\
\hline
\end{tabular}

Table 3 - Transverse tensile test results for $\mathrm{Zr}-2.5 \mathrm{Nb}$ plate material and pressure tube material

The large plate used in this study had an initial hydrogen concentration of $8 \mathrm{ppm}$. Plates 1 to 3 were electrolytically hydrided and annealed to give hydrogen concentrations of 65 ppm, 100 ppm, 40 ppm, respectively (see Section 3.2.3). 


\subsubsection{Cantilever Beam Specimens}

The geometry of the test specimens is shown in Figure 29. They are rectangular prisms with length, breadth, and depth of $33 \mathrm{~mm}, 3.2 \mathrm{~mm}$, and $6.4 \mathrm{~mm}$, respectively. After each specimen was machined, it was notched to a depth of $0.8 \mathrm{~mm}$ at its center as shown in Figure 29. Plate 1 and 2 notches were cut with Electrical Discharge Machining (EDM) and had a root radius of 50 micrometers. Plate 3 notches were notched with a broaching tool to a root radius of 10 micrometers. In each plate, half the specimens had notches in the through-thickness direction (Figure 29, labeled A) and the other half had notches in the longitdunal direction (Figure 29, labeled B). Once notched, specimen breadth and depth were measured using a micrometer; these measurements were required to calculate the desired load. The specimen identification was stamped on both ends of each specimen to ensure they were easily identified when broken open after a test.

A difference in notch root radius will effect DHC crack initiation because a sharp flaw has a higher stress intensity factor than a blunt flaw of the same size and is more likely to create a stress intensity factor that exceeds $\mathrm{K}_{\mathrm{IH}}$. Plate 3 broached notches had smaller root radii than the plate 1 and 2 wire EDM notches. The notches were not prefatigued to sharpen the initial crack.

\subsubsection{Hydrogen Addition}

Hydrogen is introduced into $\mathrm{Zr}-2.5 \mathrm{Nb}$ via a two-step process: plates 1-3 were electrolytically hydrided and then diffusion annealed. The electrolytic hydriding process used an electrolysis cell with a $\mathrm{Zr}-2.5 \mathrm{Nb}$ cathode and a lead anode in a sulfuric acid solution. A DC current was used to electrolyze the water and produce hydrogen at the cathode:

$$
\mathrm{H}^{+}(a q)+\mathrm{e}^{-} \rightarrow \mathrm{H}^{0}(5)
$$


A fraction of the atomic hydrogen produced via equation 5 at the surface of the $\mathrm{Zr}-2.5 \mathrm{Nb}$ cathode was absorbed into $\mathrm{Zr}-2.5 \mathrm{Nb}$ lattice to produce a hydride layer. The remaining hydrogen combined to form hydrogen gas via equation 6 :

$$
2 \mathrm{H}^{0} \rightarrow \mathrm{H}_{2}(g)
$$

Appendix B shows a more detailed description of the hydriding procedure. Once hydrided, plates 1-3 were annealed to diffuse hydrogen from the surface to a desired concentration in the bulk. Plates 1-3 were annealed for four days at $305^{\circ} \mathrm{C}, 345^{\circ} \mathrm{C}$, $270{ }^{\circ} \mathrm{C}$, which resulted in bulk hydrogen concentrations of $64 \mathrm{ppm}, 100 \mathrm{ppm}, 39 \mathrm{ppm}$, respectively. Hydride concentrations were determined using $\underline{\text { Hot }} \underline{\text { Vacuum }} \underline{\text { Extraction }}$

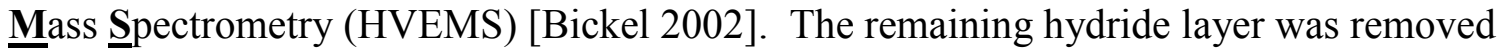
by machining $0.5 \mathrm{~mm}$ into each surface of each plate. After hydriding, annealing, and hydride layer removal, plates 1-3 were cut into cantilever beam specimens.

The procedure in Appendix B is used for hydriding curved pressure tube sections, not plates. The procedure was modified for the plate material used in this study. The four 'edge surfaces' of the plate were removed prior to annealing. These 'edge surfaces' are the surfaces perpendicular to the transverse and longitudinal directions having surface areas less than $10 \%$ that of the two surfaces perpendicular to the through-thickness direction. Removing these surfaces resulted in one-dimensional (through-thickness) diffusion during annealing. When the 'edge surface' hydride layers were not removed, the corners of the plate had higher hydrogen concentrations, likely due to their proximity to three surfaces with hydride layers.

\subsubsection{Differential Scanning Calorimetry}

A TA Instruments DSC 2910 was used to perform the DSC measurements. This instrument is based on a 'heat flux' design, which uses a constantan disk as the primary means of transferring heat to a sample and reference. As heat is transferred through the 
disk, differential heat flow to the sample and the reference is measured. Chromel and alumel wires attached to chromel wafers form the thermocouples (k-type), which directly measure the sample temperature. The reference was a hydrogen-free coupon weighing between $100 \mathrm{mg}$ and $500 \mathrm{mg}$, with the same alloy composition as the sample. The precipitation of hydrides in the sample produces a differential heat flow that is used to determine the onset TSSP. Each sample was analyzed for the phase transition temperature in at least three consecutive thermal cycle runs. The runs consisted of a heatup from room temperature to a maximum temperature, $400^{\circ} \mathrm{C}$, with a hold-time of $5 \mathrm{~min}$, followed by a cool-down to room temperature. In all runs, the heat-up and cool-down rates were $10{ }^{\circ} \mathrm{C} / \mathrm{min}$. Duplicate measurements of the onset temperature are made for each sample after an initial heat-up and cool-down conditioning cycle. No transformation of the $\beta$-phase should have taken place during the DSC measurements [Khatamian 1997].

\subsubsection{X-Ray Diffraction}

Three rectangular samples were cut, using a diamond saw, with a $3 \mathrm{~mm}$ thickness direction in the longitudinal, through-thickness, and transverse directions. Surface areas were at least $15 \mathrm{~mm}^{2}$. The sample surfaces were mechanically polished using sandpaper (600 grit) and then chemically etched to remove polishing lines. Pole figures (Figure 11) were obtained by X-Ray diffraction using a Rigaku Smartlab 9kW Cu rotating anode source using the techniques described by Winegar (1977). 


\subsection{Experimental Rigs}

This section describes the methods and practices used for measuring DHC velocities in $\mathrm{Zr}-2.5 \mathrm{Nb}$ plate specimens. Cantilever beam specimens in this report were tested on two sets of rigs at the Chalk River Laboratories of AECL. The old rigs were designed and built in the 1970's and are described by Sagat et al. (1986). This section also describes the components of the 'new' experimental rigs. The following components are discussed:

- Test Frame

- Furnace and Enclosure

- Thermocouple

- Specimen Grips

- Stepper Motor: Electromate STM232S-2AE $120 \mathrm{oz}$

- Load Cell: Interface Force Transducer Model SM-25-38; 25 lbs; S/N E26418

- Acoustic Emission Transducer: Mistras P/N\#1277-5035-002, AE2A, Amplifier System w/10kHZ-2MhZ BANDW

- Temperature Controller: Yokagawa Model UP27E

- LabVIEW Software: 2010 Profession Development System - National Instruments Part \#: 776678-35

Figure 30 shows a schematic diagram of a DHC cantilever beam rig, while Figures 31 and 32 show photographs of the DHC cantilever beam rigs. 


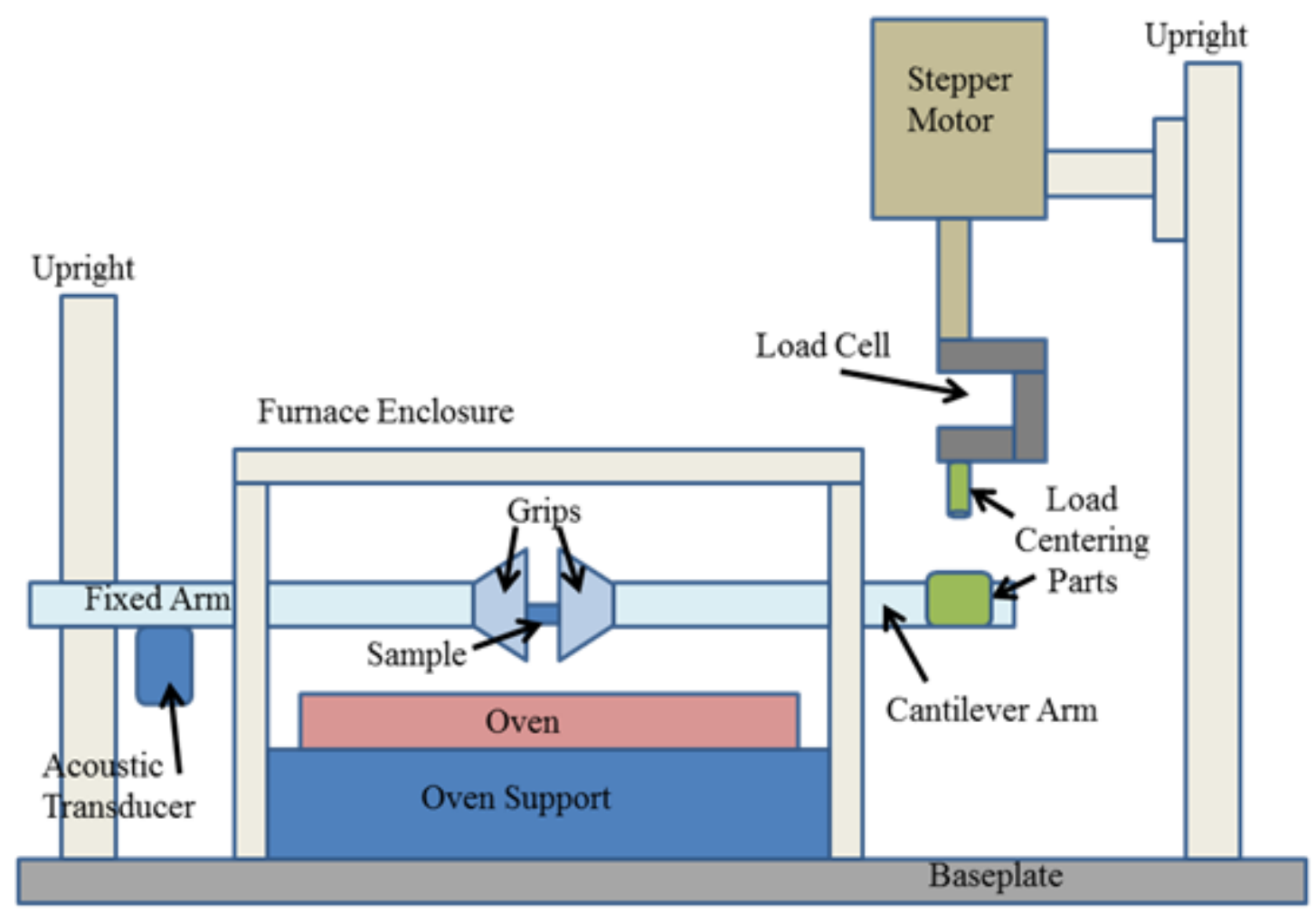

Figure 30 - Schematic diagram of a DHC cantilever beam rig

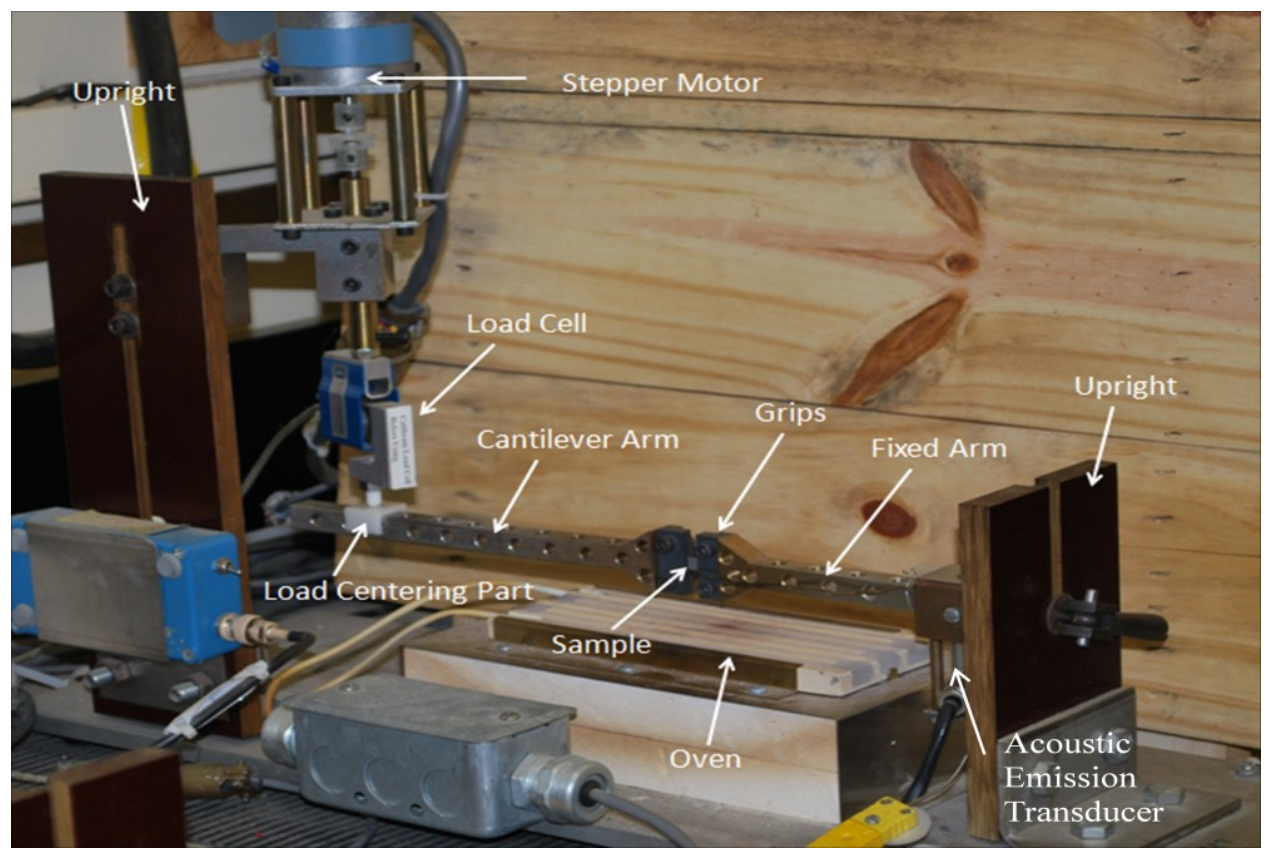

Figure 31 - Cantilever beam rig with enclosure removed 55 


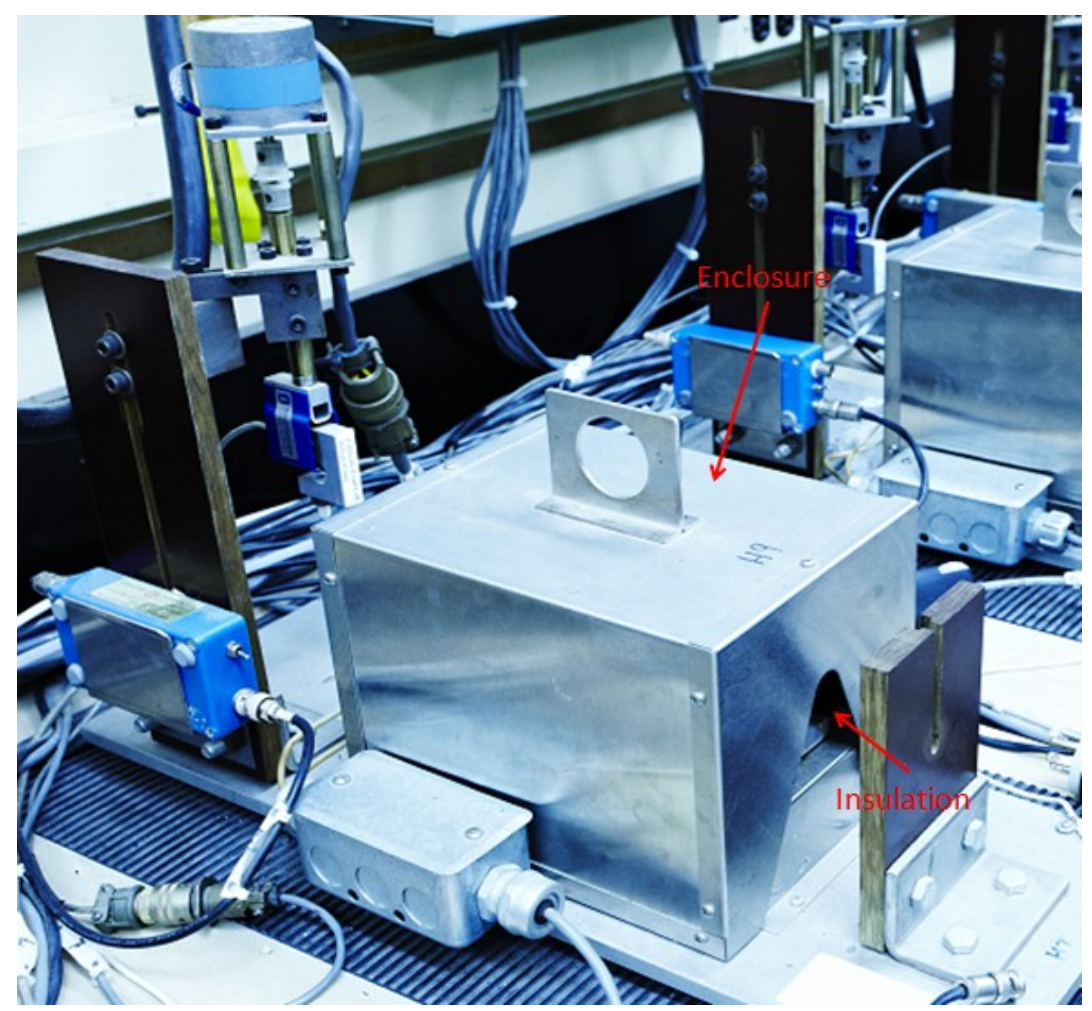

Figure 32 - Cantilever beam rig with arms removed, enclosure attached

\subsubsection{Test Frame}

The test frame consisted of a rectangular shaped metal base plate resting on four rubber feet to reduce vibration. Two vertical uprights were secured to opposite ends of the plate. The first upright provided a vertically adjustable mount for the fixed specimen grip, the second supported the specimen loading device which consisted of a stepper motor, loading screw, and load cell.

\subsubsection{Specimen Grips}

Each specimen is held in place by two identical grips. The specimen slid about $10 \mathrm{~mm}$ into the rectangular slot in each grip and was pressed against the backstops provided by the cantilever arm and fixed arm (Figure 31), so that the specimen notch was positioned 
equidistant from the ends of grips, Figure 33. The specimen fitted tightly in the grips, which prevented specimen misalignment.
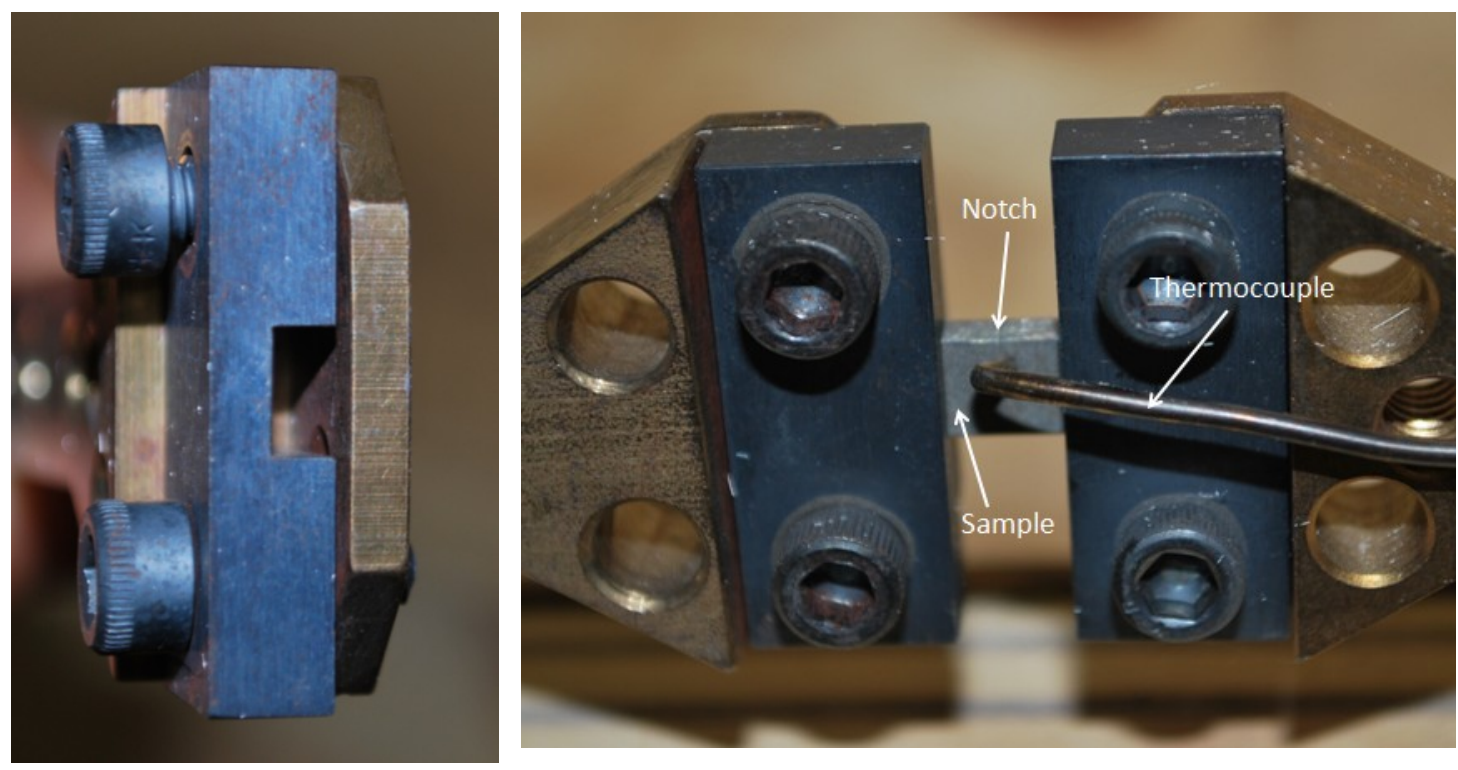

Figure 33 - Close-up view of grips and specimen

\subsubsection{Load Control System}

The load control system consisted of a stepping motor and a load cell. The stepping motor was controlled by the LabVIEW program. The motor applied a load to the specimen by way of a loading screw mounted to an upright, Figure 31 . The stepper motor had a motor step range of -3000 to 170000 , with positive 10000 screw steps being equivalent to a displacement of $2 \mathrm{~mm}$ towards the base of the rig.

\subsubsection{Acoustic Emission}

The acoustic emission transducer was mounted outside of the furnace to the fixed rig arm. The amplified signal was monitored by the LabVIEW program. 


\subsubsection{Temperature Control System}

The temperature control system of the DHC test rigs consisted of a furnace, temperature controller and a thermocouple controlled by the LabVIEW program. The furnace included a heating element mounted to the metal base plate that heated the enclosure from the bottom. The furnace was enclosed in a stainless steel shell with no bottom and cutouts on either end for the cantilever arm and rig arm. The shell could be removed without disturbing a gripped specimen. Heating rate, cooling rate, and hold times were programmable. The new rig design allows temperature to be reached before moving on to the next step of the temperature sequence by changing the junction code (see Appendix C, step \#10). The temperature can also be held at a constant value. The test was concluded and the specimen cooled when a test threshold (Section 3.4.2) was reached. The temperature was controlled to the specified test temperature $+/-1^{\circ} \mathrm{C}$.

\subsection{Procedure}

This section describes the procedure used to run DHC velocity tests using cantilever beam specimens.

\subsubsection{Starting and Running a Test}

Once the specimen is gripped, the stainless steel shell (Figure 32) is lowered into place. Insulation is packed around the open ends of the shell through which the rig arms extend. The experiment is initiated by a series of commands entered into the LabVIEW program. The details of the rig setup and control, including the LabVIEW program commands, are provided in Appendix C.

\subsubsection{Temperature Profile}

Each cantilever beam specimen was heated from room temperature to a peak temperature where all the hydrogen was in solution [CSA 2005], then cooled to a test temperature and 
held until the test was ended, see Figure. The rate of increase from room temperature to the peak temperature was $3{ }^{\circ} \mathrm{C} / \mathrm{min}$. The peak temperature was $360^{\circ} \mathrm{C}$ and was held for one hour to ensure all hydrogen was in solution. The specimen was then cooled at a rate of $1{ }^{\circ} \mathrm{C} / \mathrm{min}$ to the test temperature. If the test temperature was lower than TSSP, bulk hydrides started to precipitate at TSSP and finished precipitating by the time the load was applied. When the specimen reached the required test temperature it was held for an hour to ensure thermal equilibrium of the entire apparatus before the load was applied. The specimen remained loaded at the test temperature until the test was concluded. When each test ended, the each specimen was air cooled to room temperature.

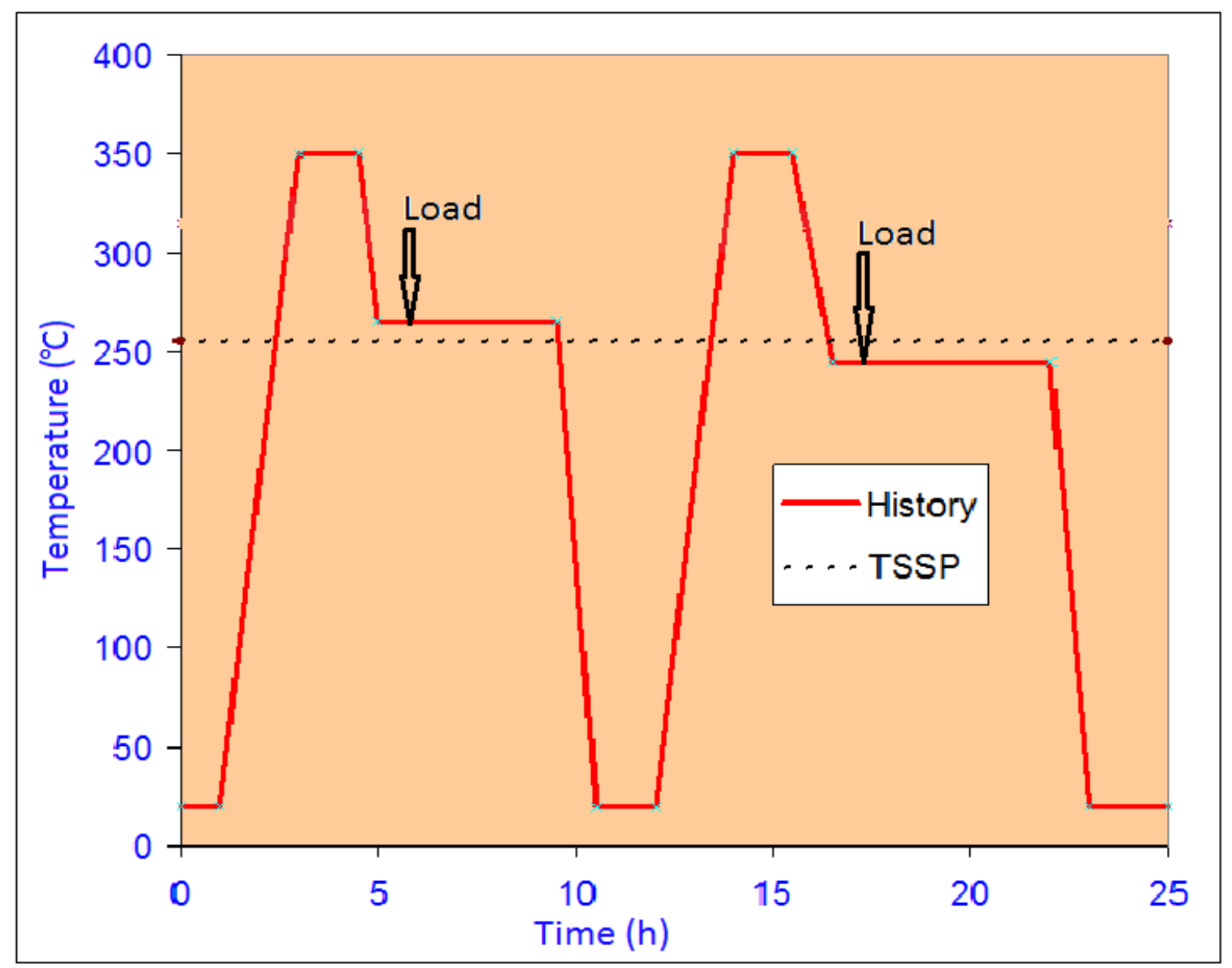

Figure 34 - Temperature profile for DHC Tests. Left - test temperature above TSSP: no bulk hydrides present. Right - test temperature below TSSP: bulk hydrides present 


\subsubsection{Load History}

Before tests were started, a $2 \mathrm{~N}$ preload was applied to ensure the cantilever apparatus was properly aligned and the grips were tight. The preload remained until the full load was applied. During loading, overshoot was avoided by increasing applied load incrementally. The load was increased from $2 \mathrm{~N}$ to within $10 \%$ of the test load after a few seconds. The motor speed then dropped to make smaller load adjustments without an overshoot of more than $5 \%$. The test loads were about $40 \mathrm{~N}$ : these were calculated using the ASTM cantilever beam standard (ASTM, E 1681-95, see Appendix D). All necessary parameters for this calculation were entered into the LabVIEW interface before the test began (Appendix C). Once the test load was reached, acoustic counts, motor steps and test time were zeroed. The test load was held constant throughout the tests, and did not vary by more than $5 \%$.

\subsubsection{Ending a Test}

Each test has one or more thresholds that can be set to end the test. Thresholds for constant load cantilever beam tests can be based on motor steps, acoustic emissions, or time. The test ends when the motor steps or acoustic emission counts reach specified values. Alternatively, the test could end when the specimen had been loaded for a specified time. The thresholds are set so that the crack lengths in all specimens are within a desired range, usually 1-2 mm.

The test accuracy for the new rigs was improved by using a stepper motor with fine control and by implementing a motor step threshold to end tests. In previous testing procedures used for the 'old' rigs, the tests ended when the acoustic counts reached a threshold [Sagat 1986]. This threshold was arbitrary and different for each rig. Acoustic emission was useful to determine whether the specimen was cracking, however, each rig had a different crack-length-per-count coefficient, which were often changed based on 
previous test results. For example, if a 100000 counts $/ \mathrm{mm}$ coefficient was used and the acoustic threshold was 200000 counts, a crack length of $2 \mathrm{~mm}$ was predicted. However, the resulting crack might only have had a length of $1 \mathrm{~mm}$, so the coefficient would have to be changed. For the next test, the new 50000 counts $/ \mathrm{mm}$ threshold might still not result in the desired crack length. All rigs had the same design and testing procedure but did not be have consistent crack-length-per-count coefficients. Ideally, each rig would have the same threshold and the resulting crack lengths would be more consistent, so a new threshold was formulated. The new rigs were designed with an option to conclude tests when the stepper motor displacement reached a threshold. The displacement was equal to the deflection of the cantilever arm, which can be related to how far the crack has opened and, therefore, is proportional to the crack length. This relationship is not exact; some of the cantilever arm displacement is from elasticity, tolerance, and relaxation rather than crack extension. However, the motor step threshold gives more consistent final crack lengths than the previous acoustic emissions threshold. For example, plate 1 specimens used acoustic emissions and had 12 of 42 specimens outside the desired 1-2 mm range, while plate 3 specimens used a motor step threshold and had only 5 out of 76 crack lengths outside that range. Not only did this new threshold improve the reproducibility of crack lengths, it simplified testing because every rig was able to use the same threshold.

\subsection{Specimen Analysis}

Once a DHC cracking test was completed, the specimen was removed from the grips. In all tests, the DHC cracks do not crack through the specimen thickness, so they were broken open with a wrench to reveal the fracture surfaces, as shown in Figure 35. 


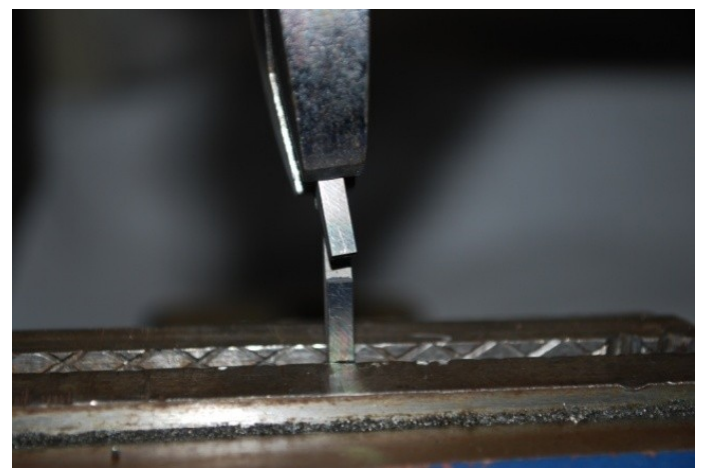

Figure 35 - Breaking specimen to expose fracture surfaces

\subsubsection{Measurement of DHC Velocity}

The revealed fracture surfaces were photographed and then analyzed with Image Pro (Version 4.5.1.22). For details see Appendix E. An example of a fracture surface is shown in Figure 4, Section 1.3. There are three distinct areas: the notch area, the DHC area, and the ductile fracture area. The notch area is rectangular, showing the notch depth of $0.8 \mathrm{~mm}$. The ductile region is a silver coloured rough surface that is the region that was pulled apart when the fracture surface was revealed. The region between the notch and the ductile region is the DHC area. It is darker in colour than the ductile region because its surface was oxidized when exposed by cracking at test temperature. The lighter colored regions at the interface of the DHC and ductile regions show where the exposed material from cracking had a thinner oxide layer due to that material having less time exposed to air at the test temperature. These are the same oxide thickness bands shown in Section 2.11. The crack generally progresses further in the middle of the specimen than at the sides. This difference in crack progression occurs because the middle of the specimen is in plane strain due to the constraint of the bulk material surrounding the plastic zone, while the sides are in plane stress because of the close proximity of the surface [Rice 1970], see Section 2.8 for more detail. The average DHC crack length was determined by manually tracing the entire DHC crack area in the Image Pro program and then dividing this area by the specimen breadth. 
The crack growth rate of each specimen was estimated by using the average DHC crack length and dividing by the loaded test time. The test time started when the test load was reached and ended when the load was removed. This method ignores the DHC incubation time, which is a measure of how long it takes for the first hydride to nucleate at the notch, grow, and fracture. The incubation times in this report were typically a few percent of the total cracking time. 


\section{Chapter 4}

\section{Results}

This chapter presents the experimental results. Longitudinal and through-thickness velocities for three different bulk hydrogen concentrations are presented, at test temperatures both above and below TSSP. The following results are presented; plate 1 at $65 \mathrm{ppm}$, plate 2 at $100 \mathrm{ppm}$, plate 3 at $40 \mathrm{ppm}$ as well as all the data presented on one combined plot. The details of each velocity measurement are shown in Appendix F.

The data are presented in graphical form as crack velocity vs. temperature and as log crack velocity vs. reciprocal temperature. TSSP onset temperature is shown using a vertical black line on each of the graphs. DSC curves for plates 1 and 3 are included.

The plate 1 specimens were the first round of specimens tested. These specimens were tested on the 'old rigs'. The procedure for these rigs is presented by Sagat et al. (1986). Cantilever beam specimens machined from plates 2 and 3 were tested on the new rigs using a motor step threshold to end the tests. The scatter of the determined crack velocities of the specimens tested on the new rigs is less than the corresponding scatter on the old rigs.

In general, the longitudinal velocity is higher than the through-thickness velocity, as observed in previous studies [Kim 2002, Jovanovic 2001, Coleman 1979, Cheadle 1996, Sagat 1994]. The velocity ratio seems to have a weak dependence on temperature, with the ratio decreasing with increasing temperature, Figure 46. 


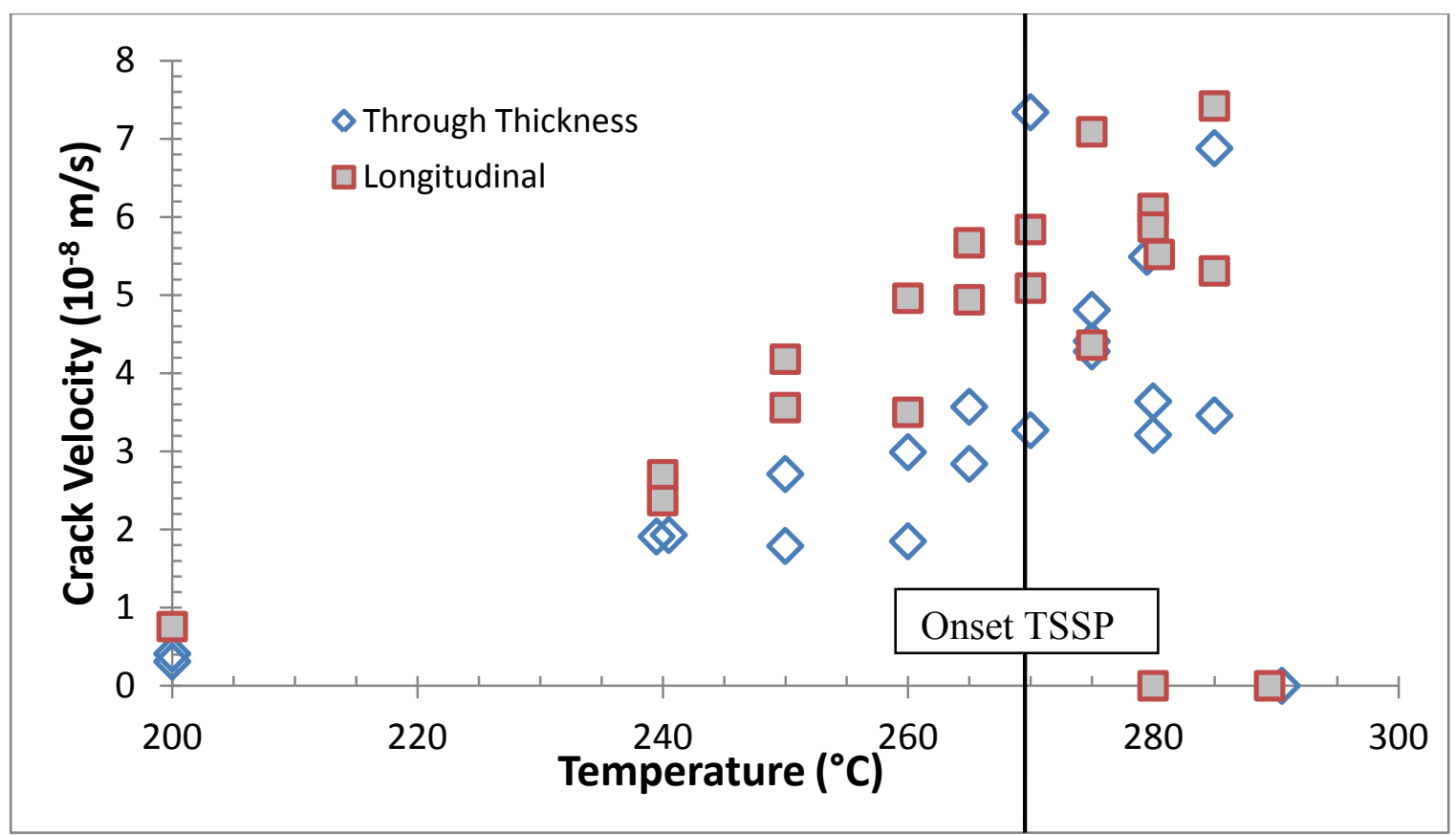

Figure 36 - Plate $1(65 \mathrm{ppm})$ through-thickness and longitudinal DHC crack velocities as a function of temperature with DSC onset temperature.

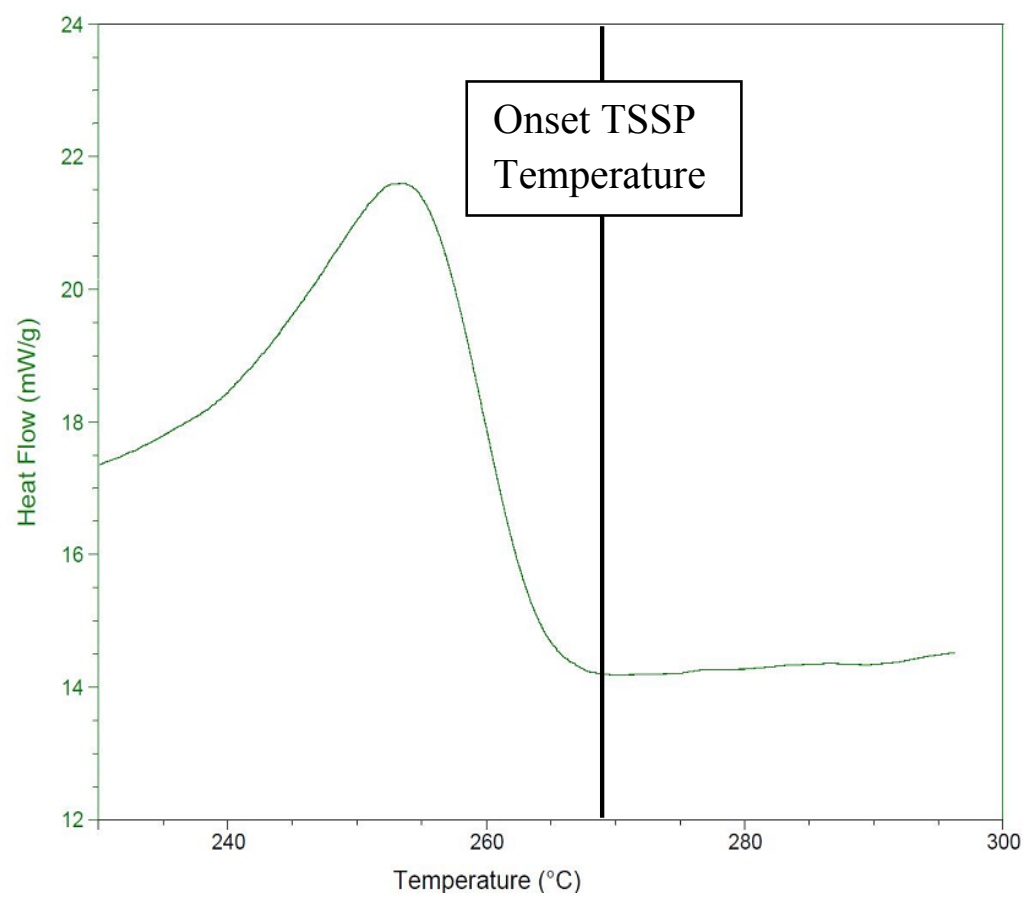

Figure 37 - Plate 1 DSC curve showing onset TSSP at $268^{\circ} \mathrm{C}$ 


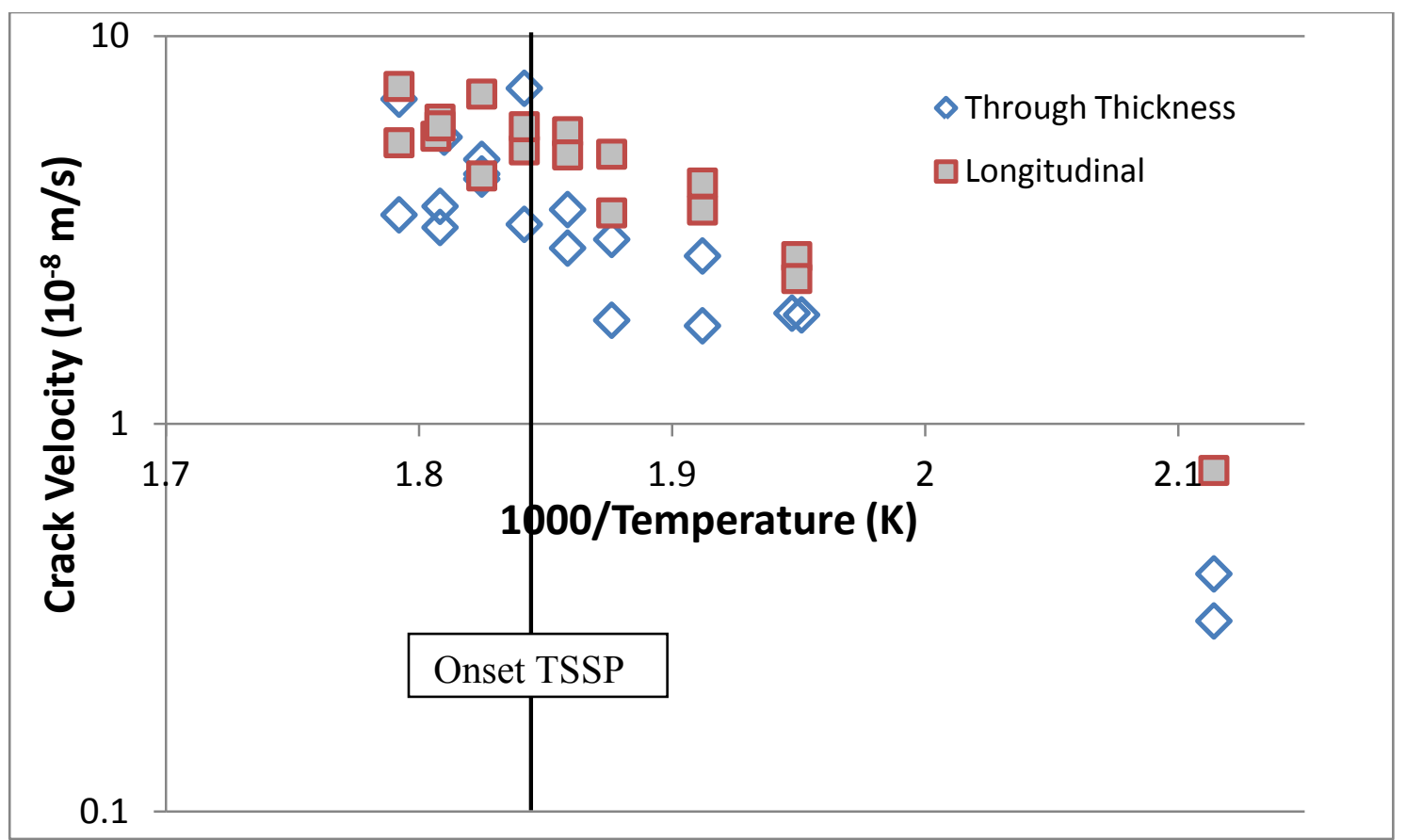

Figure 38 - Plate 1 (65 ppm) through-thickness and longitudinal DHC crack

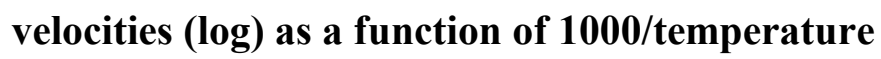

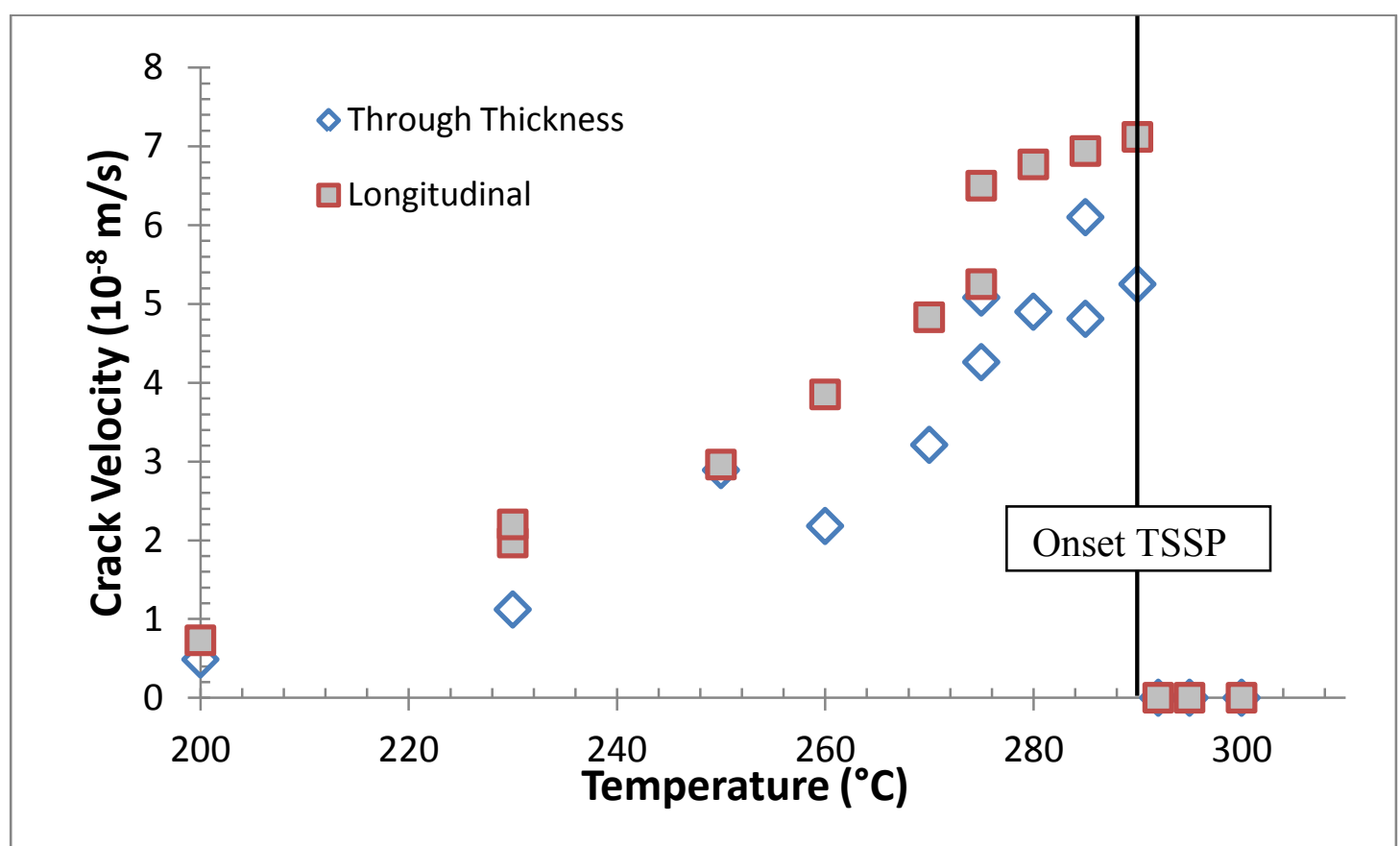

Figure 39 - Plate 2 (100 ppm) through-thickness and longitudinal DHC crack velocities as a function of temperature 


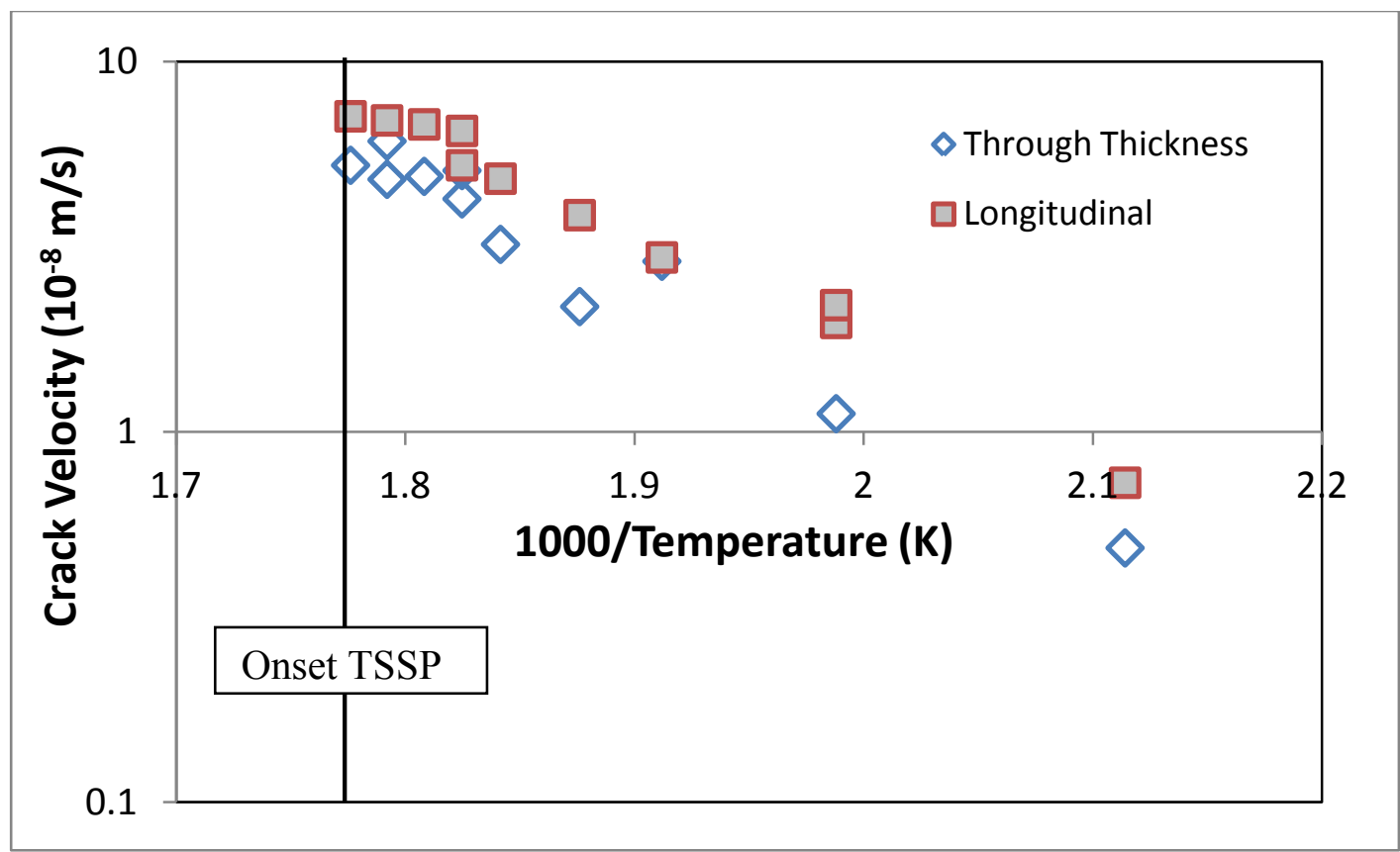

Figure 40 - Plate 2 through-thickness and longitudinal DHC crack velocities (log) as a function of $1000 /$ temperature 


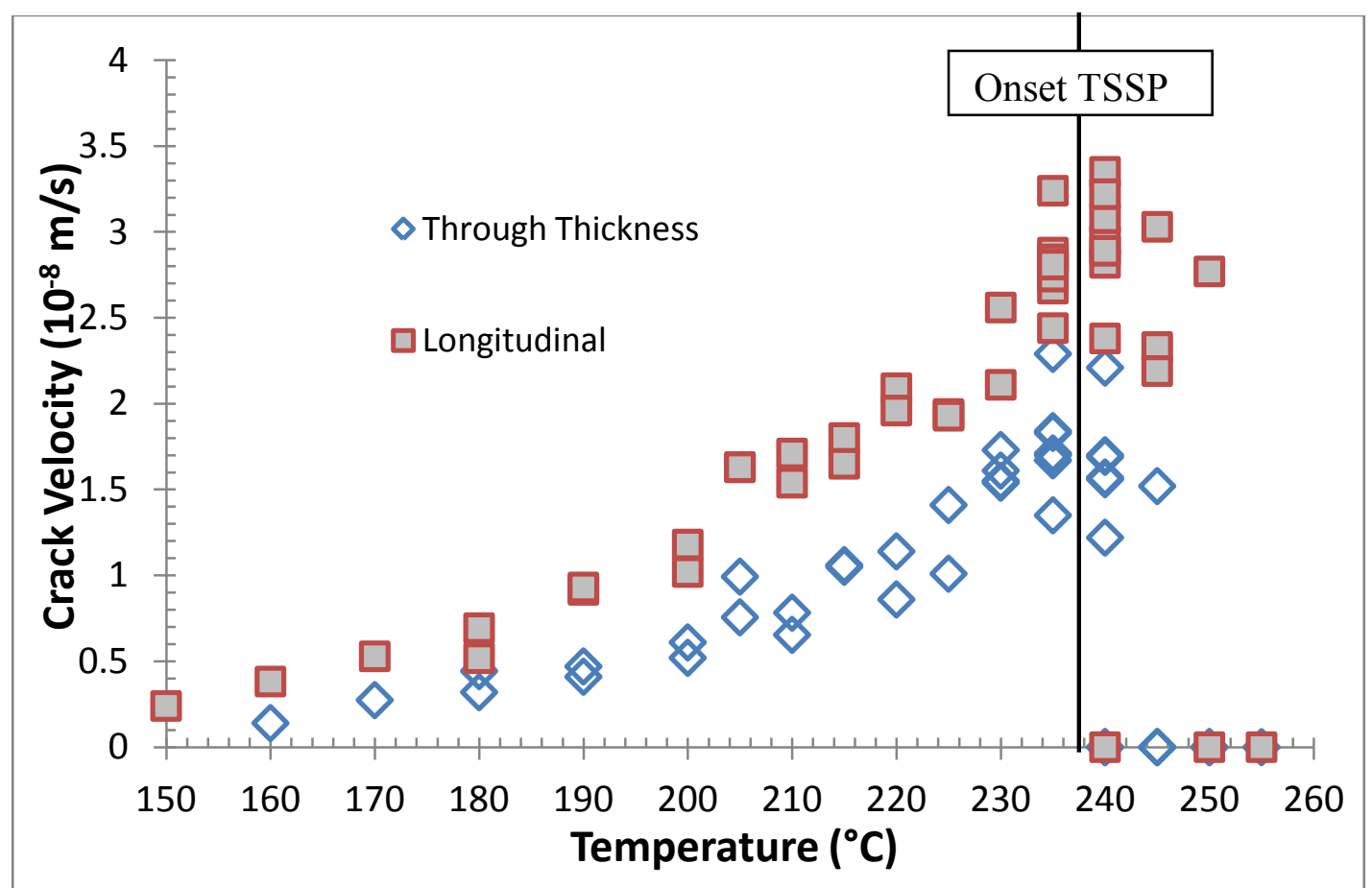

Figure 41 - Plate 3 (40 ppm) through-thickness and longitudinal DHC crack velocities as a function of temperature

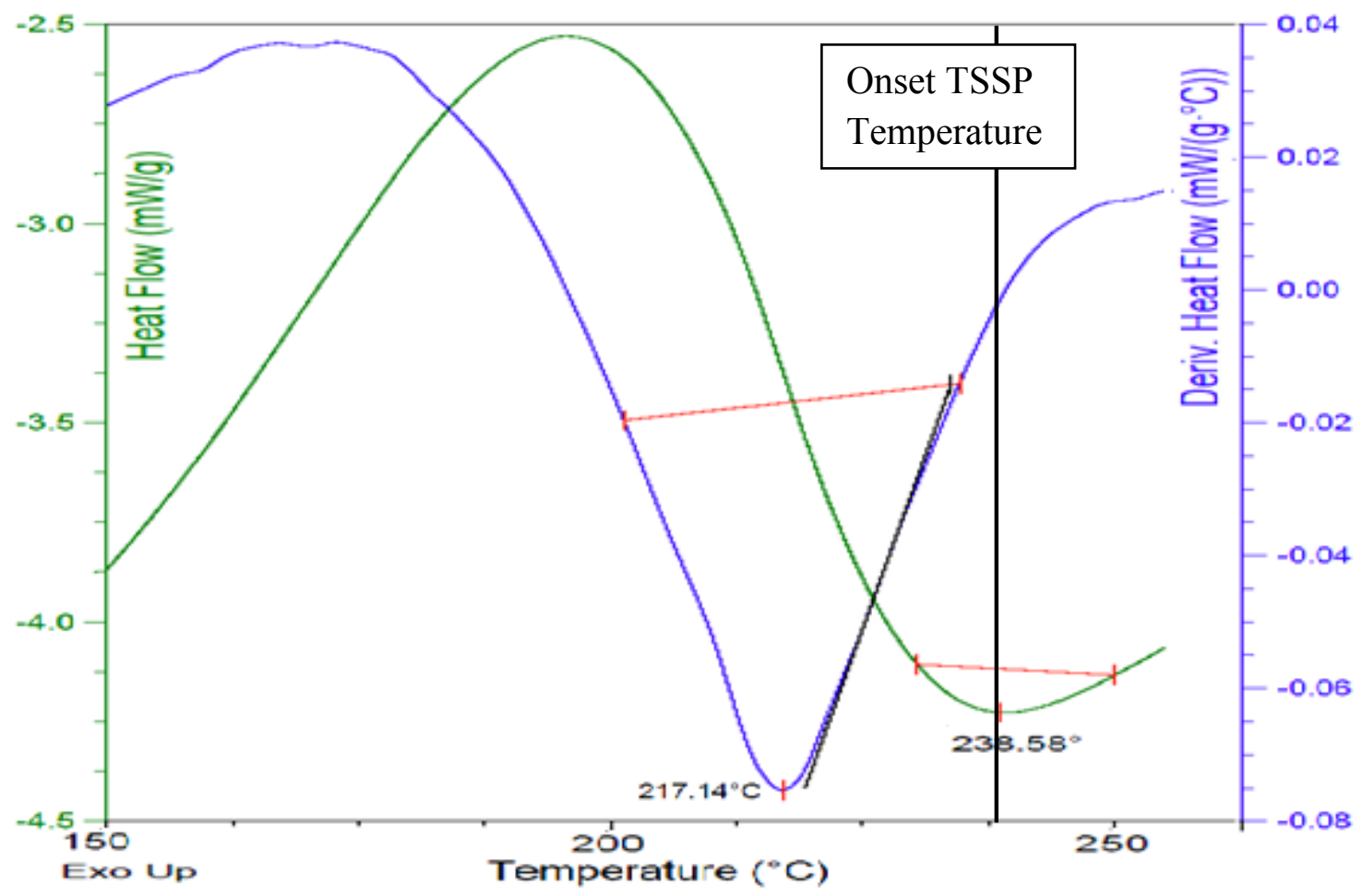

Figure 42 - Plate 3 DSC curve showing onset TSSP at $239^{\circ} \mathrm{C}$ 


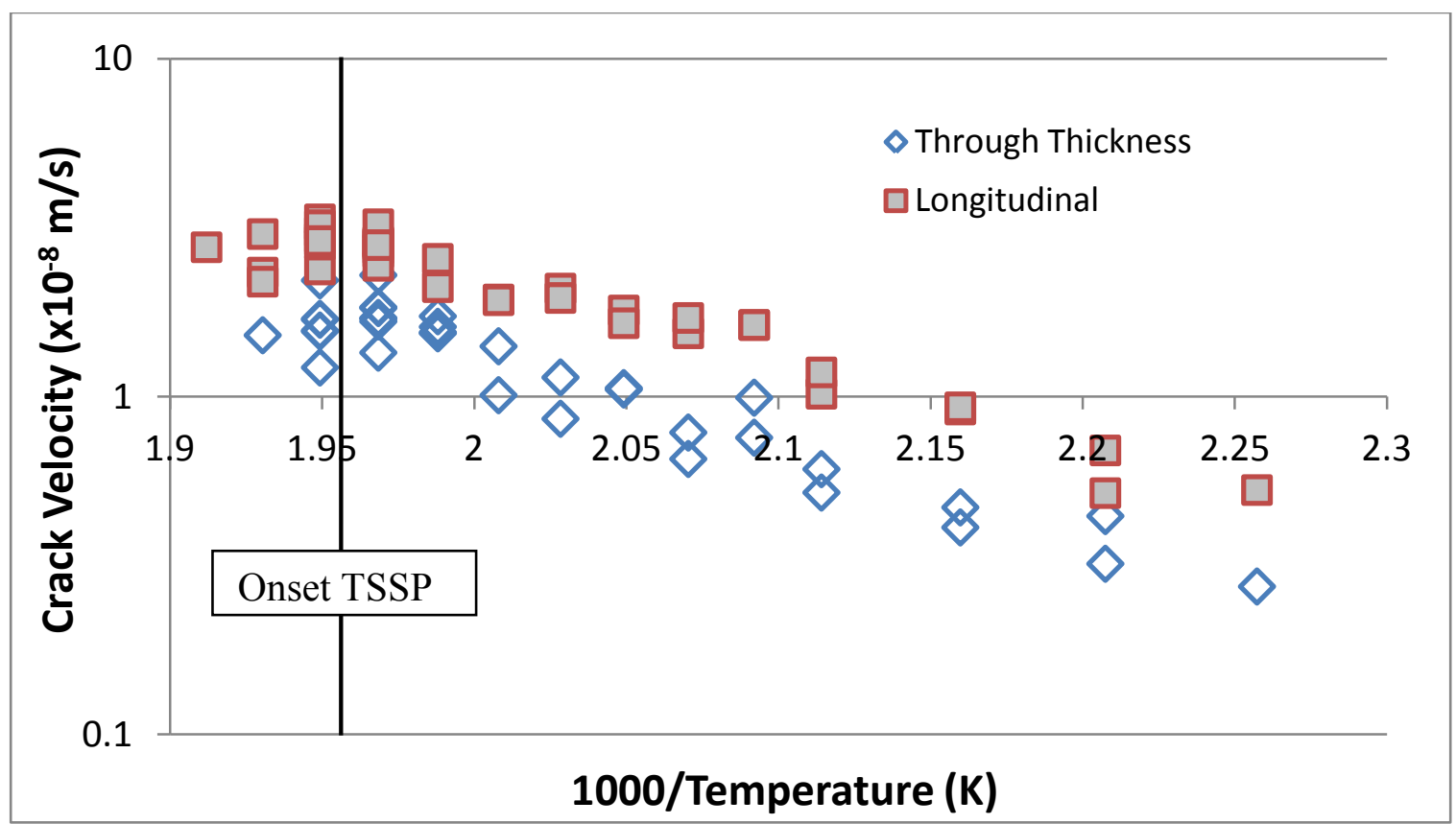

Figure 43 - Plate 3 (40 ppm) through-thickness and longitudinal DHC crack velocities (log) as a function of $\mathbf{1 0 0 0 / t e m p e r a t u r e ~}$

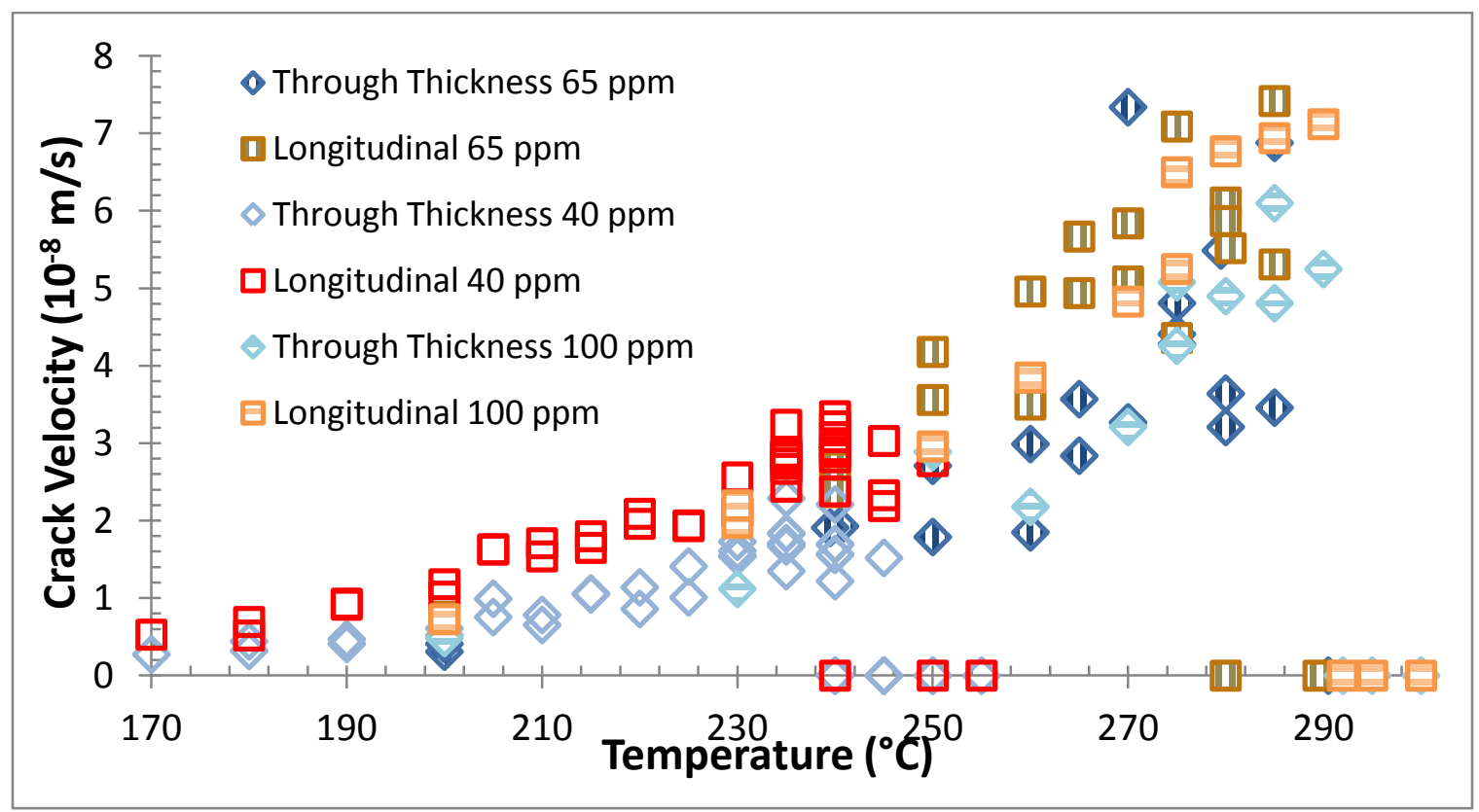

Figure 44 - Combined through-thickness and longitudinal DHC crack velocities as a function of temperature 


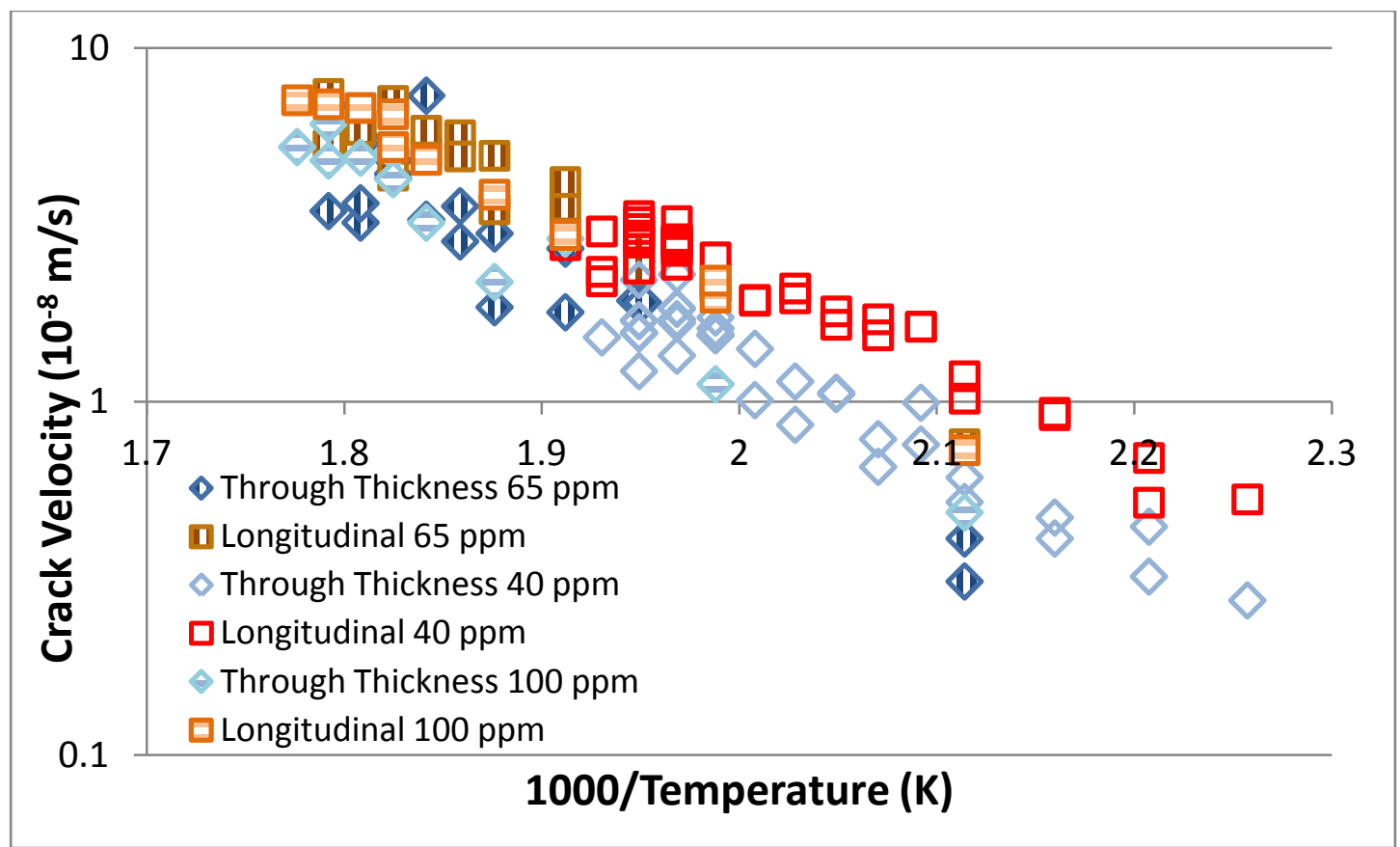

Figure 45 - Combined through-thickness and longitudinal DHC crack velocities (log) as a function of 1000/temperature

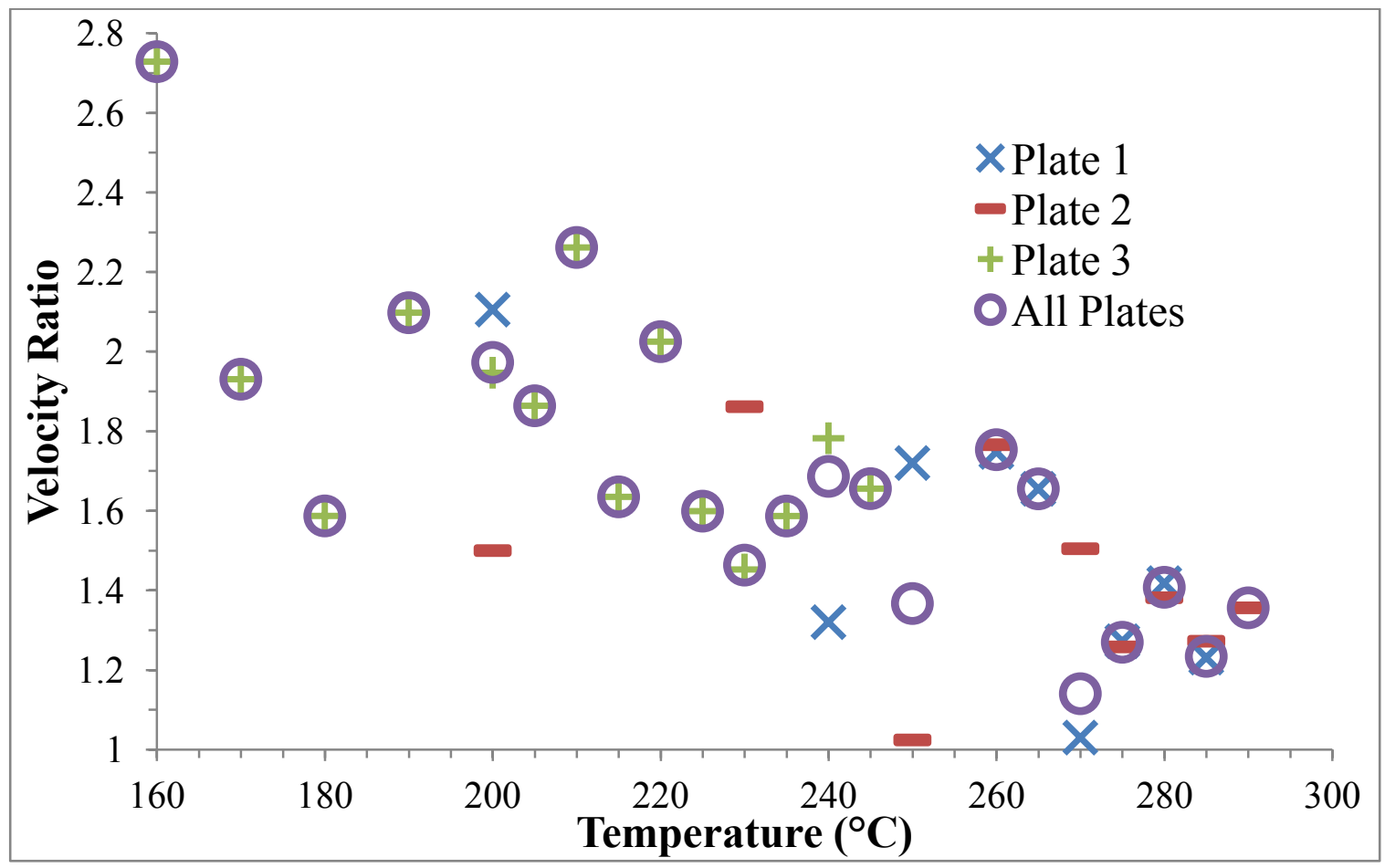

Figure 46 - Velocity ratio as a function of temperature for each plate, and for the combined data from all three plates 


\section{Chapter 5}

\section{Discussion}

In this chapter, the results presented in Chapter 4 will be analyzed in terms of how they relate to bulk hydrides contributing to the difference between longitudinal and throughthickness crack velocities. The discussion follows the chronological order in which the experiments were completed. Initially, experiments on the old rigs gave some indication that the bulk hydrides may be responsible for the velocity difference. However, subsequent experiments with the more precise new rigs did not show the same trends. It was concluded that the orientation of bulk hydrides does not significantly contribute to the velocity difference. In light of this conclusion, alternative hypotheses are presented.

\subsection{Bulk Hydride Theory}

The main objective of this thesis was to test whether or not bulk hydrides impede through-thickness cracks to a greater extent than longitudinal cracks. To test this hypothesis, DHC velocity testing was performed both above and below TSSP. The rationale for this experiment is that hydrides are present in the bulk below TSSP, but not above. Thus, the bulk hydride theory predicts a directional difference in crack velocity below TSSP, but not above.

The term bulk hydride is used to differentiate between hydrides that have nucleated in the bulk of the component rather than at a specific location such as a stress riser. DHC does not require bulk hydrides to be present, but does require hydride nucleation, growth and fracture at a flaw. When a specimen is cooled to below TSSP, some fraction of the hydrogen in the specimen will precipitate as bulk hydrides while the balance remains 
dissolved in solution. The further below TSSP the specimen is cooled, the larger the fraction of hydrogen will be in hydride form. If a specimen is cooled from a high temperature to a temperature above TSSP, no bulk hydrides will be present. Hydrides tend to form with their normal in the through-thickness direction; these are called circumferential hydrides. However, DHC direction will depend on the local stress field at the root of a flaw. In this study, all DHC cracks are in the transverse plane, which is the plane with the highest stress for in-service pressure tubes.
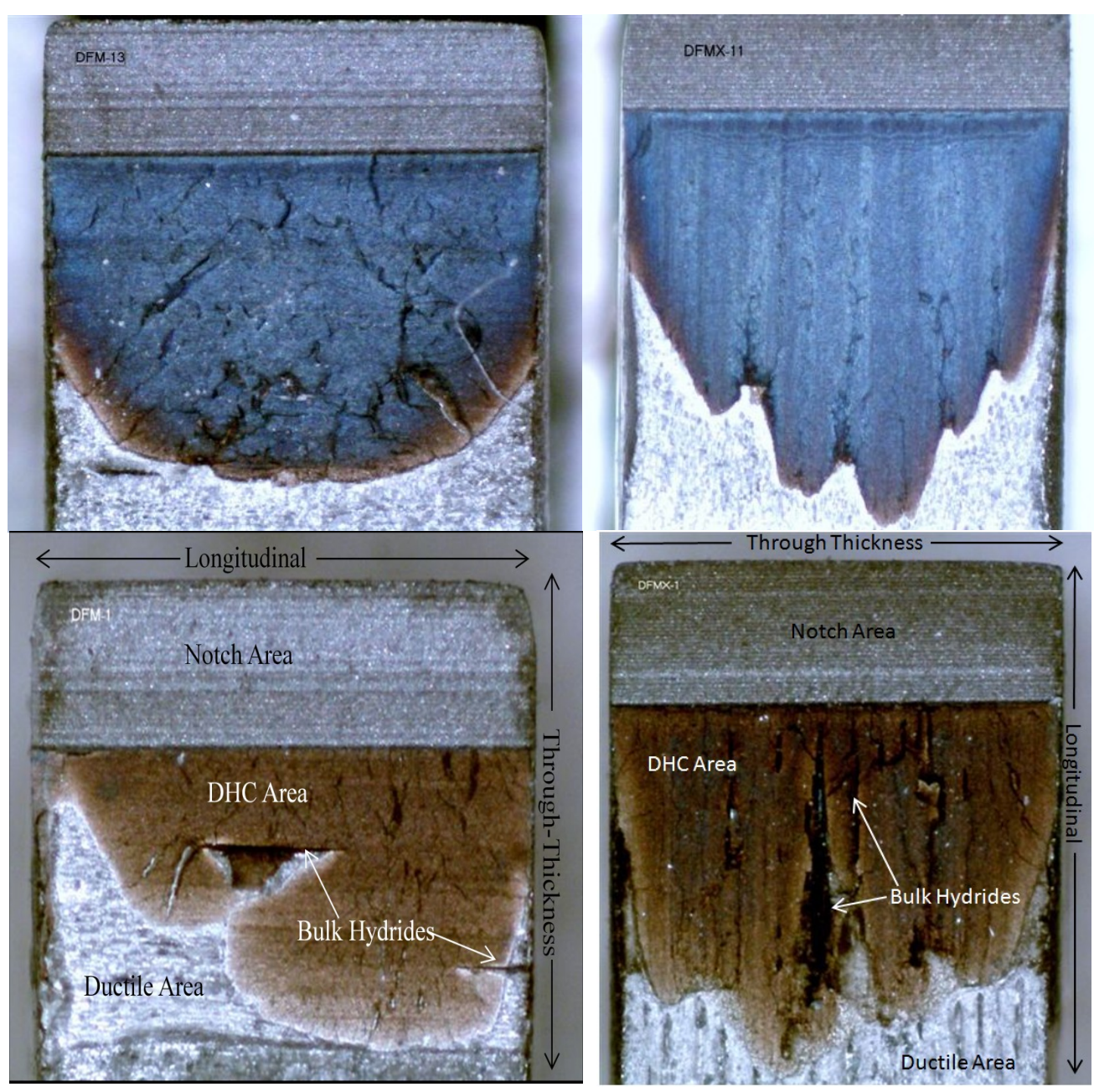

Figure 47 - Plate 1 Fracture Surfaces. Top: Through-thickness (left) and longitudinal (right) tested above onset TSSP. Bottom: Through-thickness (left) and longitudinal (right) tested below onset TSSP (same as Figure 4 and 5) 
The origin of the bulk hydride explanation for the difference between longitudinal and through-thickness crack velocities came from the analysis of fracture surfaces from DHC crack velocity tests. When cantilever beam specimens are cooled to test temperatures above TSSP, there are no bulk hydrides present (Figure 47 Top), while when specimens are cooled to below TSSP there are bulk hydrides present (Figure 47 Bottom). Bulk hydrides tend to precipitate with their normal in the through-thickness direction; in through-thickness specimens, the plane of the bulk hydrides is perpendicular to the direction of propagation of the DHC crack while longitudinal bulk hydride planes are oriented parallel to the DHC cracking direction.

The through-thickness and longitudinal cracks seem to interact with the bulk hydrides in different ways. The through-thickness fracture surfaces show the DHC crack being 'forced' around the large bulk hydrides, leaving ductile or less oxidized regions in their wake. The hydrides were theorized to act as 'speed bumps' that impede the crack, reducing the DHC crack velocity. The longitudinal fracture surfaces show a different interaction with the bulk hydrides; the hydride 'speed bump' is parallel to the direction of cracking, allowing the DHC crack to propagate at a higher rate. Thus, longitudinal cracks interact with the edge of the bulk hydrides rather than the hydride planes. The bulk hydrides are proposed to account for the lower DHC crack velocity in the radial direction.

\subsubsection{Plate 1}

The first experiments were performed on specimens machined from plate 1, which were hydrided to $65 \mathrm{ppm}$ and tested on the 'old' rigs. Below the onset TSSP, the longitudinal velocities are always above through-thickness for a given temperature (Figure 36 from results). Above TSSP, there is no clear difference in crack velocity; the velocities at specific temperatures in either direction cannot be distinguished. These preliminary results were published as an extended abstract and presented at a poster at the 2012 
Canadian Nuclear Society Conference in Saskatoon [Hanlon 2012]. This abstract is reproduced in Appendix G. The poster is shown in Appendix H.

The data in Figure 36 do not provide sufficient confidence that velocities above TSSP were indistinguishable and plate 1 had been consumed, no further specimens were available. A second plate was fabricated, hydrided and machined for further testing.

\subsubsection{Plate 2}

Plate 2 was hydrided to $100 \mathrm{ppm}$. This higher concentration, as compared with that in plate 1 , was chosen because there would be more bulk hydrides at low temperatures, which were expected to amplify the bulk hydride effect. In addition, test times would generally be shorter. The results of cantilever beam DHC crack velocity tests for plate 2 are shown in Figure 39. TSSP onset was $290^{\circ} \mathrm{C}$ for this material. Below TSSP, longitudinal crack velocities are always higher than through-thickness velocities; the same trend as observed for plate 1 . There was no cracking observed above $290{ }^{\circ} \mathrm{C}$ in either the longitudinal or through-thickness directions, thus, it was not possible to compare the directional velocity difference at temperatures above TSSP. There is a high temperature limit for DHC that depends on the yield strength. Previous studies have shown upper temperature limits between $300{ }^{\circ} \mathrm{C}$ and $350{ }^{\circ} \mathrm{C}$ [Sagat 2003, Coleman 2010]. It appears that the reason for no cracking above $290{ }^{\circ} \mathrm{C}$ in plates 1 and 2 was likely because this limit has been reached. A third plate with a lower hydrogen concentration was fabricated, hydrided and machined to avoid this apparent high temperature limit. 


\subsubsection{Plate 3}

Plate 3 was hydrided to $40 \mathrm{ppm}$. This lower concentration was chosen because a larger region of cracking temperatures above TSSP was expected. A concentration of $40 \mathrm{ppm}$ is high enough that loaded test times will be days rather than weeks or months, which would be the case for even lower concentrations. The plate 3 specimens were tested on the new rigs described in Chapter 3. The plate 3 crack velocity plot shown in Figure 41 shows a significant improvement in terms of repeatability when compared with the values shown in Figure 36. The number of plate 3 specimens was also higher than either of the other two plates.

Figure 41 shows the through-thickness velocity always being smaller than the longitudinal velocity, at a given temperature, both above and below TSSP: there is no ambiguity. Plate 3 data shows that the bulk hydride hypothesis is not valid because this hypothesis predicts no directional differences above TSSP, which disagree with observations.

\subsubsection{Combined Data}

If specimens of different concentrations are cooled to the same common temperature below the TSSP temperature for both, then the specimen with the higher initial concentration will have a greater amount of bulk hydride (each specimen should contain the same amount of hydrogen in solution). If bulk hydrides impede the crack, the specimen with the larger amount of hydrides would have the slower crack velocity. However, as Figure 44 shows, this is not true: the 100 ppm crack velocity curve is not

generally slower than the $40 \mathrm{ppm}$ crack velocity curve at temperatures below $240{ }^{\circ} \mathrm{C}$, which is the $40 \mathrm{ppm}$ TSSP temperature. Again, the bulk hydride theory is disproved. 
It was observed that the DSC onset temperature was closer than the DSC maximum slope temperature to the peak crack velocity temperature for all three plates, which is in agreement with a study using compact tension pressure tube specimens [Hanlon 2013]. This observation has been used to justify the DSC onset temperature as an estimation for the precipitation solvus temperature (see Section 2.4) [Hanlon 2013].

\subsubsection{Velocity Ratio}

In the review of previous studies in Sections 2.9 and 2.10, the velocity ratios presented showed different trends. The velocity ratios for DHC velocity tests in this study, namely plates 1 to 3 as well as combined data, are presented in Figure 46, which shows a trend of decreasing velocity ratio with increasing temperature. The rate of decrease with temperature is smaller than the CSA standard prediction (Figure 6), but larger than the data presented by Kim et al. [2002]. The reason for this decrease in velocity ratio with temperature was predicted to be due to the reduced hydride volume fraction at high temperatures, but the bulk hydride theory has been disproved so this is likely not the correct explanation for the velocity ratio trend.

\subsection{Alternative Theories}

In this section, two new explanations for the directional velocity difference are described. Although the bulk hydride model does not seem to be a good model of the data, the idea that the through-thickness cracks encounter more blockages or 'speed bumps' relative to the longitudinal cracks may have merit.

\subsection{1 $\alpha-\beta$ Boundary Anisotropic Distribution Theory}

Previous studies have theorized that both $\beta$-phase morphology and grain size affects DHC rates (see Section 2.9); the $\alpha-\beta$ Boundary Distribution theory uses some similar ideas. If 
a DHC crack interacts with a grain boundary its velocity could be reduced. As a hydride growing from a crack tip approaches a grain boundary, there will be a competition between the grain boundary and the crack tip for the diffusing hydrogen. The DHC velocity will be reduced if some of the hydride growth occurs normal to the cracking plane, or if some of the hydrogen is lost to the grain boundary. If the grain boundaries are distributed differently in the longitudinal and through-thickness directions, the distribution difference could explain the observed directional difference in crack velocities.

From the grain dimensions given in Section 2.2, the ratio of grain boundaries per length in the through-thickness and longitudinal directions is 50:1. This means that a growing hydride will interact with 50 times more boundaries in the through-thickness direction than the longitudinal direction, per unit length. Even a small grain boundary effect might be magnified by this ratio.

A hydride may grow normal to the cracking plane because of interaction with the grain boundaries. Through-thickness cracks are more frequently diverted because they encounter more grain boundaries per unit length. When calculating crack velocity, only the cracking in the transverse plane is taken into account. Any component of hydride growth in the transverse direction is ignored because the DHC areas are two-dimensional projections onto the transverse plane. The through-thickness cracks are theorized to have a greater proportion of their length in the transverse direction, which is not measured using the two-dimensional technique.

There are different types of grain boundaries in pressure tube material. It is theorized that hydrides tend to precipitate preferentially along $\alpha-\beta$ boundaries than $\alpha-\alpha$ boundaries. This preference could be used to explain why the crack velocity decreases in pressure 
tube material as the annealing time is increased. As the $\beta$-phase decomposes during annealing, the volume fraction of $\beta$-phase is reduced and $\alpha-\beta$ boundaries are replaced by $\alpha-\alpha$ boundaries. The isolated effect of replacing $\alpha-\beta$ boundaries with $\alpha-\alpha$ boundaries would cause crack velocities in both directions to increase. There are more boundaries in the through-thickness direction, therefore cracking in this direction will be increased to a greater extent than cracking in the longitudinal direction; this will decrease the longitudinal to through-thickness velocity ratio. However, as the $\beta$-phase volume decreases, the fast diffusion pathways are reduced; this will reduce the velocity to the same extent in either direction because of three-dimensional diffusion due to triaxial stress (Section 2.8). The effect of $\beta$-phase decomposition on the diffusion reduces the DHC velocity for both directions by more than an order of magnitude [Skinner 1990] while its effect on $\alpha-\beta$ or $\alpha-\alpha$ boundaries is significantly smaller; up to a factor of 2 . The overall effect of $\beta$-phase decomposition is to reduce the velocities in both directions, however, the reduction in through-thickness velocity is not as great because more $\alpha-\beta$ grain boundaries diversions are removed per length. This is similar to the argument presented by Jovanovic et al. (2001) (Section 2.9.2), but the change in velocity ratio is attributed to the $\alpha-\beta$ boundary anisotropy rather than anisotropic diffusion in the $\beta$-phase. The $\alpha-\beta$ boundary distribution theory suggests that material with no $\beta$-phase, such as Zircaloy, has a lower velocity ratio than material with $\beta$-phase, such as $\mathrm{Zr}-2.5 \mathrm{Nb}$, because of the lack of $\alpha-\beta$ boundaries that would slow cracking to a greater extent than $\alpha-\alpha$ boundaries. Results of studies on material with no $\beta$-phase have shown velocity ratios approaching one [Cheadle 1996, Coleman 2010, Sakamoto 2008].

Even though the $\beta$-phase decomposition is the dominant factor affecting DHC velocities, it affects both directions to the same extent. The factor that explains the changing velocity ratio is the interaction of the growing crack with grain boundaries; with $\alpha-\beta$ boundaries creating more tortuous cracks than $\alpha-\alpha$ boundaries. 


\subsubsection{Bridge Theory}

One of the requirements of DHC is the nucleation and growth of a hydride at a stress riser, see Section 2.8. The concentration of hydrogen in solution in the region around the growing hydride is TSSP, which is different for the $\alpha$ and $\beta$ phases. TSSP in the $\beta$-phase is at least 30 times that of the $\alpha$-phase [Sawatzky 1982]. For hydride growth in the $\beta$ phase, the local concentration of hydrogen will be at the $\beta$-phase TSSP. When a growing DHC hydride crosses an $\alpha-\beta$ boundary into the $\beta$-phase, the concentration in solution must increase from the $\alpha$-phase TSSP to the $\beta$-phase TSSP [Sawatzky 1981], which takes time. Once the $\beta$-phase TSSP is reached, the hydride will continue to grow through the $\beta$-phase and into the adjacent $\alpha$-phase. Each time a growing hydride encounters an $\alpha-\beta$ boundary, a delay will occur before a $\beta$-phase 'bridge' can form. This is consistent with micrographs that show hydrides that have grown through the $\beta$-phase [Northwood 1978]. In cold-worked $\mathrm{Zr}-2.5 \mathrm{Nb}$ pressure tubes, hydrides growing in the through-thickness direction encounter many times more $\alpha-\beta$ boundaries per unit length than in the longitudinal direction, as discussed in Section 5.2.1. The suggestion is that the cumulative delays caused by the $\beta$-phase 'bridge' accounts for the fact that the throughthickness velocity is slower than the velocity in the longitudinal direction. This theory, like the $\alpha-\beta$ Boundary Distribution theory, is consistent with the reduction of velocity ratio with the decomposition of the $\beta$-phase, see Figure 24, Section 2.8 [Jovanovic 2001]. As the $\beta$-phase is decomposed, the number of $\beta$-phase 'bridges' are reduced, so the through-thickness velocity approaches that of the longitudinal velocity. 


\section{Chapter 6}

\section{Conclusions}

The main objective of this thesis was to test whether or not bulk hydrides slow throughthickness cracks to a greater extent than longitudinal cracks. DHC fracture surfaces show hydrides lining up parallel to longitudinal cracks and perpendicular to through-thickness cracks. The bulk hydride 'speed bumps' were predicted to slow through-thickness cracks to a greater extent than longitudinal cracks. Above TSSP, where no hydrides are present, it was predicted that there would be no discernible directional difference in crack velocities. Below TSSP, where hydrides are present, the velocity ratio was predicted to increase as the volume fraction of hydrides increased. DHC crack velocities were determined using cantilever beam specimens with cracks propagating in both the longitudinal and through-thickness directions with and without bulk hydrides present, i.e., below and above TSSP. The DHC crack velocities in the longitudinal direction were observed to be higher than the corresponding through-thickness crack velocities with or without bulk hydrides present. Thus, the hypothesis is disproved; the orientation of bulk hydrides relative to the direction of DHC cracking does not explain the direction difference in crack velocities.

Previous explanations for the difference between through-thickness and longitudinal DHC crack velocities were reviewed. Kim et al. (2002) attributed the difference between longitudinal and through-thickness crack velocities to anisotropy of the stress gradient ahead of the crack tip because of differential strain hardening. However, the triaxial stress surrounding the crack tip reaches the yield strength, not the tensile strength, and the hydride fractures, not the zirconium lattice. Jovanovic et al. (2001) hypothesized that the difference between longitudinal and through-thickness crack velocities is due to anisotropic diffusion because of the morphology and distribution of the $\beta$-phase. 
However, the triaxial stress at the crack tip drives hydrogen from all directions, so any diffusion 'shortcuts' via the $\beta$-phase should speed crack growth in all directions to the same extent. Coleman et al. (1979) proposed that the difference in length between grain boundaries in longitudinal and through-thickness directions causes the observed directional difference in crack velocities. A mechanism for this observation was not provided. In addition, not all the experimental data presented in these studies was consistent. The velocity ratio as a function of temperature was reported to decrease, remain the same, or increase with temperature. DHC testing above TSSP was not performed in previous studies.

An objective of this study was to remove confounding factors, i.e., to test specimens of identical geometry using the same material, experimental rigs and specimen grips, with the only difference being the direction of cracking. In the Kim et al. (2002) study, cantilever beams specimens were flattened, possibly creating local residual stresses (see Section 2.11), and annealed, possibly removing some of the cold-work. In the Jovanovic et al. (2001) study, different grips were used to test the longitudinal and throughthickness specimens. Other studies used different specimen types for different testing directions [Sagat 1994]. In this thesis, these confounding effects were eliminated. To eliminate the geometry effect of curved pressure tubes, cantilever beam specimens manufactured from plate material were tested with the same geometry in the longitudinal and through-thickness directions.

Another objective of this study was to improve DHC velocity measurement testing procedure to discern better the differences between longitudinal and through-thickness crack velocities. A new way of ending a DHC test, called a motor step threshold, was implemented. The motor step threshold reduced scatter and simplified testing. 
Two alternative explanations for the directional velocity difference were described. The first, called the $\alpha-\beta$ boundary anisotropic distribution theory, suggests that as a growing hydride approaches a grain boundary some hydrogen accumulation or hydride growth will occur normal to the transverse plane. DHC velocity measurement projects the fracture surface onto the transverse plane, so any growth normal to this plane is ignored. Grain boundaries are distributed differently in the transverse plane cracking directions, with fifty times more boundaries per unit length in the through-thickness direction than the longitudinal direction. The increased amount of hydride growth normal to the transverse plane at grain boundaries in the through-thickness direction could explain the directional difference in velocity.

A second alternate theory, called the bridge theory, was presented. TSSP in the $\beta$-phase is higher than that of the $\alpha$-phase, so when a growing DHC hydride crosses an $\alpha-\beta$ boundary into the $\beta$-phase, the concentration in solution must increase from the $\alpha$-phase TSSP to the $\beta$-phase TSSP. Once the $\beta$-phase TSSP is reached, which takes time, the hydride will continue to grow through the $\beta$-phase and into the adjacent $\alpha$-phase. Each time a growing hydride encounters an $\alpha-\beta$ boundary, a delay will occur before a $\beta$-phase 'bridge' can form. This delay occurs fifty times more often in the through-thickness direction due to the grain aspect ratio in the transverse plane. The increased delay time in the through-thickness direction could account for the directional difference in velocity. 


\section{Future Work}

The two alternative theories presented in this report have not been examined experimentally.

Testing the $\alpha-\beta$ boundary distribution theory could involve examining micrographs to determine if there is any accumulation of hydrogen normal to the transverse plane at $\alpha-\beta$ boundaries. Specifically, the micrographs would be prepared showing DHC cracks through $\alpha-\beta$ boundaries in either the longitudinal or through-thickness plane.

The bridge theory could be examined by simulating the time delay required for the hydrogen concentration in a thin $\beta$-phase grain to increase from the $\alpha$-phase TSSP concentration to the $\beta$-phase TSSP concentration. Difficulties may arise in estimating the effective diffusion coefficient within a $\beta$-phase grain and the $\beta$-phase crack velocity. The bridge theory suggests that the time delay to reach the $\beta$-phase TSSP concentration is on the same order as the time required for a hydride to grow the average length between through-thickness grain boundaries. 


\section{References}

AITCHISON, I., (1969). "Effect of orientation of hydride precipitates on the fracture toughness of cold-rolled Zircaloy-2 and Zr-2.5 Nb." Applications-Related Phenomena for Zirconium and its Alloys, ASTM STP 458, W.R. Thomas, S.S. Christopher and P.L. Rittenhouse, Eds., American Society for Testing and Materials, Philadelphia, PA., 160178.

ALI, M. S. (2010). “An Historical Survey of Leak-Before-Break in Nuclear Plant Piping." Power-Gen Worldwide.

AMOUZOUVI, K.F., CLEGG, L.J., (1987). "Effect of Heat Treatment on Delayed Hydride Cracking in Zr-2.5 wt\% Nb.” Metal. Trans. 18A, 1687-1694.

BELL, R., (2001). "Linear Elastic Fracture Mechanics." Carleton University, MECH 5602 Lecture Notes, Chapter 3.

BICKEL, G.A., GREEM, L.W., JAMES, M.W.D., LAMARCHE, T.G., LEESON, P.K., MICHEL, H., (2002). "The determination of hydrogen and deuterium in $\mathrm{Zr}-2.5 \mathrm{Nb}$ material by hot vacuum extraction mass spectrometry." J. Nuc. Mat. 306, 21-29.

BICKEL, G.A., GRIFFITHS, M., (2008). "Manufacturing variability and deformation for $\mathrm{Zr}-2.5 \mathrm{Nb}$ pressure tubes." J. Nuc. Mat. 383, 9-13. 
BROEK, D., (1982). "Elementary Engineering Fracture Mechanics." 2nd Edition, Martinus Nijhoff Publishers.

CANADIAN STANDARDS ASSOCIATION, (2005). 'Technical requirements for inservice evaluation of zirconium alloy pressure tubes in CANDU reactors." N285.8-05

CAUSEY, A.R., URBANIC, V.F., COLEMAN,C.E., (1977). "In-reactor oxidation of crevices and cracks in cold-worked Zr-2.5 wt\% Nb." J. Nuc. Mat. 71, 25-35.

CHEADLE, B.A., CELOVSKY, A., GHAFOOR, M., BUTT, W. (1996) "Assessment of the Integrity of KANUPP Fuel Channels." 1996 CNA/CNS Conference, Fredericton, New Brunswick.

CHEADLE, B.A., COLEMAN, C.E., LICHT, H., (1981). "CANDU-PHW pressure tubes: their manufacture, inspection, and properties." Nucl. Tech., 57, 413-425.

COLEMAN, C.E., (1982). "Effect of texture on hydride reorientation and delayed hydrogen cracking in cold-worked Zr-2.5 Nb." Zirconium in the Nuclear Industry - Fifth International Symposium, ASTM STP 754, D.G. Franklin, Ed., American Society for Testing and Materials, Philadelphia, PA., 393-411.

COLEMAN, C.E., AMBLER, J.F.R., (1979). " Measurement of effective solvus temperature of hydrogen in $\mathrm{Zr}-2.5 \mathrm{wt} \% \mathrm{Nb}$ using acoustic emission." 17, 81-84. 
COLEMAN, C.E., AMBLER, J.F.R., (1977). "Susceptibility of Zirconium Alloys to Delayed Hydride Cracking." Amer. Soc. for Testing and Materials, pp 589-607.

COLEMAN, C.E., AMBLER, J.F.R., (1979). "Delayed Hydride Cracking in Zr-2.5 wt\% Nb Alloy." Reviews on Coatings and Corrosion, Vol. 111, No. 2 \& 3, 105-157.

COLEMAN, C., GRIGORIEV, V., INOZEMTSEV, V., MARKELEV, V., ROTH, M., MAKEREVICIUS, V., KIM, Y. S., KANWAR, L. A., CHAKRAVARTTY, J. K., MIZRAHI, R., LALGUDI, R., (2010). “Delayed Hydride Cracking in Zircaloy Fuel Cladding_-An IAEA Coordinated Research Programme." Nucl. Eng. Technol.: Int. J. Korean Nucl. Soc., Vol. 41, pp. 171-178.

COLEMAN, C.E., HARDIE, D., (1966). J. Nucl. Mat. 19, 201.

COLEMAN, C.E., INOZEMTSEV, V.V., (2008). "Measurement of Rates of Delayed Hydride Cracking (DHC) in Zr-2.5 Nb alloys - an IAEA Coordinated Research Project." J. ASTM International, 5, Paper ID JAI 101091, (also 15th ASTM Symposium on Zirconium in the Nuclear Industry, ASTM STP 1505, 244-266).

COLEMAN, C.E., MCRAE, G.A., LEITCH, B.W., (2011). "Evaluating the risk of delayed hydride cracking in components made from zirconium alloys." Eighth ATI Corrosion Solutions Conference, Lake Louise AB.

COLEMAN, C.E., SIMPSON, L.A., (1988). "Evaluation of a leaking crack in an irradiated CANDU pressure tube.” IAEA Specialists Meeting, Stuttgart, Germany. 25-27. 
DAVIES, P.H., STEARNS, C.P., (1986). "Fracture toughness testing of Zircaloy-2 pressure tube material with radial hydrides using direct-current potential drop." Fracture Mechanics: Seventeenth Volume, ASTM STP 905, J.H. Underwood, R. Chait, C.W. Smith, D.P. Wilhem, W.A. Andrews and J.C. Newman, Eds., American Society for Testing and Materials, Philadelphia, PA., 379-400.

DIETER, G.E., (1961). "Mechanical Metallurgy." McGraw-Hill Book Co.

DUNDULIS, G., GRYBENAS, A., MAKAREVICIUS, V., JANULIONI, R. (2010). "Application of "Leak Before Break" Assessment for Pressure Tube in Delayed Hydride Cracking." Laboratory of Nuclear Installation Safety, Lithuanian Energy Institute

DUNN, J.T., JACKMAN, A.H., (1982). "Replacement of a cracked pressure tube in Bruce GS Unit 2." AECL Report, AECL-7537.

ELLS, C.E., (1968). "Hydride precipitation in zirconium alloys - a review." J. Nucl. Mat., 28, (1968), 129-151.

ERICKSON, W.H., HARDIE, D., (1964). "The influence of alloying elements on the terminal solubility of hydrogen in $\alpha$-zirconium." J. Nuc. Mat. 13, 254-262

GULBRANSEN, E.A., ANDREW, K.F., (1954). "Diffusion of Hydrogen and Deuterium in High Purity Zirconium." J. Electrochem. Soc. Vol 101, 560-566. 
HANLON, S.M., READ, S., DOUCHANT, A., PRIMEAU, M., KIDD, K., WILSON, P., MCRAE, G.A., COLEMAN, C.E., (2012). "The Effect of Testing Direction on DHC Growth Rate Using a Zr-2.5Nb Plate." 33rd CNS Annual Conference and 36th Annual CNS-CNA Student Conference, Saskatoon, Jun 10 - Jun 13. Won Best Poster Award at Masters Level.

HANLON, S.M., READ, S., MCRAE, G.A., COLEMAN, C.E., (2013). "Precipitation Temperatures and DHC Velocities." 34th CNS Annual Conference and 37th Annual CNS-CNA Student Conference, Toronto, Jun 9 - Jun 12.

HARDIE, D., SHANAHAN, M.W., (1973). "The effect of residual stresses on hydride orientation in a zirconium-2.5\% niobium alloy." J. Nuc. Mat. 50, 40-46.

HUNTER, T.A., VAN WINSSEN, J., (1976). "Pickering and Bruce rolled joint development program results for pressure tube cracking problem." CGE Report R76CAP17.

IAEA (2004). "Delayed Hydride Cracking in Zirconium Alloys in Pressure Tube Nuclear Reactors." TECDOC-1410.

JOVANOVIC, M.T., EADIE, R.L., MA,Y., ANDERSON, M., SAGAT, S., PEROVIC, V., (2001). "The effect of annealing on hardness, microstructure and delayed hydride cracking in $\mathrm{Zr}-2.5 \mathrm{Nb}$ pressure tube material." Materials Characterization 47, 259- 268. 
KEARNS, J.J., (1965). "Thermal expansion and preferred orientation in Zircaloy." Westinghouse Electric Corp., Bettis Atomic Power Lab., Report No. WAPD-TM- 472.

KHATAMIAN, D., LING, V.C., (1997). "Hydrogen solubility limits in $\alpha$ - and $\beta$ zirconium." J. of Alloys and Comps., 253-254, 162-166

KHATAMIAN, D., ROOT, J.H., (2006). "Comparison of TSSD results obtained by differential scanning calorimetry and neutron diffraction." AECL Report 153-128000440-002.

KIM, Y.S., ET AL. (2002). "Anisotropic threshold stress intensity factor, KIH, and crack growth rate in delayed hydride cracking of $\mathrm{Zr}-2.5 \mathrm{Nb}$ pressure tubes." Met. Mater. Trans., $33,919-925$

KNOTT, J.F., (1973). "Fundamentals of Fracture Mechanics." John Wiley \& Sons.

LOUTHAN, M.R.,(JR)., MARSHALL, R.P., (1963). "Control of hydride orientation in Zircaloy." J. Nucl. Mat., 9, 170-184.

LUNDIN, C.E., COX, R.H., (1962). "The determination of the equilibrium phase diagram, Zirconium-Niobium." Proc. USAEC Symposium on Zirconium alloy development, Pleasanton, CA., Compiled by H.H. Klepfer, GEAP-4089. 
MOAN, G. D., COLEMAN, C.E., PRICE, E. G., RODGERS, D.K, SAGAT, S., (1990). "Leak-Before-Break in the Pressure Tubes of CANDU Reactors." Int. J. Pres. Ves. \& Piping 43, 1 - 21

MCMINN, A., DARBY, E.C., SCHOFIELD, J.S. (2000). "The terminal solid solubility of hydrogen in zirconium alloys." Zirconium in the Nuclear Industry - Twelfth International Symposium, ASTM STP 1354, G.P. Sabol and G.D. Moan, eds., American Society for Testing and Materials, West Conshohocken, PA 173-195.

MCRAE, G.A., COLEMAN, C.E., LEITCH, B.W. (2010), "The first step for delayed hydride cracking in zirconium alloys." J. Nucl. Mater., 396,130-143.

NHO, K.M, KIM, W.B, SIM, W.G (1997). "Assessment of Leak Detection Capability of CANDU 6 Annulus Gas System Using Moisture Injection Tests." J. Korean Nuclear Society, Vol 30, Num 5, pp. 403-415.

NORTHWOOD, D.O., GILBERT, R.W., (1978). "Hydrides in zirconium-2.5 wt. \% niobium pressure tubing." J. Nuc. Mat. 78, 112-116

NUTTALL, K., ROGOWSKI, A.J., (1978). "Some fractographic aspects of hydrogeninduced cracking in Zr-2.5Nb Alloys." J. Nuc. Mat. 80, 279-290

PAN, Z.L., RITCHIE, I.G., PULS, M.P. (1996). "The terminal solid solubility of hydrogen and deuterium in Zr-2.5Nb alloys." J.Nucl. Mat. 228, 227-237. 
PARRY, G.W., (1966). "Stress reorientation of hydrides in cold-worked Zr-2.5Nb pressure tubes." AECL Report, AECL-2624.

PARRY, G.W., EVANS, W., (1962). "The effect of strain on the directional precipitation of zirconium hydride in Zircaloy-2." AECL Report, AECL-1707.

PERRYMAN, E.C.W., (1978). "Pickering pressure tube cracking experience." Nucl. Energy, 17, 95-105.

PLATONOV, P.A., (1988). "Delayed Hydride Cracking in Russian RBMK Zr-2.5Nb pressure tubes." Poster at 8th ASTM Zr Conference. (Also available as AECL report RC87).

PULS, M.P. (1997). "Assessment of Aging of Zr-2.5Nb Pressure Tubes in CANDU Rectors." Nuclear Engineering and Design, Vol. 171, pp. 137-148.

PULS, M.P., SIMPSON, L.A., DUTTON, R. (1982). "Hydride-Induced Crack Growth in Zirconium Alloys." In Fracture problems and Solutions in the Energy Industry, Oxford and New York: Pergamon Press, 13-25.

RAE, H.K., (1997). "CANDU and its development." Chapter 10: Canada enters the nuclear age, 191-214. 
RICE, J.R., JOHNSON, M.A., (1970). "The role of large crack tip geometry changes in plane strain fracture, Inelastic Behavior of Solids." M.F. Kanninen, W.G. Adler, A.R. Rosenfield and R.I. Jaffee, Eds., McGraw-Hill Book Co., New York, 641-672.

RODGERS, D.K., COLEMAN, C.E., GRIFFITHS, M., BICKEL, G.A., THEAKER, J.R., MUIR, I., BAHURMUZ, A.A., (2008). "In-reactor performance of pressure tubes in CANDU reactors." J. Nuc. Mat, 383, 22-27.

ROOT, J.H., SMALL, W.M., KHATAMIAN, D., WOO, O.T. (2003). "Kinetics of the $\delta$ to $\gamma$ zirconium hydride transformation in Zr-2.5 Nb." Acta Mat., 51, 2041-2053.

SAGAT, S., AMBLER, J.F.R., COLEMAN, C.E., (1986). "Application of Acoustic Emission to Hydride Cracking." AECL-9258. Presented at 29th Acoustic Emission Working Group Meeting, June 23-26.

SAGAT, S., COLEMAN, C.E., GRIFFITHS, M., WILKINS, B.J.S., (1994). "The Effect of Fluence and Irradiation Temperature on Delayed Hydride Cracking in Zr-2.5Nb." Zirconium in the Nuclear Industry: 10th Int. Symp., ASTM STP 1245, Garde, A.M., Bradley, E.R., eds., ASTM, Philadelphia, PA, pp. 35-61.

SAGAT, S., PULS, M.P., (2003). "Temperature Limit for Delayed Hydride Cracking in Zr-2.5Nb Alloys." 17th International Conference on Structural Mechanics in Reactor Technology (SMiRT 17, Paper G06-4). 
SAHOO, A.K. (2009). "Models for Assessment of Flaws in Pressure Tubes of CANDU Reactors." PhD Thesis submitted to the University of Waterloo.

SAKAMOTO, K., NAKASUKA, M., and HIGUCHI, T., (2008). "Simulation of Cracking During Outside-In Type Failure of High Burn-Up Fuel Cladding Tubes," Water Reactor Fuel Performance Meeting, Seoul, Korea, October 19-23, 2008. Korean Nuclear Society, Paper 8009.

SAWATZKY, A., LEDOUX, G.A., TOUGH, R.L., CANN, C.D., (1982). "Hydrogen Diffusion in Zirconium-Niobium Alloys." AECL-7265.

SIMPSON, L.A., (1981). "Criteria for fracture initiation at hydrides in zirconium2.5 pct niobium alloys." Met. Trans., 12A, 2113-2124

SIMPSON, L.A., CANN, C.D., (1984). "The Effect of Microstructure on Rates of Delayed Hydride Cracking in Zr-2.5\% Nb Alloy.” J. Nucl. Mat., 126, 70-73.

SIMPSON, L.A., ELLS, C.E., (1974). "Delayed Hydrogen Embrittlement in Zr-2.5 wt\% Nb." J. Nuc. Mat., 52, 289-295.

SKINNER, B.C., DUTTON, R. (1990). "Hydrogen diffusivity in alpha-beta zirconium alloys and its role in delayed hydride cracking." Hydrogen Effects on Material Behavior, N.R. Moody and A.W. Thompson, Eds., The Minerals, Metals \& Material Soc., $73-83$ 
THEAKER, J.R., CHOUBEY, R., MOAN, G.D., ALDRIDGE, S.A., DAVIS, L., GRAHAM, R.A., COLEMAN, C.E., (1994). "Fabrication of Zr-2.5Nb Pressure Tubes to Minimize the Harmful Effects of Trace Elements." Zirc. in the Nuc. Industry: 10th Int. Symposium. A.M. Garde and E.R. Bradley, Eds., American Society for Test. and Mat. pp. 221-242.

WALKER, J.R. (1990). "A probabilistic approach to Leak-Before-Break in CANDU Pressure Tubes." Int. J. Pres. Ves. \& Piping, 43, p 229-239

WEATHERLY, G.C., (1981). "The precipitation of $\gamma$-hydride plates in zirconium." Acta Met., 29, (1981), 501-512.

WILKINS, B.J.S., NUTTALL, K., (1978). "Secondary cracking in hydrided Zr-2.5 wt\% Nb alloys." J. Nucl. Mat., 75, 125-130.

WINEGAR, J.E., (1977). "Measurement of crystallographic texture at chalk river nuclear laboratories." AECL-5626.

XIE, L. (1999), "The effect of characteristic crack sizes on the leak-beforebreak case of pressure vessels and piping with multiple cracks." Int. J. of Pressure Vessels and Piping, Vol.76, pp. 435-439

YUNCHANG, F., KOSS, D.A., (1985). "The influence of multiaxial states of stress on the hydrogen embrittlement of zirconium alloy sheet." Met. Trans., 16A, $675-681$. 
ZHAO, Z., ET AL, (2008). "Characterization of zirconium hydrides and phase field approach to a mesoscopic-scale modeling of their precipitation." J. ASTM International, 5, Paper ID JAI 101161, (also 15th ASTM Symposium on Zirconium in the Nuclear Industry, ASTM STP 1505, (2008), 29-50).

ZUZEK, E., ABRIATA, J.P., SAN-MARTIN, A., MANCHESTER, F.D., (1990) "The H-Zr (Hydrogen-Zirconium) system." Bull. Alloy Phase Diagrams, 11, 385-395. 


\section{APPENDIX A: Plate Manufacturing Procedure}

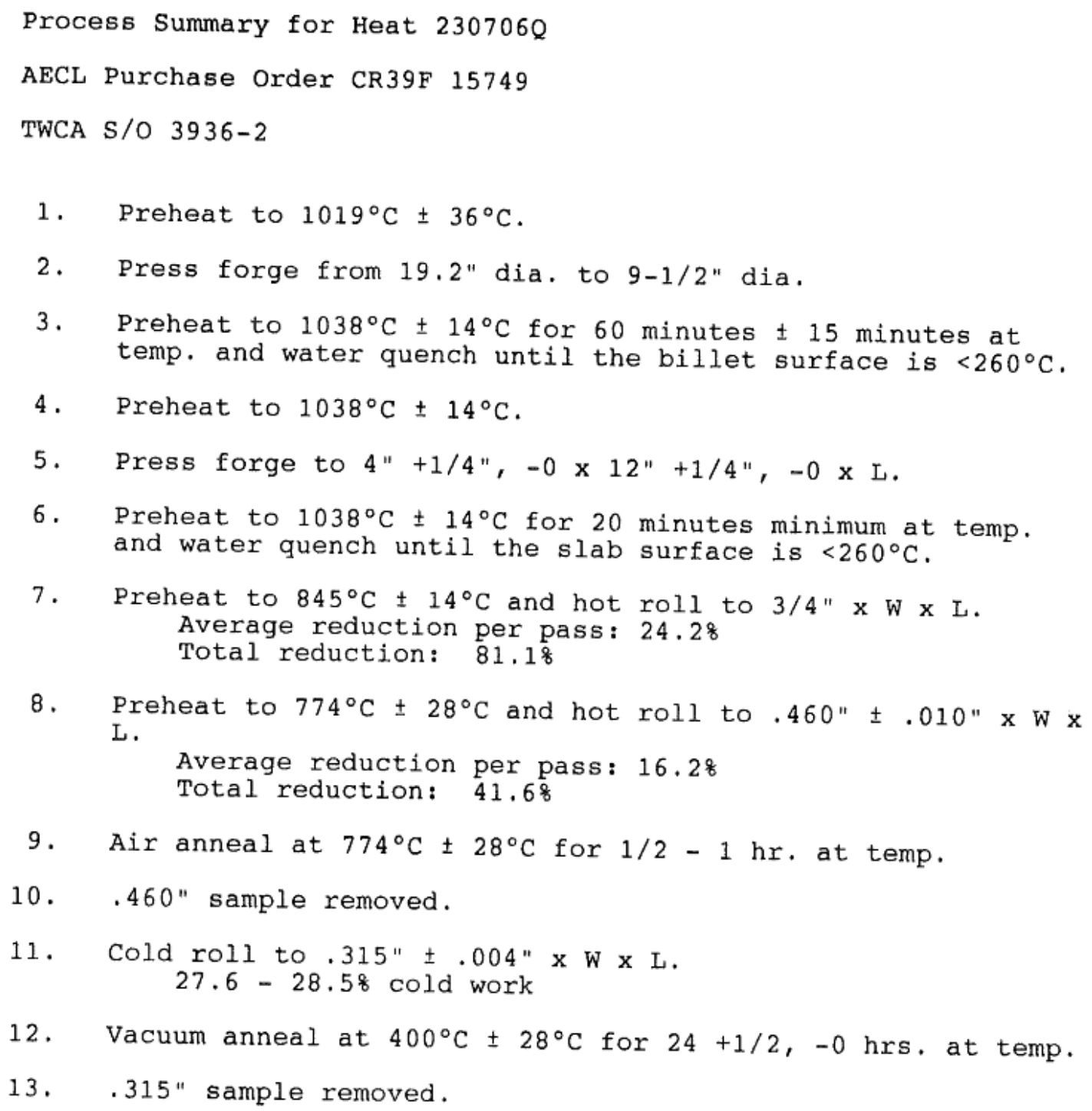

8. Preheat to $774^{\circ} \mathrm{C} \pm 28^{\circ} \mathrm{C}$ and hot roll to $.460^{\prime \prime} \pm .010^{\prime \prime} \mathrm{x} \mathrm{W} \times$ L.

NOTE: Material air cooled after all hot work steps except water quench steps \#3 and \#7. 


\section{APPENDIX B: AECL Hydriding Procedure}

This Appendix includes a copy of the detailed AECL lab procedure (with hand-written annotations)

\section{PROCEDURE FOR HYDRIDING SINGIE 5 cm LONG CANDU-TYPE PRESSURE TUBE RINGS}

USE GLOVES AND SAFETY GLASSES WHEN TOUCHING ANY OF THE EQUIPMENT ASSOCIATED WITH THE APPARATUS IN ALL THE FOLLOWING STEPS

\section{Personal Protective Equipment}

- Latex / rubber gloves

- Safety glasses

- Lab Coat

- Face shield

- Safety shoes

\section{List of Equipment Needed}

- 8L Beaker (Pyrex brand cylindrical jar : C69429L)

- Digital stirrer / hot plate (Corning PC-620D), with external temperature controller

- Heat shrinking tubing (1/8" ID before heating)

- Two 10" section of 4-40 aluminium rod

- Two 10" lengths of lead sheet

- Two 10-24 brass screws and nuts

- Two 4-40 brass nuts and washers

- Power supply (Xantrex HPD 15-20)

- Connection leads

- Nylon lid for the beaker

- Metallic tray (In store: T030290)

- Demineralised water

- Sulphuric acid

- Dow Corning silicone adhesives / sealants (732, 3oz tube, black)

\section{Ring Preparation}

- Cut a $5 \mathrm{~cm}$ ring from the pressure tube.

- Arrange for machine shop to remove the outside skin of oxide from the pressure tube ring and to drill 4-40 threaded holes, $180^{\circ}$ apart on the cut end of the ring.

- Secure an $8 \mathrm{~L}$ beaker to hold the apparatus and ring. 
- Cut two 10" lengths of lead sheet (Figure 1). Lead can be reconditioned and reused 10 times. When it starts cracking and breaking down it is time to use a new piece.

- Mould the lead by pressing along the length of a cylinder, Figure 2, being careful to fit without exerting pressure on the glass.

- When lead is form fitted use the cutters to make two 1" cuts into the lead, Figure 3 to enable it to be folded over the top of the beaker, Figure 4.

- Drill a hole in each of the folded lips of the lead and insert a nut, washer and bolt assembly into the lead to act as anode for the assembly. One connection by lead plate.

- Cut two 10" section of 4-40 rod.

- Cover the rod end with silicone and thread the rod into the ring, Figure 6.

- Pull heat shrinkable tubing along 7" of the rod, Figure 6. Make sure the shrinkable tubing extends the same length on each rod so the ring will be evenly suspended inside the beaker.

- Heat the shrinkable tubing along the rods, push down to where they are threaded into the ring to reduce acid erosion from the sulphuric acid mixture in the beaker.

- Clean away any surplus silicone on the ring.

- Gently wash the inside and outside of the pressure tube ring using a scotch brite pad. At this point the ring cannot be handled without using gloves.

- Clean the beaker, pressure tube and cap with acetone.

\section{Starting the test}

- Slide the two rods through the beaker lid, Figure 7, so the ring is centered. Use the brass washer and nuts to secure the rods tightly to the lid while ensuring the ring will be suspended $~ 2$ " from the bottom of the beaker, and $1 / 2$ " higher than the bottom of the lead, Figure 8.

- Make any necessary adjustments with the washer/nut assembly on the lid to make sure the ring is suspended levelly. Remove sections of the heat shrinking tubing if needed.

- Set the $8 \mathrm{~L}$ beaker on the hot plate and fill with distilled water to $~ 2 "$ from the top of the beaker.

- Set the magnetic stirrer speed to $400 \mathrm{rpm}$ (by hitting button, selecting 400 and hitting button again if using set-up in B375).

- Pour $80 \mathrm{ml}$ of acid into the water, into the vortex created by the stirrer. (Solution concentration: $10 \%$ ).

- Insert the thermometer.

- Set the temperature to $70^{\circ} \mathrm{C}$. (hit button, select temperature and hit battongain so the "probe" indication lights up if using set-up in B375). Do not forget to insert the temperature probe in the solution.

- Clean the connecting ends of the power supply wires with sand paper and connect the wires to the anode (positive wire to bolts in lead) and cathode (negative wire to aluminium rods), Figure 9. Make sure the wires are not touching the hot plate. 
- Channel the wires to the back of the beaker so they don't interfere with the process of adding water to the beaker. Add water until it measures to about 1 " to the top of the beaker.

- Apparatus is now ready to start the hydriding process, Figure 10.

- DO NOT TURN THE POWER SUPPLY ON UNTIL THE TEMPERATURE OF THE WATER/ACID REACHES $70^{\circ} \mathrm{C}$.

- At temperature, turn the Voltage and Current to 0.

- Turn the Voltage to Max

- Turn the current to 18 Amps.

- Check to see that the connectors are not too hot. If the connectors are too hot, reduce the current and check the connection.

\section{Test Surveillance}

- Allow to simmer at $70^{\circ} \mathrm{C}$. Every few hours check the level of the water. Top up the water when needed (every 6 or 7 hours through the day), top up again at 9:00 10:00 p.m. then again first thing next morning. Do not allow the level to drop below the level of the ring.

- After two days of hydriding, turn the amps down to 5 amps and very gently turn the lid $90^{\circ}$. This allows lead exposure to the opposite sides of the ring.

- Allow the process to continue for 2 more days.

- Do not top up water on the last night, but come in at night to check the rig.

- On the fifth day, turn the oven on to $310^{\circ} \mathrm{C}$ at mid-morning or $2 \mathrm{hrs}$ before annealing the ring.

\section{Disassembling the set up}

- After 96 hours, turn off the hotplate and the stirrer. Turn off the voltage on the power supply and unplug the power supply.

- Take the thermometer from the top of the beaker.

- Disconnect the electrical connection.

- Lift the ring out by the rods, place in a metallic tray and carry to sink area.

- Rinse the ring, lid and rod in clean water to remove the excess of acid and lead. Block the drain of the sink in order to keep the excess of lead.

- Using a clamp, remove the rods from the ring.

- Wait for the acid to cool down before removing the lead plate and cleaning the beaker.

- Remove the lead plates from the beaker, place in the metallic tray and clean under water.

- Carefully bring the beaker to the sink and clean under water.

\section{Ring Annealing}

- Clean ring lightly with scotch brite to remove any lead residue.

- Clean the ring with acetone.

- When the oven reaches temperature $\left(310^{\circ} \mathrm{C}\right)$, place the ring on an inverted Pyrex dish. Do not place the ring directly on the oven floor. 
- Do not let the thermocouples touch the walls of the oven or the ring. Leave the ring at temperature for at least $50 \mathrm{hrs}$ (for a $5 \mathrm{~cm}$ long ring).

- After the allotted time in the oven, turn the oven off but do not open the door until the oven slow cools to less than $150^{\circ} \mathrm{C}$.

\section{Lead Reconditioning}

- Flatten the lead plate.

- Pour water in a metallic tray and add $\mathrm{NaOH}$ crystals ( $1 / 2$ cup) bring to ebullition on a hot plate.

- Place a plate of lead one at a time in the solution for about 15 minutes.

- Rinse under clean water.

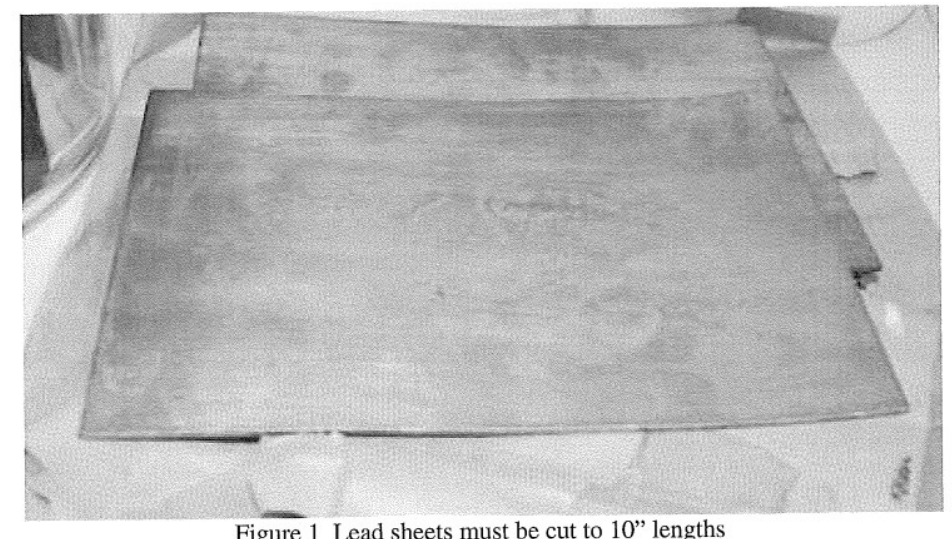

Figure 1 Lead sheets must be cut to 10 " lengths

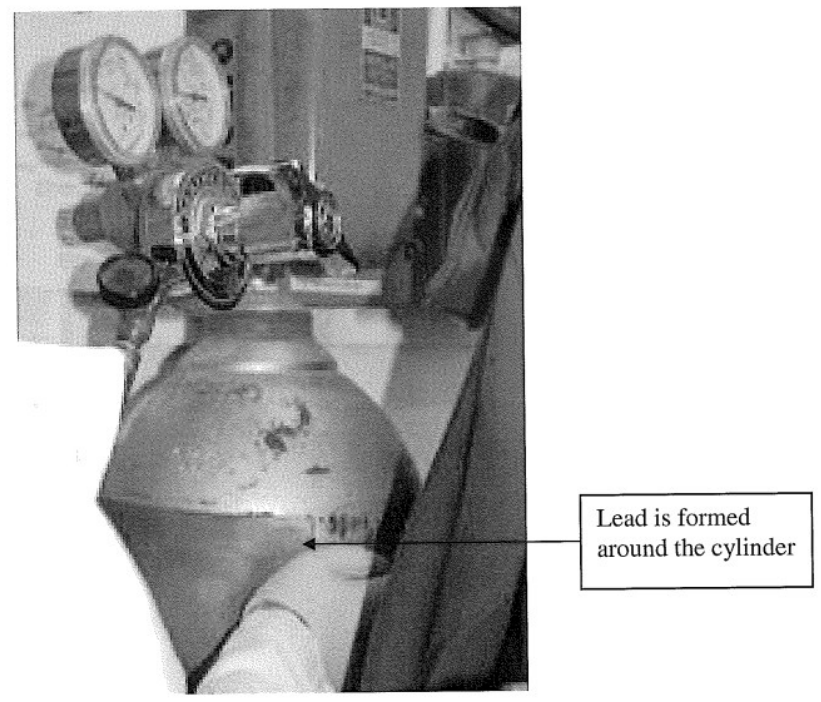

Figure 2 Lead Sheet is wrapped around a cylinder to help form the lead to the inside surface of the beaker 


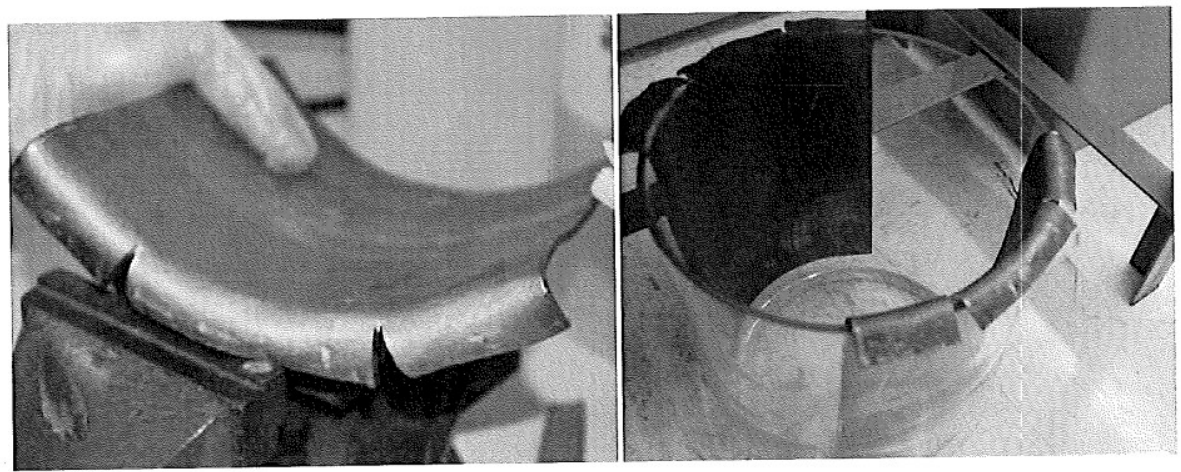

Figure 3 Lead is cut and folded down to hang over the beaker lip

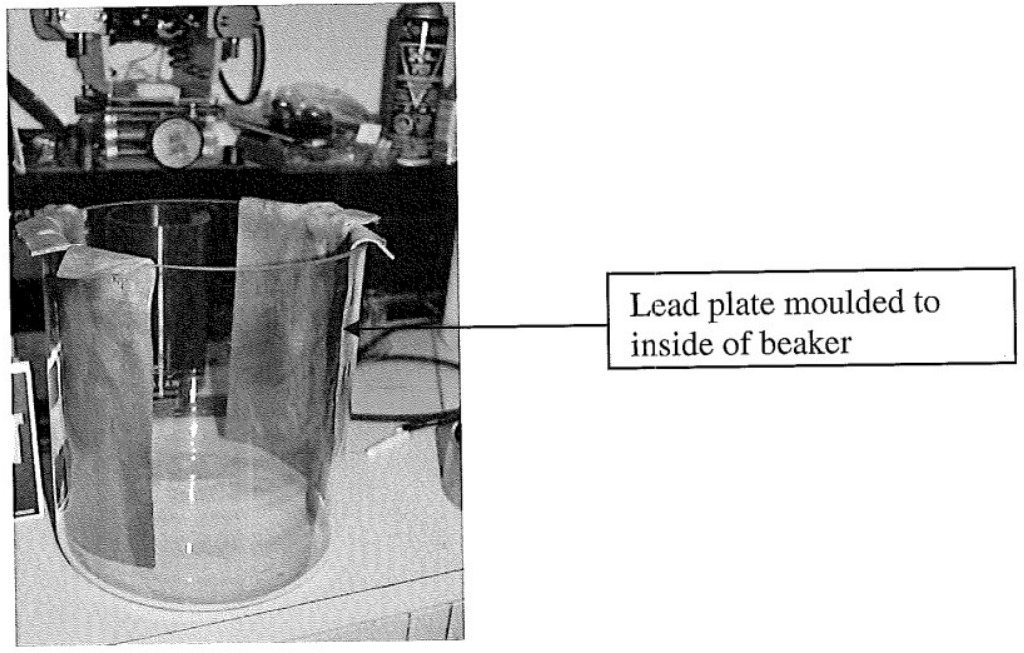

Figure 4 Lead is hanging from beaker lip and is formed to the inside surface

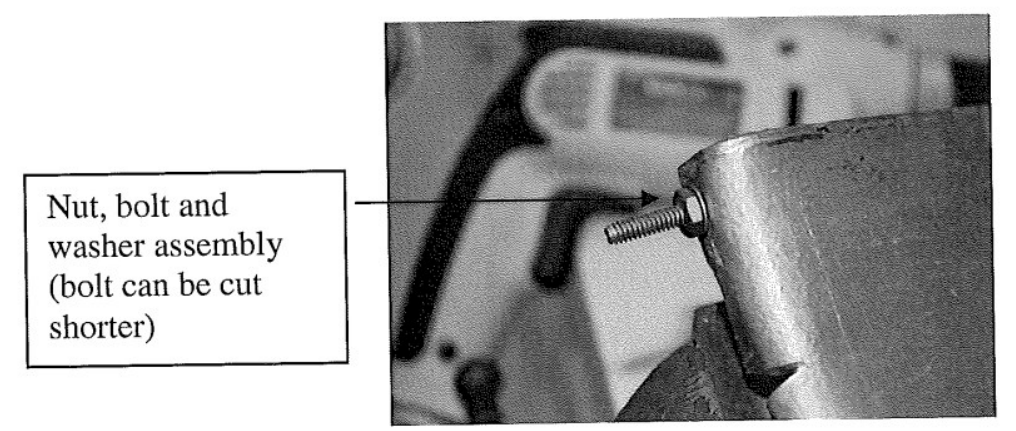

Figure 5 Hole is drilled into the lead and a nut, bolt and washer assembly acts as anode 


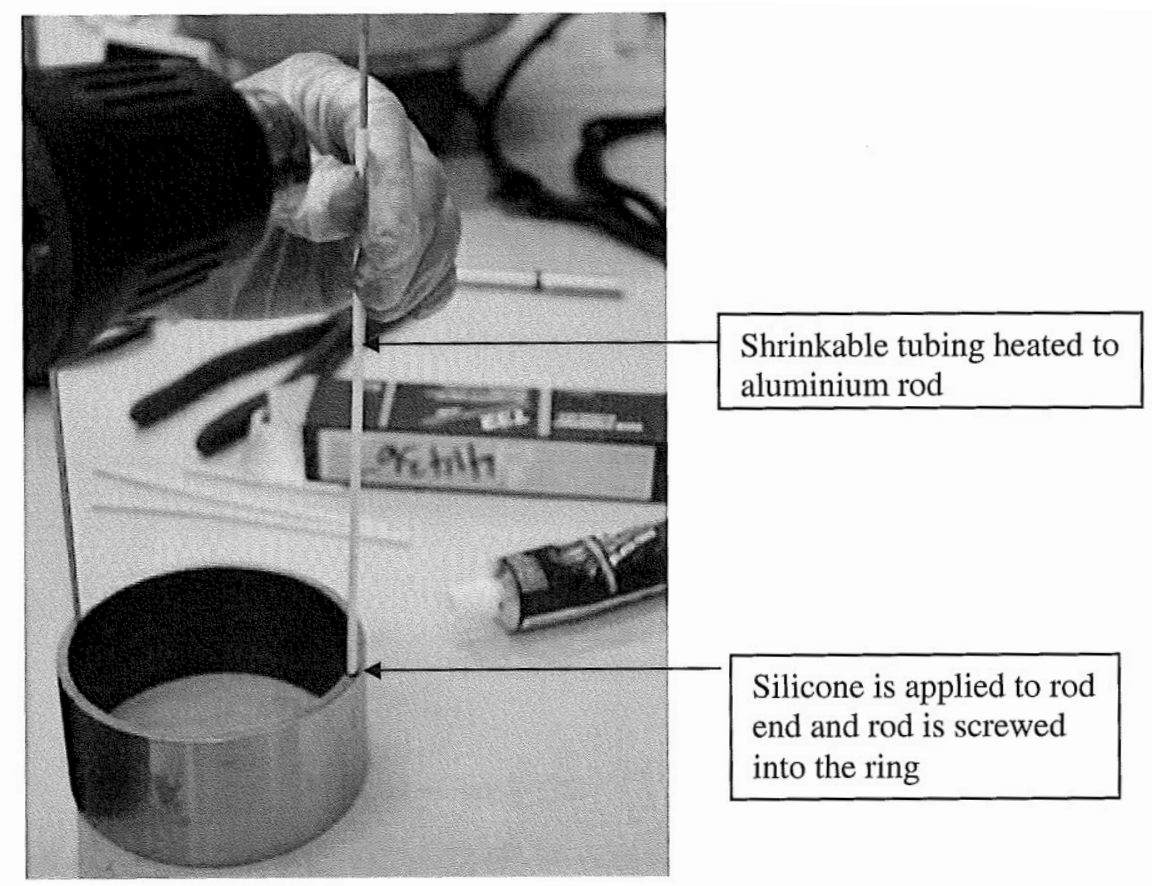

Figure 6: Rods are covered with shrinkable tubing, silicone is applied to the threads before screwing into the ring and the tubing is heated with a heat gun to deter acid erosion to the rods. Top of rod is left bare to accommodate nut, washer and bolt assembly to secure rods to the lid and to act as the cathode.

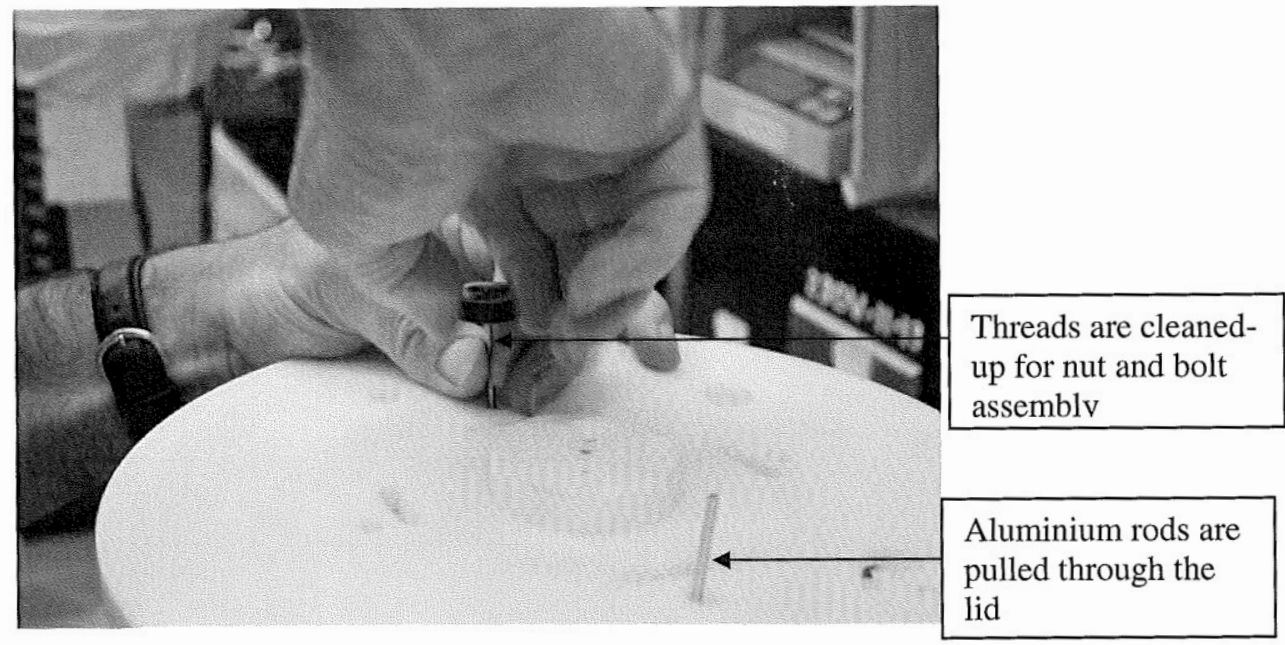

Figure 7: Rods are pulled through the assembly's cover and the thread is prepared for nut, bolt and washer assembly. The rods will be the cathodes for the assembly 


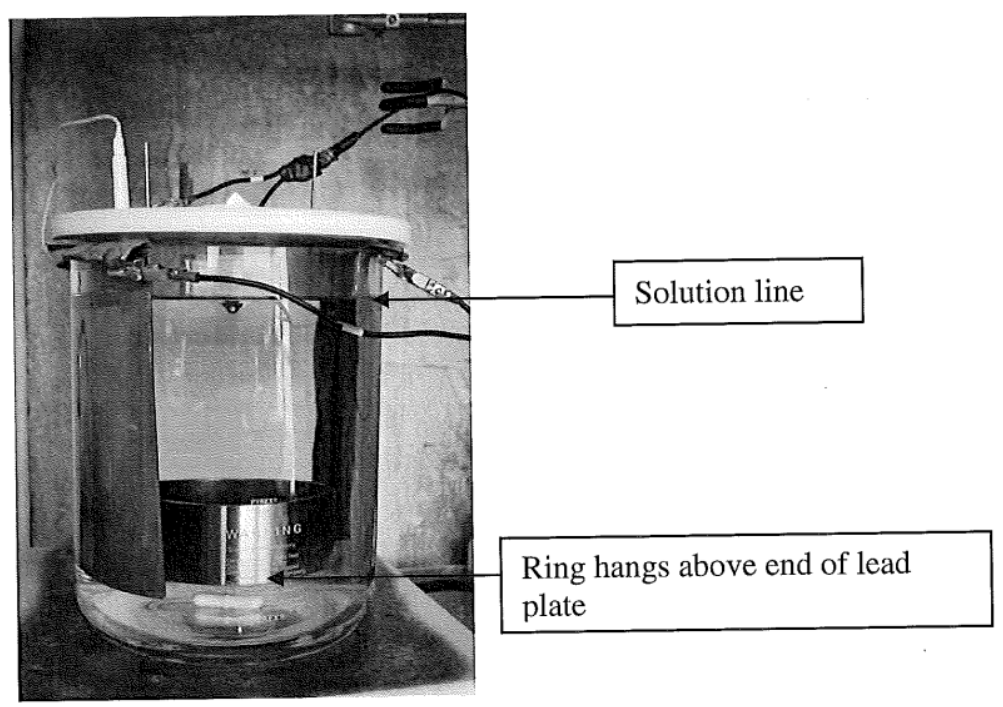

Figure 8 Ring is suspended from lid. Note the level of the solution is about 1.5"-2" from the top of the beaker

Power supply is connected to the lead plates (anode $(+)$ )

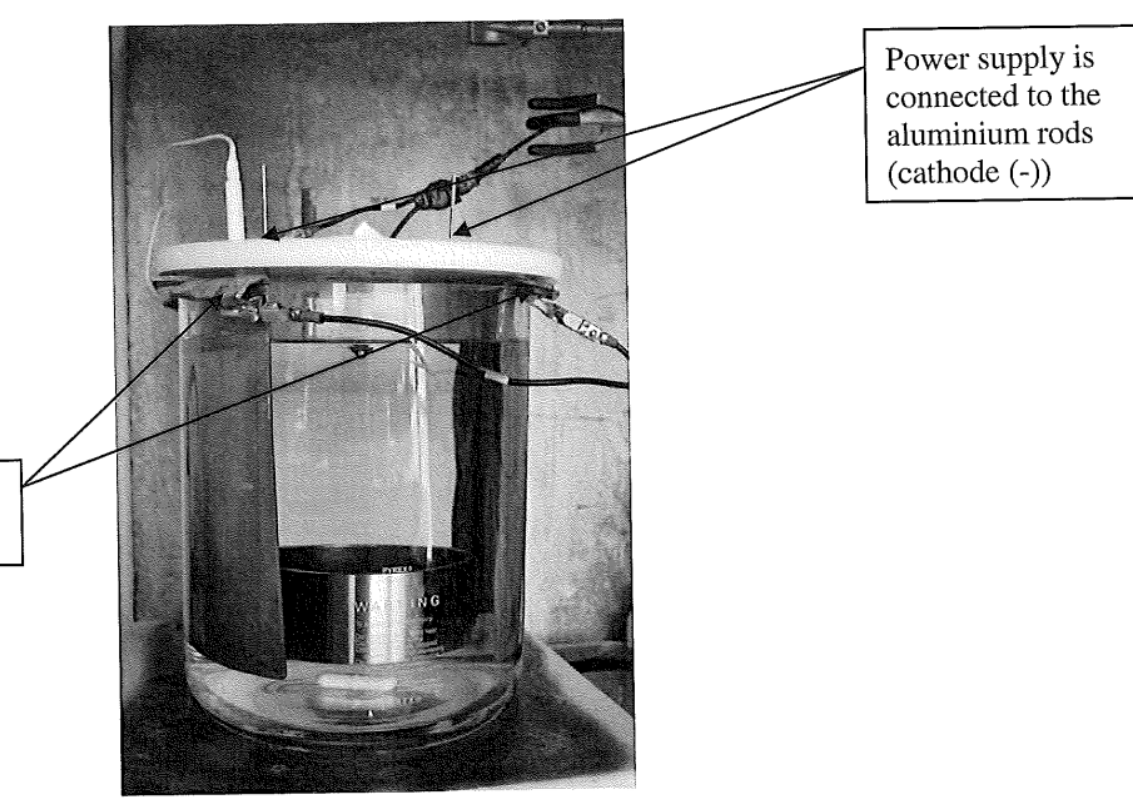

Figure 9: Power supply with connection to anode and cathode 


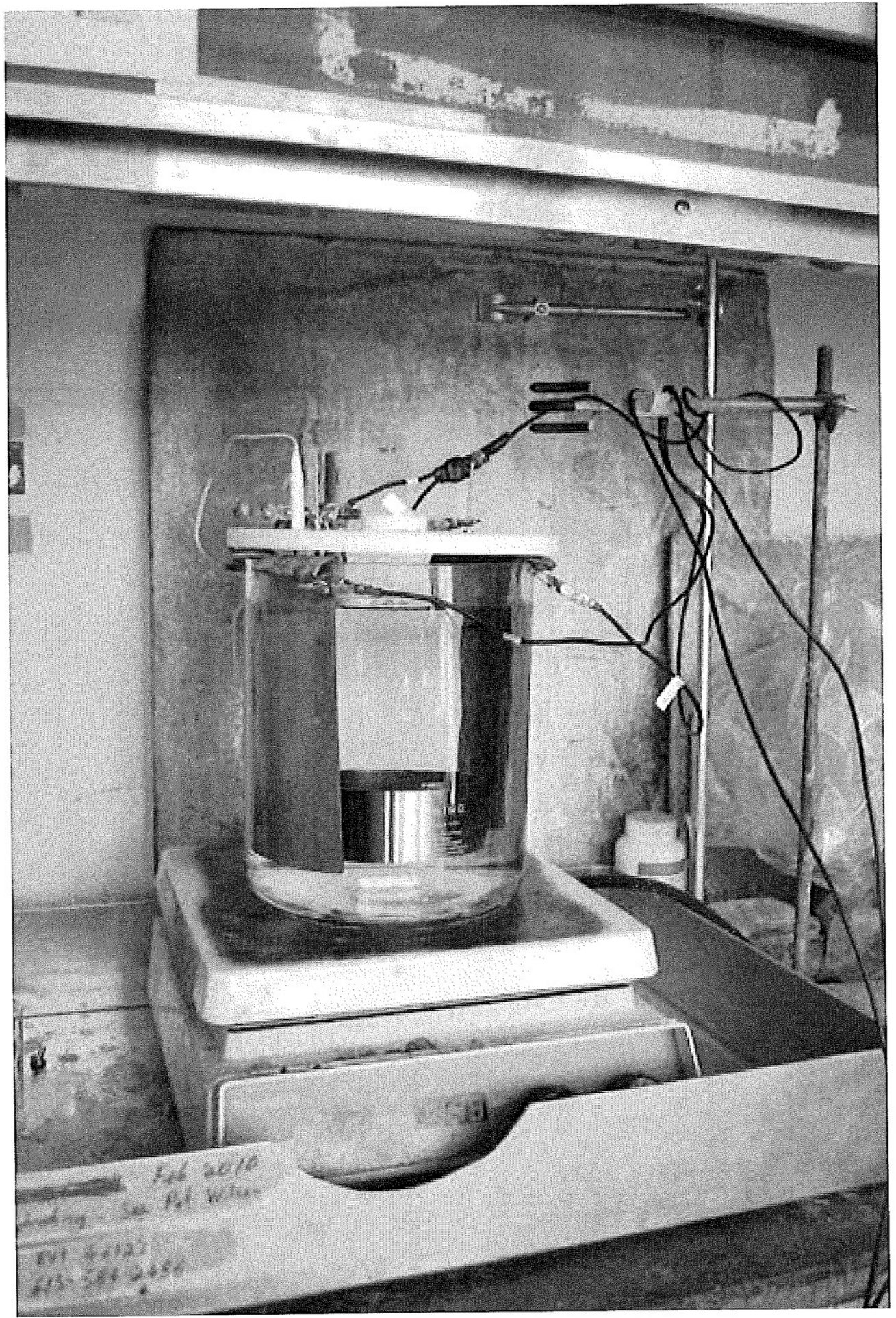

Figure 10 Apparatus is hooked up to power supply, a thermometer controls the temperature (70C) and the stirrer is set to $400 \mathrm{rpm}$ 


\section{APPENDIX C: DHC Testing Procedure}

\section{LAB 213 Procedure For Running a Cantilever Beam Test}

Set-Up
A. Remove furnace enclosure
B. Remove cantilever arm
C. Retrieve a specimen
D. Ensure both ends of the specimen are clearly stamped with the specimen ID
E. Insert one end of the specimen into the cantilever arm and tighten grip screws.

One screw should be hand tightened, then the other tightened with the appropriate Allan key. The hand tightened screw can now be tightened with the same Allan key

F. Insert other end of specimen into the fixed arm and tighten grips using the same method as in C. Ensure the specimen fits tightly in the grips and the notch is in the intended direction

G. Orient the thermocouple so it is in contact with the specimen

H. Add insulation above and below the rig arms on each side to minimize temperature gradients inside the furnace during testing

I. Attach the furnace enclosure on top of the heater platform and rig arms

J. Attach the white plastic load centering component to the cantilever arm with the dimple located directly under the stepping motor screw. This will ensure the stepper motor will not slip relative to the cantilever arm

\section{DHC Quality Control Data Sheet}

Before entering values into the LabVIEW program one should fill out a DHC Quality Control Data Sheet. This one page form describes all the necessary information for a 
DHC test and is mounted in the lab during testing to verify parameters are correct in the LabVIEW program. Some important parameters included in this form are:

- $\quad$ Specimen ID

- Specimen Geometry

- Hydrogen Concentration

- Notch Depth

- Notch Root Radius

- Rig Number

- $\quad$ Test Type (Constant Load)

- Peak and Test Temperatures

- Starting Stress Intensity Factor

\section{LAB 213 Procedure Starting For Calibation of DHC Load Cells}

1. At lab computer, select "Single Rig \#".

2. Select 'Setting' tab.

3. Select 'Calibrate'

4. Leave the page on the desktop and select 'Single Rig' tab.

5. Manually raise the upper arm using the UP job arrow until the load cell is in a position remote from the rig arm.

6. Go to the 'Calibrate' page and enter ' 0 ' $\mathrm{kg}$ in the "Applied Load" area of the sheet.

7. Select the 'Commit' button. The slope on the scale should go up.

8. Retrieve a $500 \mathrm{~g}$ weight and suspend it from the load cell

9. On the 'Applied Load' area of the calibration page, enter $0.5 \mathrm{Kg}$

10. Select 'Commit'. The slope on the scale should go down.

11. Repeat Line 8 with a $1000 \mathrm{~g}$ weight.

12. Select the 'Save' tab on the calibration page.

13. Select the 'Save' tab on the Load Cell Page.

14. Repeat the exercise for Rigs 1-10. 


\section{Starting a Test}

Assuming a test was being started on Rig \#1, the Tower \#1 computer would be used.

1. Select Rig \#1 on left hand tab

2. Select "Single Rig" on main top tab, see Figure 48.

3. Check that the motor on the rig is retracted and that the motor counts (at the bottom left of the screen) are close to Zero. Do NOT reset "Motor Counts". If the motor position needs to be adjusted to allow the insertion of the test specimen or to remove the load from the arm, use the UP jog arrow on the main screen.

Note: If the motor position is lower than $\mathbf{- 3 0 0 0}$ or higher than 17000 an error signal will be displayed on the screen and the test will not load properly as these are set limits

4. Reset "AE Counts"on bottom left hand corner of the main screen.

5. Check that "Motor Speed" is 300, the standard for constant load tests

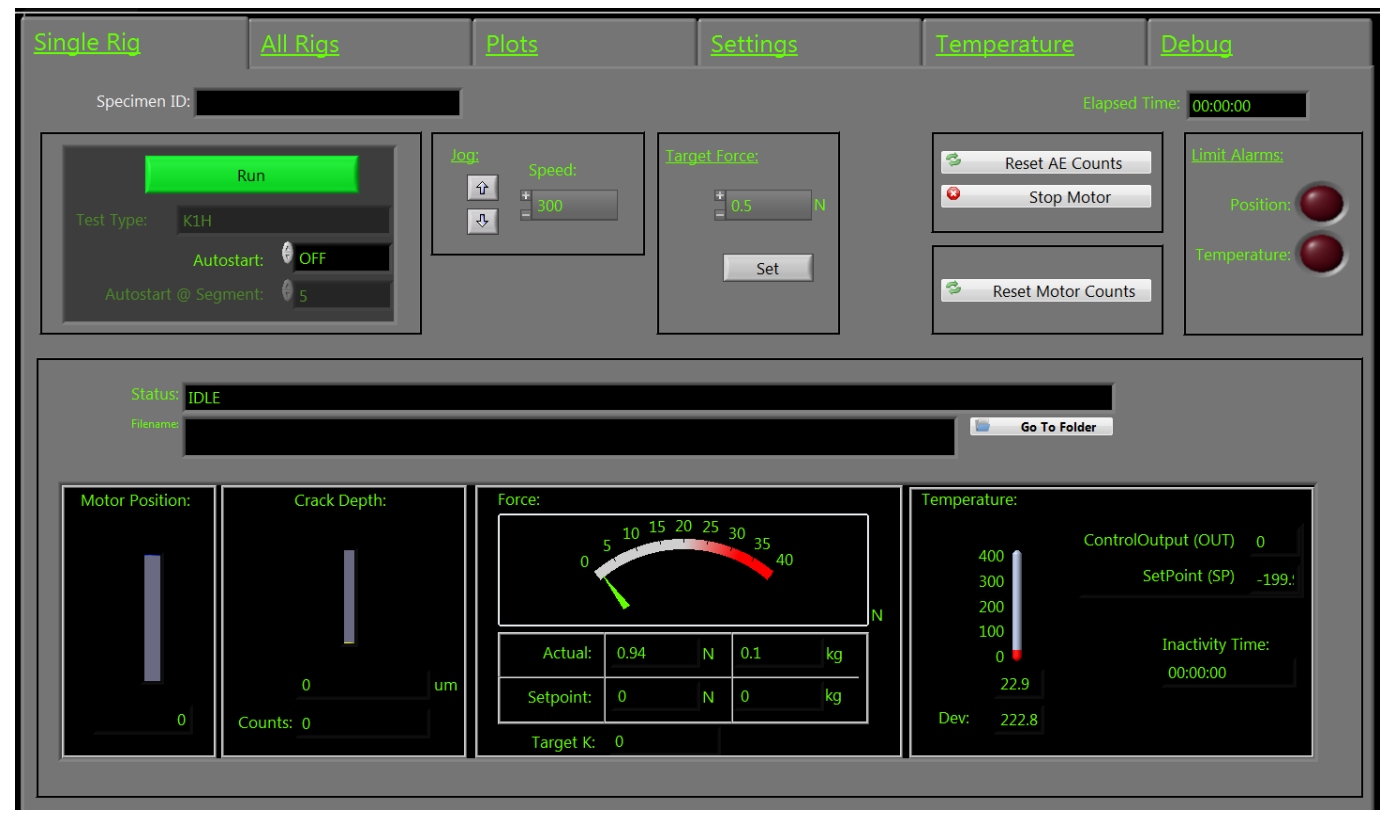

Figure 48 - LabVIEW screenshot: single rig tab

6. Select 'SETTINGS' tab at the top of the page, see Figure 49. 
7. Select "'SPECIMEN ID' subtab. Enter the parameters from the DHC Quality Control Sheet and select 'SAVE'.

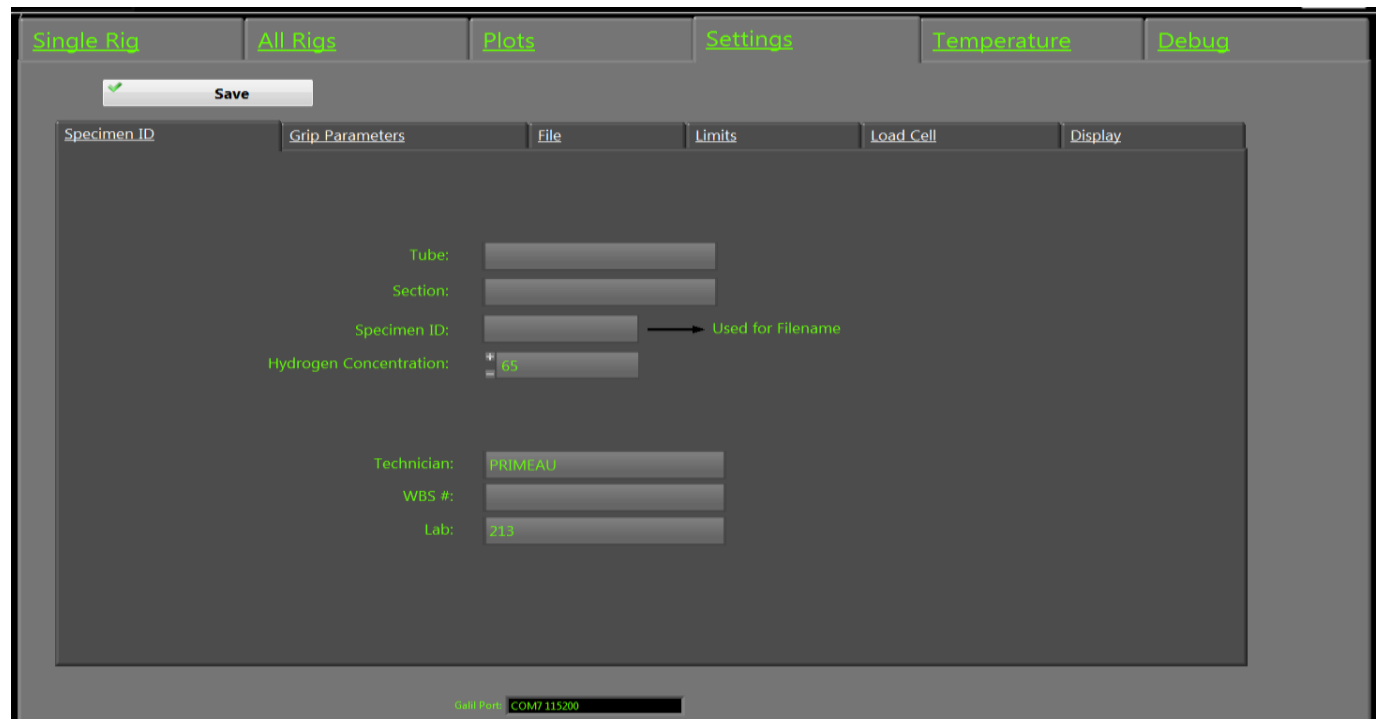

Figure 49 - LabVIEW screenshot: specimen ID subtab

8. Select 'Grip Parameters" subtab. See Figure 50. Enter the parameters and select 'SAVE'.

9. Select 'Velocity - Constant Load' test type. Enter Velocity Settings and select 'SAVE'. Check that the calculated target load is close to an expected value.

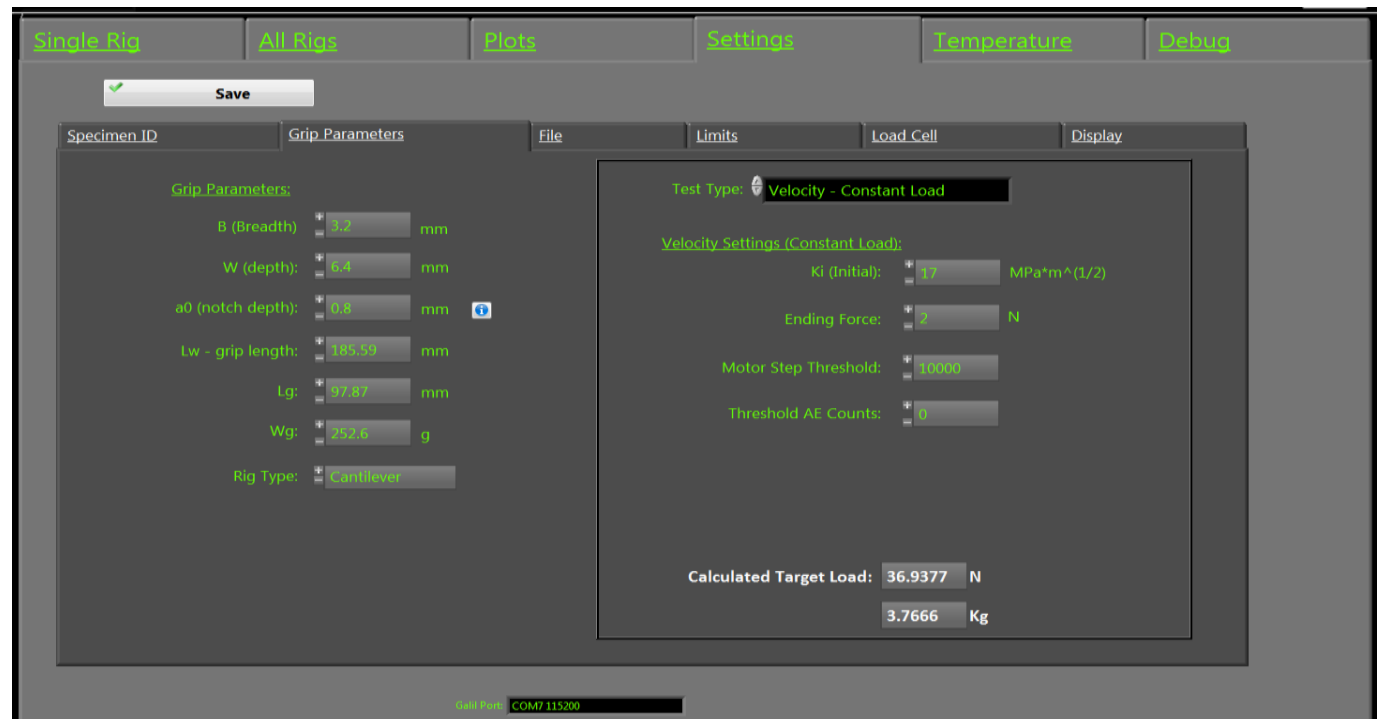

Figure 50 - LabVIEW screen shot - grip parameters subtab 
10. Select 'Temperature'tab. An example of temperature settings for a standard constant load is shown below:

\section{$\operatorname{Temp}(\mathrm{C}) \quad$ Duration(minutes) Junction}

\begin{tabular}{|c|c|c|}
\hline 1. 360 & 120 & 1 \\
\hline 2. 360 & 60 & 0 \\
\hline 3. 320 & 40 & 1 \\
\hline 4. 250 & 70 & 1 \\
\hline 5. 250 & 60 & 0 \\
\hline $\begin{array}{ll}6.250\end{array}$ & 60 & 2 \\
\hline \multicolumn{3}{|c|}{$\begin{array}{l}\text { (Junction code } 1 \text { indicates an increase or decrease in temperature to the indicated } \\
\text { temperature parameter at the indicated rate (duration) ; } 0 \text { indicates no heating or } \\
\text { cooling (i.e. soak) for the duration, and } 2 \text { means indefinite stay at the indicated } \\
\text { temperature parameter - used to prevent the furnace from shutting off. }\end{array}$} \\
\hline
\end{tabular}

11. Check that the temperature parameters are accurate, but do not press the "Start Cycle" button yet.

12. Return to the "Single Rig" Tab

13. Set the "Target force" to 0.5 for a radial velocity constant load test.

14. When selecting the target force button, make sure the desired load is within $0.2 \mathrm{~N}$ of the desired Target Force. If the actual force is not within $0.2 \mathrm{~N}$ of the desired force the test will not load.

15. Check that the Counts are zeroed.

16. Check that the "Auto Segment" is \#6 (the point where the load has been achieved and the soak time is complete)

17. Double check the 'Test Type', i.e. 'Constant Load Velocity'

18. Go back to the 'Temperature' page and start the temperature cycle by selecting "Start Cycle". 
19. Check the temperature controller to see that the output on the controller is reacting to the command. The thermocouple should begin reading higher temperatures within minutes.

20. Double check the rig setup and all parameters entered.

21. Go back to the Single Rig page and press the green "RUN" button. This button will turn Red and the status on this page should read "Waiting for Segment". 


\section{APPENDIX D: ASTM Standard for Cantilever Beam Stress Intensity}

ASTM, E 1681-95

Formula for Calculating $\mathrm{K}_{\mathrm{I}}$ in cantilever beam specimens:

$$
K_{I}=\frac{M}{B(W)^{3 / 2}} f\left(a_{0} / W\right)
$$

where:

$$
\begin{gathered}
f\left(a_{0} / W\right)=\frac{6\left(a_{0} / W\right)^{0.5}}{\alpha^{3 / 2}}\left\{1.9878-1.3253\left(a_{0} / W\right)\right. \\
+\alpha\left(a_{0} / W\right)\left[-3.8308+10.1081\left(a_{0} / W\right)-17.9415\left(a_{0} / W\right)^{2}\right. \\
\left.\left.+16.8282\left(a_{0} / W\right)^{3}-6.2241\left(a_{0} / W\right)^{4}\right]\right\}
\end{gathered}
$$

Where: $\quad \alpha=1-\left(\mathrm{a}_{0} / \mathrm{W}\right)$

$\mathrm{M}=$ bending moment on the crack plane

$\mathrm{B}=$ specimen breadth

$\mathrm{W}=$ specimen depth

$\mathrm{a}_{0}=$ notch + crack

This expression for $\mathrm{K}$ is valid for $0<\mathrm{a} / \mathrm{W}<1$. 


\section{APPENDIX E: DHC Test Analysis \\ Procedure For Analyzing Cantilever Beam Test Results}

A. Open the Image Pro File.

B. Open the fracture surface's photo file. Ensure the specimen identification is on the photo.

C. Calibrate the image by selecting the tabs: Measure - Measurements -Calibration - Spatial. Click in the 'Spatial' tab

i. On the right hand side of this menu select 'New', then go to the space for 'Name' to assign a new file name for this calibration file.

ii. To select measurement units, place curser in area marked 'Unit', to select 'microns' from the drop down menu

iii. Select the 'Image' button to bring up the photo of the fracture face with a white line intersecting through the photo.

iv. Align the white line with the breadth of the photo by placing te curser over the tabs at either end of the line. Make any adjustments to capture the breadth of the specimen with the line, ensuring the line is perfectly straight

v. Assign the known breadth of the specimen (from the Experimental Process Control sheet into the space indicated by the question, 'Reference represents how many units?' (NOTE: this measurement is in microns so multiply the specimen breath measurement taken from the Process Control sheet which is in milimeters, by 1000 , accordingly.

vi. Select "OK" in this window and again in the "Spacial Tab" window.

vii. In Image Pro select "Measure - Measurements - Calibration Save Active, then Save the calibration files to correspond with the specimen I.D. It is important to save the calibration files for future reference. 
D. Select the "Measure -Measurement tab, which will provide a menu. Select the second tab - Measurement.

E. Select the line drawing tool ' $\backslash$ ' and trace the breadth of the Specimen. In the Features column, label this measurement "Breadth".

F. Select the rectangle tool,' $\square$ ' and trace the notch area of the specimen. Be sure the two short sides of the rectangle intersect with either side of the Notch Area rectangle. In the features column, label this measurement "Notch Area" on the corresponding line.

G. Using a calculator, calculate the Average Notch Length by dividing the notch area measurement by the breadth. Go to the measurements tools and select the line drawing tool. Draw a line from the top of the notch to the bottom of the notch. Label this measurement "Average Notch Length" in the Features area. This measurement must correspond to the calculated average notch area measurement. If it does not - recheck your calculation and recheck the drawn lines. The rectangle of the notch area must intersect with the breadth line on both sides and the average notch line must intersect with the top and bottom of the rectangle.

$\mathrm{H}$. Using the polygon measuring tool,$\square$, trace the outline of the fracture surface. Do not include the notch area. Label this measurement DHC Area in the features column.

I. Using a calculator, calculate the Average DHC length by dividing the $\mathrm{DHC}$ area measurement by the breadth measurement.

J. From the measurement tools, select the line drawing tool. Draw a line from the top of the DHC fracture area (where it meets the notch) towards the end of the crack, stopping when the measurement in the features menu matches the calculated average DHC fracture measurement. Label this measurement 'Average DHC'.

$\mathrm{K}$. On the fracture surface, draw a line with the line drawing tool from the top of the fracture surface, where it meets the notch, straight down to the deepest part of the crack - label this area 'Maximum DHC'

L. Go to the Input/Output tab on the Measurements menu. 
M. Select the Save option and save the Image Pro file under a name corresponding to the specimen identity. The Save option will save the measurements with an .msr extension. Once the msr file has been saved, save the information a second time with an .out extension found in the dropdown menu under "Save as type". These two calibration files can be resurrected at a later date to review the measurements in Image pro.

N. To write a report file in Image Pro, select the 'Measurements' icon, then the Input/Output tab and select the 'DDE to Excel' button in the Input/output tab. The 'DDE to Excel' button will send the measurement information to an open Excel file and will allow the photo and measurement to be imported into a report.

O. In the Image Pro Page, launch the 'Report' page by selecting the red folder in the menu bar.

P. In the 'Report' page, select 'Insert', then 'Image with Overlay'. Selecting 'Image with Overlay' will import the photo with its measurements into the report. This photo can be manipulated and sized by selecting it with the cursor then using the arrows to manipulate the photo.

Q. The set-up of 'Report' page can be manipulated using the options in the template to create appropriate labels for the Report.

R. Save the Report by naming it to correspond to the specimen identity. 


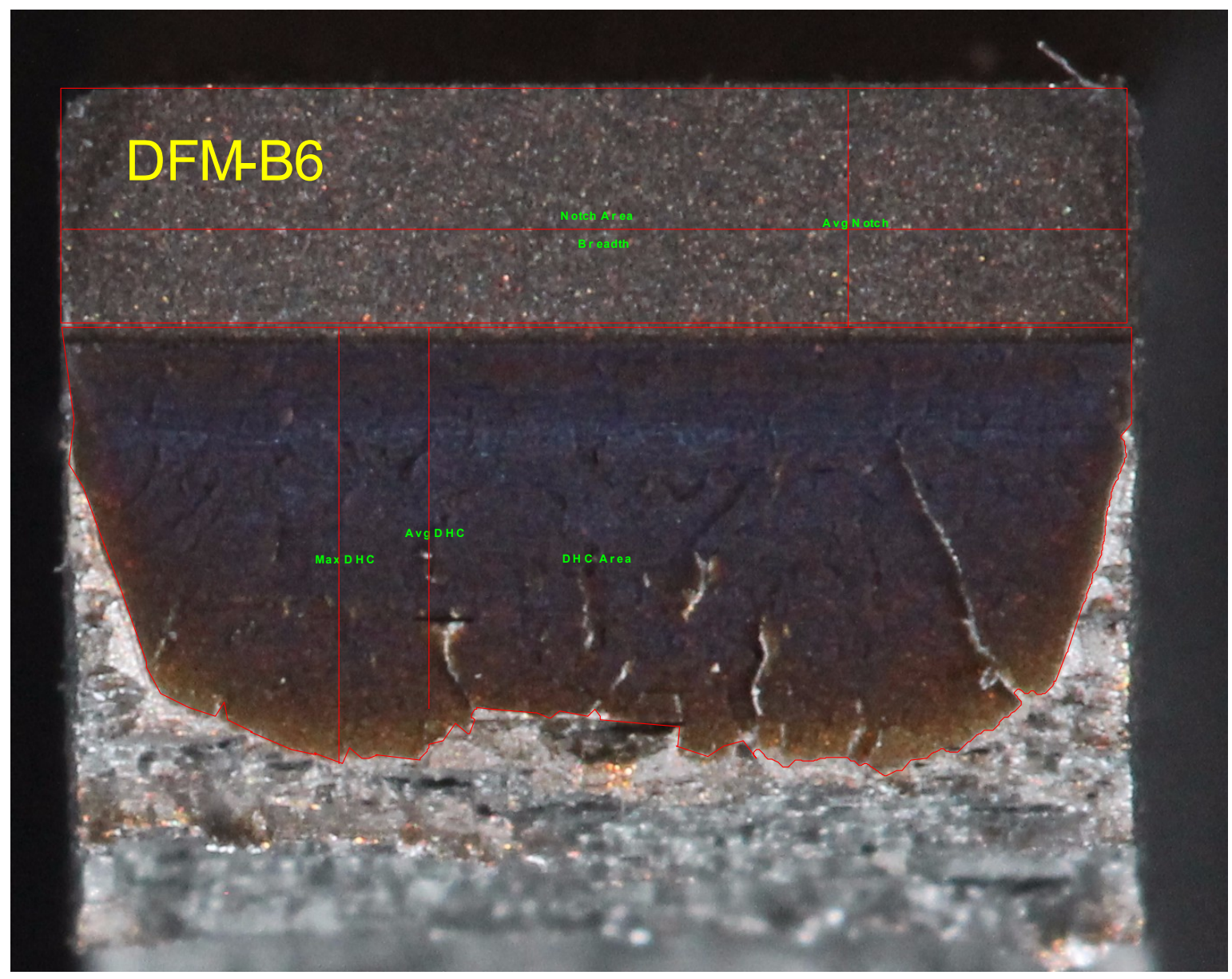

\begin{tabular}{|l|l|l|}
\hline Features & Measurement & Value \\
\hline Breadth & Length $(\mu \mathrm{m})$ & 3125 \\
\hline Notch & Area $\left(\mu \mathrm{m}^{2}\right)$ & 2185371 \\
\hline Avg Notch & Length $(\mu \mathrm{m})$ & 699.3187 \\
\hline DHC Area & Area $\left(\mu \mathrm{m}^{2}\right)$ & 3514269 \\
\hline Avg DHC & Length $(\mu \mathrm{m})$ & 1125.103 \\
\hline Max DHC & Length $(\mu \mathrm{m})$ & 1285.095 \\
\hline
\end{tabular}




\section{APPENDIX F: Experimental Data}

Plate 1 Radial

\begin{tabular}{|c|c|c|c|c|c|c|c|c|c|}
\hline $\begin{array}{l}\text { DFM - } \\
\text { Radial }\end{array}$ & $\begin{array}{l}\text { Anneal } \\
\text { Temp }\end{array}$ & $\begin{array}{l}\text { Test } \\
\text { Temp }\end{array}$ & 1/T (K) & $\begin{array}{l}\text { Velocity } \\
\mathrm{xE}^{-08}\end{array}$ & Rig & $\begin{array}{l}\text { Avg } \\
\text { DHC } \\
(\mathrm{mm})\end{array}$ & Final $\mathrm{K}$ & $\begin{array}{l}\text { Total } \\
\text { Crack } \\
\text { Time } \\
\text { (h) }\end{array}$ & $\begin{array}{l}\text { Max } \\
\text { Slope } \\
\text { TSSP }\end{array}$ \\
\hline DFM-1 & 340 & 250 & 1.91 & 1.79 & 1 & 1.15 & 31.1 & 17.8 & 269 \\
\hline DFM-2 & 360 & 285 & 1.79 & 3.46 & 4 & 1.92 & 39.7 & 15.4 & 271 \\
\hline DFM-3 & 360 & 270 & 1.84 & 7.34 & 1 & 0.57 & 22.9 & 2.2 & 268 \\
\hline DFM-4 & 360 & 250 & 1.91 & 2.71 & 1 & 1.69 & 36.2 & 17.4 & 273 \\
\hline DFM-5 & 360 & 240 & 1.95 & 1.93 & 3 & 1.32 & 31.6 & 19.0 & 263 \\
\hline DFM-6 & 360 & 285 & 1.79 & 6.88 & 2 & 1.82 & 38.5 & 7.4 & 267 \\
\hline DFM-7 & 360 & 260 & 1.88 & 1.85 & 3 & 1.89 & 39.0 & 28.4 & 269 \\
\hline DFM-8 & 360 & 265 & 1.86 & 2.84 & 1 & 2.00 & 41.2 & 19.6 & 265 \\
\hline DFM-9 & 360 & 240 & 1.95 & 1.91 & 1 & 1.73 & 36.7 & 25.2 & 266 \\
\hline DFM-10 & 360 & 280 & 1.81 & 3.21 & 2 & 1.94 & 40.0 & 16.8 & 267 \\
\hline DFM-11 & 360 & 265 & 1.86 & 3.57 & 1 & 1.80 & 38.1 & 14.0 & 270 \\
\hline DFM-12 & 360 & 290 & 1.77 & 0 & & & Quench & & \\
\hline DFM-13 & 360 & 280 & 1.81 & 3.64 & 4 & 1.87 & 39.3 & 14.3 & 258 \\
\hline DFM-16 & 360 & 260 & 1.88 & 2.99 & 3 & 1.34 & 33.4 & 12.4 & 256 \\
\hline DFM-17 & 360 & 270 & 1.84 & 3.27 & 3 & 1.93 & 41.5 & 16.4 & 267 \\
\hline DFM-18 & 360 & 280 & 1.81 & 5.49 & 1 & 0.72 & 24.3 & 3.7 & 268 \\
\hline DFM-20 & 360 & 200 & 2.11 & 0.31 & 10 & 0.74 & 24.4 & 64.9 & \\
\hline DFM-21 & 260 & 200 & 2.11 & 0.41 & 4 & 1.09 & 28.2 & 61.9 & \\
\hline DFM-24 & 360 & 275 & 1.82 & 4.28 & 3 & 1.60 & 34.0 & 10.4 & \\
\hline DFM-26 & 360 & 275 & 1.82 & 4.41 & 4 & 0.99 & 26.6 & 6.0 & \\
\hline DFM-27 & 360 & 275 & 1.82 & 4.81 & 9 & 1.10 & 27.5 & 6.4 & \\
\hline
\end{tabular}


Plate 1 Axial

\begin{tabular}{|c|c|c|c|c|c|c|c|c|c|}
\hline $\begin{array}{l}\text { DMFX } \\
\text { (Axial) }\end{array}$ & $\begin{array}{l}\text { Anneal } \\
\text { Temp }\end{array}$ & $\begin{array}{c}\text { Test } \\
\text { Temp }\end{array}$ & $1 / \mathrm{T}(\mathrm{K})$ & $\begin{array}{l}\text { Velocity } \\
\mathrm{xE}^{-08}\end{array}$ & Rig & $\begin{array}{l}\text { Avg } \\
\text { DHC }\end{array}$ & Final $\mathrm{K}$ & $\begin{array}{l}\text { Total } \\
\text { Crack } \\
\text { Time } \\
\end{array}$ & $\begin{array}{l}\text { Max } \\
\text { Slope } \\
\text { TSSP } \\
\end{array}$ \\
\hline DFMX-1 & 360 & 250 & 1.91 & 3.56 & 1 & 1.96 & 41.9 & 15.3 & 264 \\
\hline DFMX-2 & 360 & 280 & 1.81 & 5.52 & 3 & 2.21 & 47.0 & 11.1 & 264 \\
\hline DFMX-3 & 360 & 290 & 1.78 & 0 & & & Quenche & & \\
\hline DFMX-4 & 340 & 250 & 1.91 & 4.18 & 1 & 1.91 & 44.2 & 12.7 & \\
\hline DFMX-5 & 360 & 285 & 1.79 & 5.31 & 3 & 2.09 & 41.8 & 33.6 & 260 \\
\hline DFMX-6 & 360 & 260 & 1.88 & 3.5 & 2 & 1.87 & 39.2 & 14.8 & 265 \\
\hline DFMX-7 & 360 & 265 & 1.86 & 5.67 & 1 & 2.06 & 42.4 & 10.1 & 271 \\
\hline DFMX-9 & 360 & 270 & 1.84 & 5.09 & 3 & 1.98 & 46.6 & 10.9 & 264 \\
\hline DFMX-10 & 360 & 240 & 1.95 & 2.7 & 1 & 1.80 & 38.3 & 18.5 & \\
\hline DFMX-11 & 360 & 280 & 1.81 & 6.11 & 1 & 1.98 & 40.7 & 9.0 & 267 \\
\hline DFMX-12 & 360 & 285 & 1.79 & 7.42 & 2 & 1.39 & 40.4 & 5.2 & 267 \\
\hline DFMX-13 & 360 & 265 & 1.86 & 4.94 & 3 & 1.87 & 40.7 & 10.5 & 262 \\
\hline DFMX-14 & 360 & 280 & 1.81 & 5.87 & 3 & 1.48 & 35.5 & 7.0 & \\
\hline DFMX-15 & 360 & 260 & 1.88 & 4.96 & 3 & 2.11 & 46.6 & 11.8 & 260 \\
\hline DFMX-16 & 360 & 270 & 1.84 & 5.84 & 4 & 1.10 & 20.0 & 5.2 & 266 \\
\hline DFMX-17 & 360 & 240 & 1.95 & 2.37 & 3 & 1.28 & 35.8 & & 269 \\
\hline DFMX-20 & 360 & 275 & 1.82 & 7.09 & 4 & 1.12 & 28.2 & 4.4 & \\
\hline DFMX-21 & 360 & 275 & 1.82 & 4.36 & 10 & 0.95 & 26.7 & 6.0 & \\
\hline DFMX-22 & 360 & 200 & 2.11 & 0.758 & 9 & 1.25 & 29.9 & 45.9 & \\
\hline
\end{tabular}


Plate 2

\begin{tabular}{|c|c|c|c|c|c|c|c|c|}
\hline $\begin{array}{l}\text { DFM-B - } \\
\text { Radial }\end{array}$ & $\begin{array}{l}\text { Anneal } \\
\text { Temp }\end{array}$ & $\begin{array}{c}\text { Test } \\
\text { Temp }\end{array}$ & $1 / \mathrm{T}(\mathrm{K})$ & $\begin{array}{l}\text { Velocity } \\
\mathrm{XE}^{-08}\end{array}$ & Rig & $\begin{array}{l}\text { Avg } \\
\text { DHC } \\
(\mathrm{mm})\end{array}$ & Final $\mathrm{K}$ & $\begin{array}{l}\text { Total } \\
\text { Crack } \\
\text { Time (h) }\end{array}$ \\
\hline DFM-B1 & 360 & 260 & 1.88 & 2.18 & 2 & 1.54 & 33.4 & 19.6 \\
\hline DFM-B2 & 360 & 292 & 1.77 & 0.00 & 9 & & & no crack \\
\hline DFM-B3 & 360 & 285 & 1.79 & 4.81 & 9 & 1.04 & 27.3 & 6.0 \\
\hline DFM-B4 & 360 & 275 & 1.82 & 5.08 & 9 & 1.17 & 28.8 & 6.4 \\
\hline DFM-B6 & 360 & 275 & 1.82 & 4.26 & 3 & 1.13 & 27.4 & 7.2 \\
\hline DFM-B8 & 360 & 285 & 1.79 & 6.10 & 4 & 1.06 & 27.2 & 4.9 \\
\hline DFM-B10 & 360 & 290 & 1.78 & 5.25 & 2 & 0.99 & 27.2 & 5.2 \\
\hline DFM-B18 & 360 & 270 & 1.84 & 3.21 & 4 & 1.42 & 32.1 & 12.3 \\
\hline DFM-B19 & 360 & 280 & 1.81 & 4.90 & 1 & 1.05 & 28.1 & 5.9 \\
\hline DFM-B21 & 360 & 250 & 1.91 & 2.89 & 9 & 0.98 & 27.1 & 2.9 \\
\hline DFM-B22 & 360 & 300 & 1.75 & 0.00 & 10 & & & no crack \\
\hline DFM-B23 & 360 & 200 & 2.11 & 0.49 & 9 & 0.89 & 25.5 & 50.7 \\
\hline DFM-B24 & 360 & 295 & 1.76 & 0.00 & 9 & $\mathrm{n} / \mathrm{a}$ & $\mathrm{n} / \mathrm{a}$ & no crack \\
\hline DFM-B26 & 360 & 230 & 1.99 & 1.12 & 6 & 1.10 & 28.3 & 27.5 \\
\hline
\end{tabular}

\begin{tabular}{|c|c|c|c|c|c|c|c|c|}
\hline $\begin{array}{l}\text { DFM-BX } \\
\text { (Axial) }\end{array}$ & $\begin{array}{l}\text { Anneal } \\
\text { Temp }\end{array}$ & $\begin{array}{c}\text { Test } \\
\text { Temp }\end{array}$ & $\begin{array}{l}1 / \mathrm{T} \\
(\mathrm{K}) \\
\end{array}$ & $\begin{array}{l}\text { Velocity } \\
\mathrm{XE}^{-08}\end{array}$ & Rig & $\begin{array}{l}\text { Avg } \\
\text { DHC } \\
(\mathrm{mm}) \\
\end{array}$ & Final $\mathrm{K}$ & $\begin{array}{l}\text { Total } \\
\text { Crack } \\
\text { Time (h) }\end{array}$ \\
\hline DFM-BX1 & 360 & 260 & 1.88 & 3.85 & 2 & 1.79 & & 12.9 \\
\hline DFM-BX2 & 360 & 250 & 1.91 & 2.96 & 3 & 1.17 & 28.4 & 11.0 \\
\hline DFM-BX3 & 360 & 285 & 1.79 & 6.94 & 3 & $\begin{array}{r}1169.7 \\
0 \\
\end{array}$ & 28.5 & 4.7 \\
\hline DFM-BX7 & 360 & 300 & 1.75 & 0.00 & 4 & $\mathrm{n} / \mathrm{a}$ & $\mathrm{n} / \mathrm{a}$ & no crack \\
\hline DFM-BX9 & 360 & 200 & 2.11 & 0.73 & 2 & 1.05 & 27.4 & 40.0 \\
\hline DFM-BX12 & 360 & 295 & 1.76 & 0.00 & 10 & $\mathrm{n} / \mathrm{a}$ & $\mathrm{n} / \mathrm{a}$ & no crack \\
\hline DFM-BX13 & 360 & 230 & 1.99 & 1.97 & 3 & 1.14 & 27.6 & 16.1 \\
\hline DFM-BX14 & 360 & 280 & 1.81 & 6.77 & 4 & 1.17 & 28.7 & 4.8 \\
\hline DFM-BX17 & 360 & 275 & 1.82 & 6.50 & 9 & 1.56 & 29.3 & 5.1 \\
\hline DFM-BX21 & 360 & 292 & 1.77 & 0.00 & 1 & & & no crack \\
\hline DFM-BX27 & 360 & 230 & 1.99 & 2.20 & 9 & 1.20 & 29.5 & 15.1 \\
\hline DFM-BX29 & 360 & 275 & 1.82 & 5.25 & 9 & 1.21 & 27.1 & 6.4 \\
\hline DFM-BX35 & 360 & 290 & 1.78 & 7.12 & 3 & 1.74 & 36.4 & 6.8 \\
\hline DFM-BX36 & 360 & 270 & 1.84 & 4.83 & 3 & 1.96 & & 11.3 \\
\hline
\end{tabular}


Plate 3 Radial

\begin{tabular}{|c|c|c|c|c|c|c|c|c|}
\hline $\begin{array}{l}\text { DFM-B } \\
\text { (Radial) }\end{array}$ & $\begin{array}{l}\text { Anneal } \\
\text { Temp }\end{array}$ & $\begin{array}{c}\text { Test } \\
\text { Temp } \\
\end{array}$ & $\begin{array}{l}1 / \mathrm{T} \\
(\mathrm{K}) \\
\end{array}$ & $\begin{array}{l}\text { Velocity } \\
\mathrm{E}^{-08}\end{array}$ & Rig & $\begin{array}{l}\text { Avg } \\
\text { DHC } \\
(\mathrm{mm}) \\
\end{array}$ & Final $\mathrm{K}$ & $\begin{array}{l}\text { Crack } \\
\text { Time (h) }\end{array}$ \\
\hline DFM-E4 & 360 & 235 & 1.97 & 1.71 & 1 & 1.29 & 30.4 & 21.0 \\
\hline DFM-E4 & 360 & 245 & 1.93 & 0.00 & 1 & & & no crack \\
\hline DFM-E4 & 360 & 205 & 2.09 & 0.76 & 1 & 1.03 & 29.6 & 37.7 \\
\hline DFM-E5 & 369 & 235 & 1.97 & 1.83 & 1 & 1.24 & 29.7 & 18.9 \\
\hline DFM-E5 & 360 & 160 & 2.31 & 0.14 & 1 & 1.06 & 29.1 & 214.5 \\
\hline DFM-E6 & 360 & 230 & 1.99 & 1.55 & 2 & 1.76 & 36.6 & 31.5 \\
\hline DFM-E7 & 360 & 180 & 2.21 & 0.32 & 6 & 1.79 & 37.7 & 155.3 \\
\hline DFM-E8 & 360 & 215 & 2.05 & 1.06 & 2 & 1.77 & 36.3 & 46.6 \\
\hline DFM-E9 & 360 & 235 & 1.97 & 1.84 & 7 & 1.12 & 28.5 & 17.0 \\
\hline DFM-E9 & 360 & 180 & 2.21 & 0.44 & 7 & 1.10 & 28.3 & 68.6 \\
\hline DFM-E12 & 360 & 235 & 1.97 & 1.35 & 1 & 1.72 & 36.3 & 35.3 \\
\hline DFM-E13 & 360 & 235 & 1.97 & 1.67 & 3 & 2.12 & 43.6 & 35.3 \\
\hline DFM-E15 & 360 & 230 & 1.99 & 1.61 & 3 & 1.64 & 35.3 & 28.7 \\
\hline DFM-E16 & 360 & 240 & 1.95 & 1.56 & 1 & 1.55 & 33.7 & 27.5 \\
\hline DFM-E17 & 360 & 225 & 2.01 & 1.41 & 1 & 1.73 & 36.7 & 33.9 \\
\hline DFM-E18 & 360 & 240 & 1.95 & 1.57 & 5 & 1.63 & 35.9 & 28.9 \\
\hline DFM-E19 & 360 & 240 & 1.95 & 2.21 & 7 & 0.69 & 24.5 & 8.7 \\
\hline DFM-E19 & 360 & 245 & 1.93 & 1.52 & 7 & 1.29 & 29.7 & 23.6 \\
\hline DFM-E20 & 360 & 250 & 1.91 & 0.00 & 3 & & & No crack \\
\hline DFM-E20 & 360 & 200 & 2.11 & 0.61 & 3 & 1.02 & 29.1 & 46.2 \\
\hline DFM-E21 & 360 & 225 & 2.01 & 1.01 & 2 & 1.83 & 37.5 & 50.3 \\
\hline DFM-E22 & 360 & 220 & 2.03 & 0.86 & 6 & 1.86 & 37.9 & 60.2 \\
\hline DFM-E23 & 360 & 220 & 2.03 & 1.14 & 2 & 1.86 & 38.5 & 45.3 \\
\hline DFM-E30 & 360 & 190 & 2.16 & 0.47 & 9 & 2.96 & 27.9 & 56.5 \\
\hline DFM-E31 & 360 & 230 & 1.99 & 1.73 & 5 & 1.16 & 28.8 & 18.7 \\
\hline DFM-E31 & 360 & 240 & 1.95 & 0.00 & 5 & & & No crack \\
\hline DFM-E32 & 360 & 240 & 1.95 & 1.69 & 9 & 1.10 & 27.9 & 18.1 \\
\hline DFM-E32 & 360 & 255 & 1.89 & 0.00 & 9 & & & \\
\hline DFM-E32 & 360 & 190 & 2.16 & 0.41 & 9 & 1.03 & 26.9 & 66.3 \\
\hline DFM-E33 & 360 & 210 & 2.07 & 0.78 & 7 & 1.70 & 35.4 & 60.5 \\
\hline DFM-E34 & 360 & 215 & 2.05 & 1.05 & 1 & 1.72 & 36.0 & 45.6 \\
\hline DFM-E35 & 360 & 235 & 1.97 & 1.70 & 6 & 1.20 & 29.0 & 19.6 \\
\hline DFM-E35 & 360 & 245 & 1.93 & 0.00 & 6 & & & no crack \\
\hline
\end{tabular}




\begin{tabular}{|l|r|r|r|r|r|r|r|r|}
\hline DFM-E35 & 360 & 205 & 2.09 & 0.99 & 6 & 1.08 & 29.5 & 30.2 \\
\hline DFM-E37 & 360 & 210 & 2.07 & 0.65 & 2 & 1.82 & 37.4 & 77.2 \\
\hline DFM-E38 & 360 & 230 & 1.99 & 1.54 & 3 & 1.15 & 28.8 & 21.1 \\
\hline DFM-E38 & 360 & 240 & 1.95 & 1.22 & 3 & 1.15 & 29.5 & 26.1 \\
\hline DFM-E39 & 360 & 240 & 1.95 & 1.70 & 7 & 1.15 & 28.6 & 19.5 \\
\hline DFM-E39 & 360 & 250 & 1.91 & 0.00 & 7 & & & $>531$ \\
\hline DFM-E39 & 360 & 170 & 2.26 & 0.27 & 7 & 1.06 & 29.9 & 106.8 \\
\hline DFM-E41 & 360 & 240 & 1.95 & 0.00 & & & & no crack \\
\hline DFM-E41 & 360 & 235 & 1.97 & 2.29 & 1 & 1.33 & 36.3 & 20.2 \\
\hline DFM-E41 & 360 & 245 & 1.93 & 0.00 & & & & no crack \\
\hline DFM-E42 & 360 & 200 & 2.11 & 0.52 & 3 & 1.54 & 33.1 & 82.3 \\
\hline
\end{tabular}

Plate 3 Axial

\begin{tabular}{|c|c|c|c|c|c|c|c|c|}
\hline $\begin{array}{l}\text { DFM-BX } \\
\text { (Axial) } \\
\end{array}$ & $\begin{array}{l}\text { Anneal } \\
\text { Temp }\end{array}$ & $\begin{array}{c}\text { Test } \\
\text { Temp }\end{array}$ & $\begin{array}{l}1 / T \\
(K)\end{array}$ & $\begin{array}{l}\text { Velocity } \\
\mathrm{E}^{-08}\end{array}$ & Rig & $\begin{array}{l}\text { Avg } \\
\text { DHC } \\
(\mathrm{mm})\end{array}$ & Final $\mathrm{K}$ & $\begin{array}{l}\text { Crack } \\
\text { Time (h) }\end{array}$ \\
\hline DFM-EX1 & 360 & 240 & 1.95 & 0.00 & 2 & & & no crack \\
\hline DFM-EX1 & 360 & 250 & 1.91 & 0.00 & 2 & & & no crack \\
\hline DFM-EX1 & 360 & 170 & 2.26 & 0.53 & 2 & 1.06 & & 55.5 \\
\hline DFM-EX3 & 360 & 225 & 2.01 & 1.94 & 3 & 1.82 & 38.0 & 26.0 \\
\hline DFM-EX4 & 360 & 210 & 2.07 & 1.54 & 1 & 1.82 & 37.9 & 32.7 \\
\hline DFM-EX5 & 360 & 235 & 1.97 & 2.85 & 6 & 1.93 & 39.3 & 18.9 \\
\hline DFM-EX6 & 360 & 235 & 1.97 & 2.88 & 7 & 1.14 & 28.2 & 11.0 \\
\hline DFM-EX6 & 360 & 150 & 2.36 & 0.24 & 7 & 0.69 & 21.1 & 84.7 \\
\hline DFM-EX8 & 360 & 235 & 1.97 & 2.67 & 1 & 1.32 & 30.8 & 13.7 \\
\hline DFM-EX8 & 360 & 205 & 2.09 & 1.63 & 1 & 1.07 & 30.7 & 18.8 \\
\hline DFM-EX9 & 360 & 235 & 1.97 & 2.74 & 3 & 1.19 & 29.2 & 12.1 \\
\hline DFM-EX9 & 360 & 205 & 2.09 & 1.63 & 3 & 1.13 & 29.5 & 19.2 \\
\hline DFM-EX10 & 360 & 235 & 1.97 & 2.84 & 6 & 1.37 & 31.1 & 13.4 \\
\hline DFM-EX10 & 360 & 180 & 2.21 & 0.69 & 6 & 1.01 & 31.1 & 43.0 \\
\hline DFM-EX11 & 360 & 240 & 1.95 & 3.35 & 7 & 1.14 & 28.3 & 10.0 \\
\hline DFM-EX11 & 360 & 250 & 1.91 & 2.77 & 9 & 1.09 & 28.0 & 11.1 \\
\hline DFM-EX12 & 360 & 240 & 1.95 & 2.95 & 5 & 1.05 & 27.6 & 9.9 \\
\hline DFM-EX12 & 360 & 245 & 1.93 & 2.33 & 5 & 1.27 & 29.6 & 15.1 \\
\hline DFM-EX13 & 360 & 180 & 2.21 & 0.52 & 2 & 1.92 & 39.5 & 102.7 \\
\hline
\end{tabular}




\begin{tabular}{|l|r|r|r|r|r|r|r|r|}
\hline DFM-EX14 & 360 & 240 & 1.95 & 2.38 & 3 & 1.98 & 40.8 & 27.0 \\
\hline DFM-EX15 & 360 & 220 & 2.03 & 2.09 & 6 & 1.87 & 38.7 & 24.9 \\
\hline DFM-EX16 & 360 & 220 & 2.03 & 1.96 & 2 & 1.90 & 38.9 & 26.9 \\
\hline DFM-EX17 & 360 & 235 & 1.97 & 3.24 & 10 & 1.19 & 28.6 & 10.2 \\
\hline DFM-EX17 & 360 & 160 & 2.31 & 0.38 & 10 & 1.05 & 28.0 & 76.6 \\
\hline DFM-EX18 & 360 & 230 & 1.99 & 2.11 & 2 & 1.85 & 38.1 & 24.4 \\
\hline DFM-EX19 & 360 & 240 & 1.95 & 2.82 & 6 & 1.83 & 38.4 & 18.0 \\
\hline DFM-EX22 & 360 & 235 & 1.97 & 2.44 & 6 & 1.94 & 37.4 & 22.1 \\
\hline DFM-EX23 & 360 & 225 & 2.01 & 1.93 & 1 & 1.87 & 38.1 & 26.8 \\
\hline DFM-EX24 & 360 & 215 & 2.05 & 1.80 & 3 & 1.93 & 39.6 & 29.9 \\
\hline DFM-EX25 & 360 & 210 & 2.07 & 1.71 & 2 & 1.79 & 37.9 & 29.1 \\
\hline DFM-EX26 & 360 & 200 & 2.11 & 1.02 & 9 & 1.81 & 37.9 & 49.3 \\
\hline DFM-EX28 & 360 & 240 & 1.95 & 3.08 & 10 & 1.20 & 29.0 & 10.8 \\
\hline DFM-EX28 & 360 & 255 & 1.89 & 0.00 & 10 & & & $>540$ \\
\hline DFM-EX28 & 360 & 190 & 2.16 & 0.92 & 10 & 1.03 & 27.9 & 31.2 \\
\hline DFM-EX31 & 360 & 240 & 1.95 & 3.22 & 6 & 1.29 & 30.2 & 11.1 \\
\hline DFM-EX31 & 360 & 245 & 1.93 & 3.03 & 6 & 1.04 & 29.6 & 10.2 \\
\hline DFM-EX32 & 360 & 200 & 2.11 & 1.18 & 5 & 1.10 & 28.3 & 25.8 \\
\hline DFM-EX33 & 360 & 190 & 2.16 & 0.93 & 10 & 0.99 & 27.7 & 30.6 \\
\hline DFM-EX35 & 360 & 230 & 1.99 & 2.56 & 6 & 1.86 & 38.2 & 20.1 \\
\hline DFM-EX39 & 360 & 215 & 2.05 & 1.65 & 6 & 1.71 & 36.7 & 28.8 \\
\hline DFM-EX41 & 360 & 240 & 1.95 & 2.89 & 5 & 1.11 & 28.3 & 10.7 \\
\hline DFM-EX41 & 360 & 245 & 1.93 & 2.19 & 5 & 1.06 & 27.4 & 13.5 \\
\hline DFM-EX42 & 360 & 235 & 1.97 & 2.81 & 3 & 1.94 & 40.6 & 19.2 \\
\hline
\end{tabular}




\title{
APPENDIX G: CNS Conference Submission
}

\author{
2012 CNS Conference Submission
}

\begin{abstract}
Summary
Delayed Hydride Cracking (DHC) is a fracture mechanism responsible for several failures of zirconium alloy components. These components have anisotropic grain structure due to extrusion and heat treatment. Disk shaped hydrides preferentially form on certain planes, thus giving rise to orientation of bulk hydrides that are hypothesized to slow crack growth rates depending on the relative direction of the cracking. This hypothesis suggests that no difference in crack velocities will be observed upon cooling to temperatures above the terminal solid solubility for precipitation (TSSP) for hydrogen because there will be no hydrides in the bulk, but that the velocities will begin to diverge at lower temperatures as oriented hydrides interfere more-or-less depending on the relative direction of crack propagation. By extension, comparing crack velocities in different directions can be used to determine TSSP directly from DHC experiments. Cantilever beam samples from a $\mathrm{Zr}-2.5 \mathrm{Nb}$ plate with pressure tube structure were used to produce plots to estimate TSSP.
\end{abstract}

\section{Extended Abstract}

During the corrosion of zirconium alloys hydrogen is released, some fraction of which is absorbed by the component. When the Terminal Solid Solubility of Precipitation (TSSP) for hydrogen in zirconium is exceeded, brittle disk-shaped hydrides are formed that can crack under certain conditions. This cracking can be time-dependent due to the movement of hydrogen in solution in the gradient of chemical potential, which can be written in terms of gradients of concentration, temperature, alloying elements and stress. Delayed Hydride Cracking (DHC) is the time-dependant mechanism of fracture responsible for several failures of zirconium alloy components in nuclear reactors. This mechanism requires a component to contain a stress-raiser, such as a crack or notch, and a source of tensile stress. DHC has limits associated with hydrogen concentration, stress intensity factor and temperature history. Staying within these limits and utilizing conservative safety margins allow for safe operation of zirconium components [1]. There are three basic steps involved in DHC. These are (1) the diffusion of sufficient hydrogen to nucleate a hydride at the stress raiser followed by (2) growth of the hydride until (3) fracture occurs. These steps then repeat as the crack grows [2]. 
Cracking occurs in the longitudinal and through-thickness directions in pressure tube material. The longitudinal direction is parallel to the extrusion and drawing directions. The crack could travel from the inside surface to the outside or vice versa in the throughthickness direction and lead to leakage of water from the heat-transport system. There have been several studies to determine the DHC velocities in pressure tubes for reactor conditions. Based on the data provided to the Canadian Standards Association (CSA), the current CSA standard acknowledges that longitudinal cracks generally have higher velocities than through-thickness cracks [3]. The longitudinal velocities are used to defend leak-before-break in the reactors; this approach ensures the reactor remains safe if a through-thickness crack develops. The reason for the difference in crack velocities is not well understood. This study investigates the reason for the difference.

The material used in this study was zirconium- $2.5 \%$ niobium plate. The plate was thoroughly tested to ensure it had similar strength, texture and microstructure to that of pressure tube material. The longitudinal, transverse and through-thickness directions in the plate are equivalent to the axial, circumferential and radial directions in a tube, respectively. The geometry of the test specimens is shown in Figure 1. The strength in the transverse direction is provided in Table 1 . Hydrogen was added to the plate to provide a concentration of approximately 64 parts per million by weight (ppm). Cantilever beam samples were machined from the plate and notches, with a root radius of 50 micrometers, were cut into the sample using electrical discharge machining (EDM). Half of these notches were parallel to the longitudinal direction while the other half were parallel to the through-thickness direction. During testing the samples were brought to a maximum temperature of $360^{\circ} \mathrm{C}$ for an hour to dissolve all the hydrogen and then cooled to their respective test temperatures at a rate of approximately $1^{\circ} \mathrm{C}$ per minute. Samples were then held at the test temperature for an hour before the load was applied. The applied load was held constant during each test and created an initial stress intensity factor of 17 $\mathrm{MPa} \sqrt{m}$ in each sample. Tests were concluded when the acoustic emissions, or the displacement of the cantilever arm reached pre-determined values. On cooling, the specimens were broken open and the fracture surfaces were examined. Figure 2 shows examples of these fracture surfaces for both through-thickness and longitudinal cracks at $250{ }^{\circ} \mathrm{C}$. The crack growth was estimated by measuring the area of cracking and dividing by the specimen thickness. The rate of crack growth was calculated from the amount of crack growth divided by the cracking time. A graph of crack velocity versus test temperature was produced to observe whether the expected behaviour would be produced and to determine a range for the maximum value. Current data are shown in Figure 3.

A factor controlling the difference between the longitudinal and through-thickness velocities is the orientation of the bulk hydrides. For the material used in this study, the normal vectors to the disk-like bulk-hydrides are parallel to the through-thickness 
direction, which means that cracks propagating in the through-thickness directions will interact with the plane of the hydride while the longitudinal cracks will only interact with the edge of the hydride. Analyses of crack faces show that radial DHC cracks travel around the transverse rupture of bulk hydrides rather than passing through them, suggesting these cracked hydrides act as obstructions that reduce the overall throughthickness crack velocity. This process only applies at temperatures where many large hydrides are present. This hypothesis suggests that the crack growth rates in each direction will be the same for a given temperature above the solubility limit but will begin to diverge at temperatures just below this limit. This method can be used to determine TSSP directly from DHC experiments. Preliminary results shown in Figure 3 are consistent with the given hypothesis. At temperatures below $270{ }^{\circ} \mathrm{C}$ the longitudinal crack growth rates are consistently higher than the through-thickness crack growth rates, while above $270{ }^{\circ} \mathrm{C}$ the velocities at specific temperatures in either direction are indistinguishable. The temperature for the solubility limit based on an examination for the fractured large hydrides in the fracture surfaces is in the range of 260 to $280{ }^{\circ} \mathrm{C}$ while Differential Scanning Calorimetry (DSC) shows a solubility limit range of 250 to $265^{\circ} \mathrm{C}$, depending on the criterion used to evaluate it. Figure 3 indicates that the maximum crack growth rate is between 275 and $285^{\circ} \mathrm{C}$.

\section{Acknowledgement}

S.H and S. R would like to thank AECL for access to experimental facilities and both AECL and NSERC for financial support.

\begin{tabular}{|l|c|c|}
\cline { 2 - 3 } \multicolumn{1}{c|}{} & Sample 1 & Sample 2 \\
\hline Temp & $20^{\circ} \mathrm{C}$ & $250{ }^{\circ} \mathrm{C}$ \\
\hline UTS (MPa) & 844 & 577 \\
\hline $\begin{array}{l}0.2 \% \text { Yield } \\
\text { (MPa) }\end{array}$ & 732 & 501 \\
\hline Elongation & $14.40 \%$ & $11.40 \%$ \\
\hline
\end{tabular}

Table 4 - Tensile Test Results 


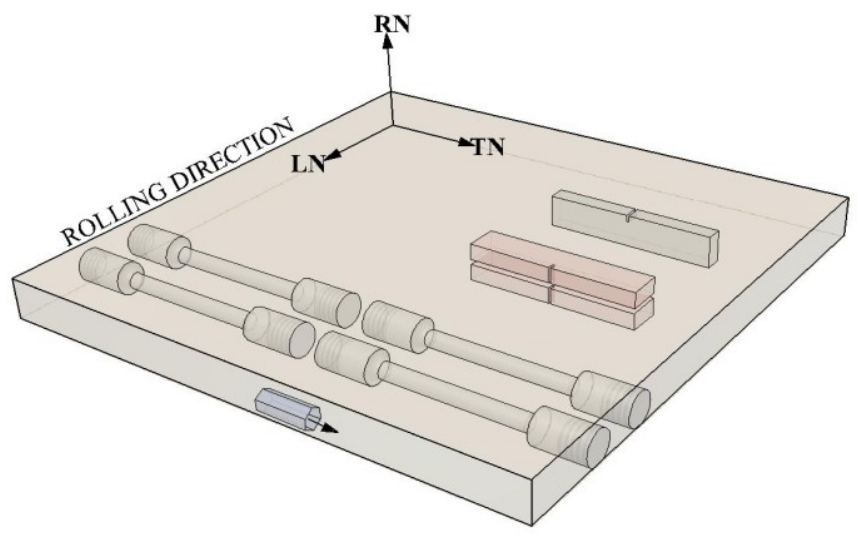

Figure 1 - Plate and Sample Geometry

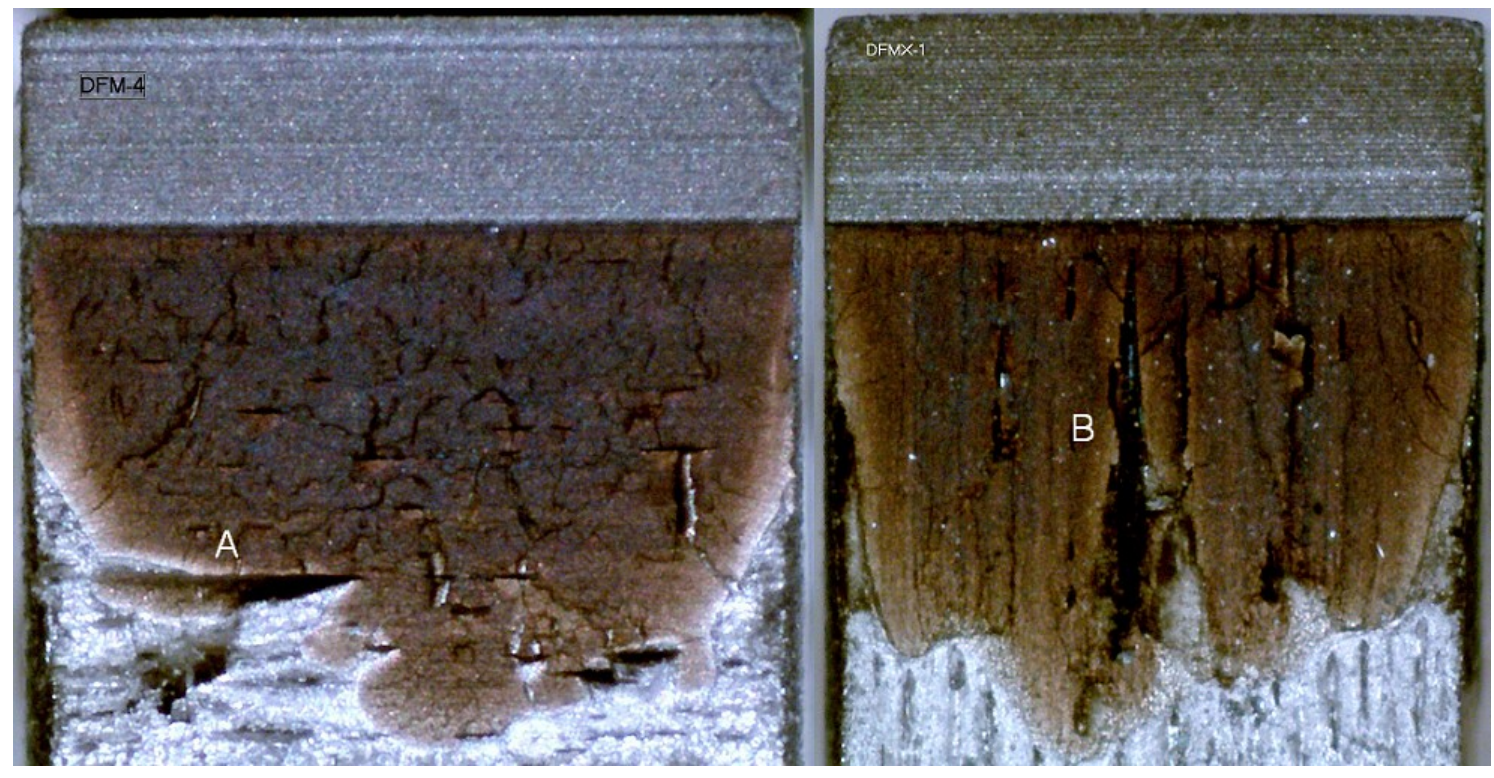

Figure 2 - Fracture Surfaces: Through-thickness (left) and Longitudinal (right). Fractured bulk hydrides shown at $A$ and $B$. Samples tested at $250{ }^{\circ} \mathrm{C}$. 


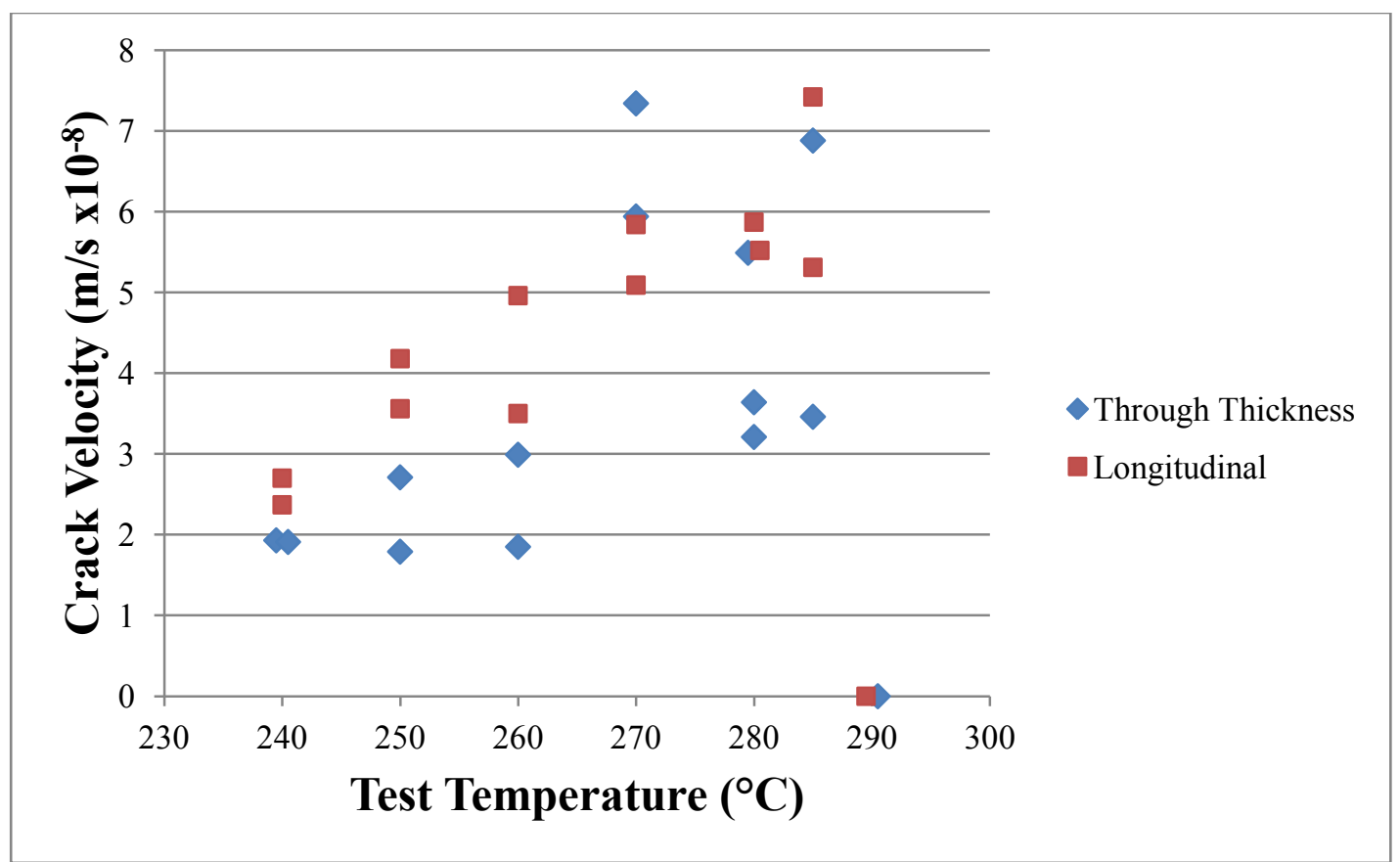

Figure 3 - Longitudinal and Through-Thickness Crack Velocities as a function of temperature. Data with superimposed symbols were moved $+/-0.5{ }^{\circ} \mathrm{C}$ for clarity.

References:

[1] Coleman, C.E., McRae, G.A., Leitch, B.W., "Evaluating the risk of delayed hydride cracking in components made from zirconium alloys", Eighth ATI Corrosion Solutions Conference, Lake Louise AB (2011).

[2] McRae, G.A., Coleman, C.E., Leitch, B.W., "The first step for delayed hydride cracking in zirconium alloys", J. Nucl. Mater., 396, (2010),130-143.

[3] Canadian Standards Association, Technical requirements for in-service evaluation of zirconium alloy pressure tubes in CANDU reactors, N285.8-05, (2005). 


\section{APPENDIX H: 2012 CNS Conference Poster}

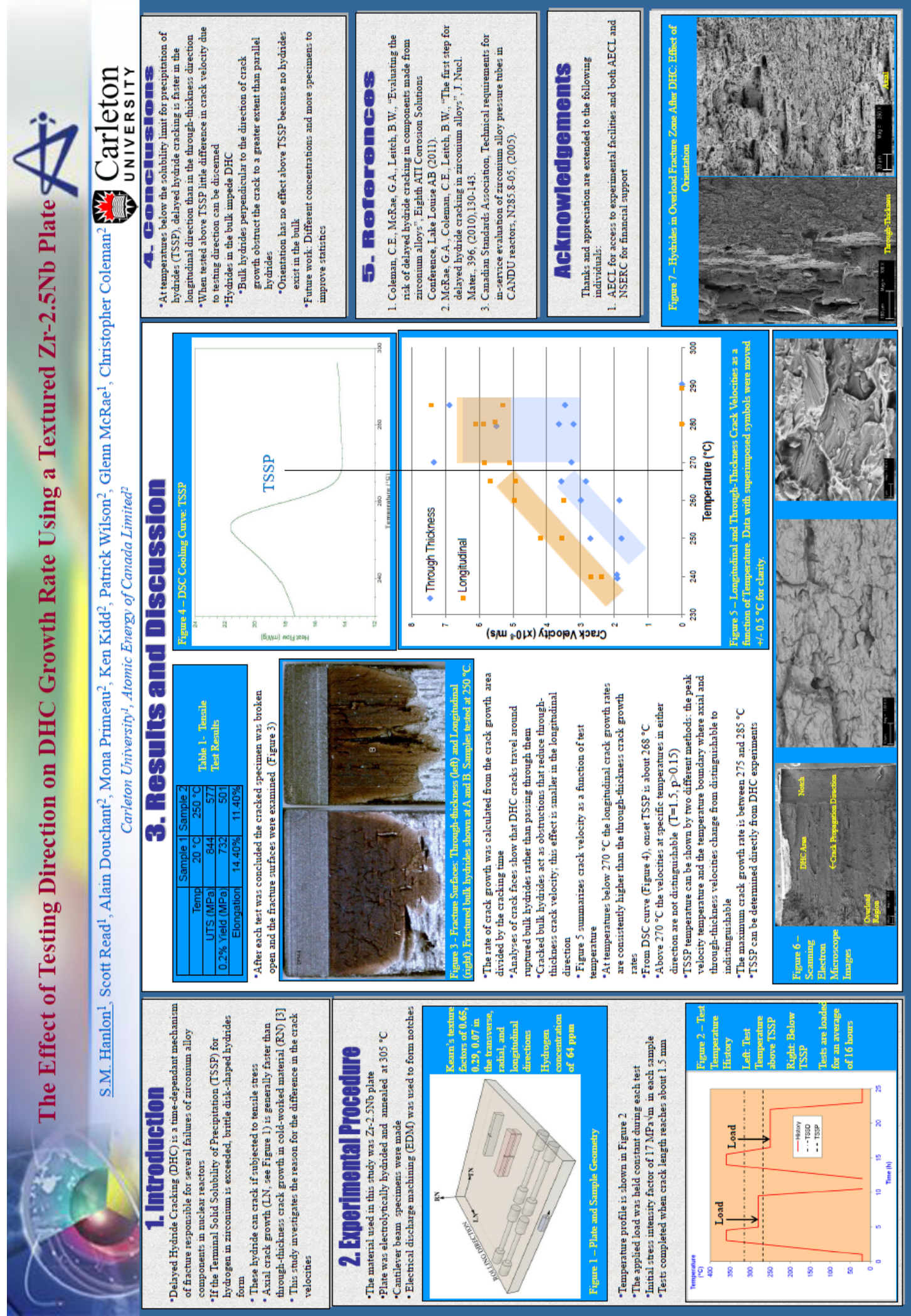

